\title{
Renal protection in off pump coronary artery bypass grafting
}

Citation for published version (APA):

Kanchi, M. (2020). Renal protection in off pump coronary artery bypass grafting. [Doctoral Thesis, Maastricht University]. Maastricht University. https://doi.org/10.26481/dis.20201110km

Document status and date:

Published: 01/01/2020

DOI:

10.26481/dis.20201110km

Document Version:

Publisher's PDF, also known as Version of record

\section{Please check the document version of this publication:}

- A submitted manuscript is the version of the article upon submission and before peer-review. There can be important differences between the submitted version and the official published version of record.

People interested in the research are advised to contact the author for the final version of the publication, or visit the DOI to the publisher's website.

- The final author version and the galley proof are versions of the publication after peer review.

- The final published version features the final layout of the paper including the volume, issue and page numbers.

Link to publication

\footnotetext{
General rights rights.

- You may freely distribute the URL identifying the publication in the public portal. please follow below link for the End User Agreement:

www.umlib.nl/taverne-license

Take down policy

If you believe that this document breaches copyright please contact us at:

repository@maastrichtuniversity.nl

providing details and we will investigate your claim.
}

Copyright and moral rights for the publications made accessible in the public portal are retained by the authors and/or other copyright owners and it is a condition of accessing publications that users recognise and abide by the legal requirements associated with these

- Users may download and print one copy of any publication from the public portal for the purpose of private study or research.

- You may not further distribute the material or use it for any profit-making activity or commercial gain

If the publication is distributed under the terms of Article $25 \mathrm{fa}$ of the Dutch Copyright Act, indicated by the "Taverne" license above, 


\section{RENAL PROTECTION \\ in \\ OFF PUMP CORONARY ARTERY BYPASS \\ GRAFTING}


(C) 2020 Muralidhar Kanchi, Maastricht

ISBN/EAN: $\quad$ 978-90-830990-1-9

Production: Andi Smart Print Solutions 


\title{
RENAL PROTECTION \\ in
}

\section{OFF PUMP CORONARY ARTERY BYPASS GRAFTING}

\section{DISSERTATION}

to obtain the degree of Doctor at

Maastricht University

on the authority of the Rector Magnificus,

Prof.dr. Rianne M. Letschert,

in accordance with the decision of the Board of Deans,

to be defended in public on Tuesday $10^{\text {th }}$ November 2020 at 13:00 hrs.

\author{
By \\ Dr. Muralidhar K \\ MD, FIACTA, FICA, MBA, FASE
}

Approved,

after corrections

Prof.dr. Rianne M. Letschert,

Rector magnificus 
Supervisors:

Professor Dr. J.G. Maessen

Professor Dr. Lloyd Vincent, Narayana Health city, Bommasandra, Bengaluru

Co-Supervisor:

Dr. Y. Ganushchak

\author{
ASSESSMENT COMMITTEE MEMBERS: \\ Prof. Dr. R. LORUSSO (Chair) \\ Prof. Dr. B.W. KRAMER \\ Prof. Dr. S.R.B. HEYMANS \\ Prof. Dr. J. ENDER, University of Leipzig, Germany. \\ Prof. Dr. K. BELANI, University of Minnesota, \\ Minneapolis, USA.
}




\section{Contents}

$\begin{array}{ll}\text { Foreword } & 7\end{array}$

$\begin{array}{lll}\text { Chapter } 1 & \text { Introduction }\end{array}$

Chapter 2 Renal function following CABG: on-pump vs 53

Chapter $3 \quad$ Determinants of renal replacement therapy 69

Chapter $4 \quad$ Genetic factors predisposing to acute

85

kidney injury in patients undergoing off-

pump coronary artery bypass graft (op-

CABG) surgery

Chapter 5

Neutrophil gelatinase-associated lipocalin as a biomarker for predicting acute kidney injury during off-pump coronary artery

Chapter 6

Chapter 7

Chapter 8

Summary

Samenvatting

Valorization

Acknowledgements bypass grafting

$\mathrm{N}$-acetylcysteine does not prevent renal dysfunction after off-pump coronary artery bypass surgery

Effect of sodium bicarbonate infusion in offpump coronary artery bypass grafting in patients with renal dysfunction - a pilot study.

General discussion

Curriculum vitae

Qualifications

Work experience

Book chapters

List of publications

9 3 69 85 



\section{Foreword}

Acute kidney injury (AKI) is a sudden onset of loss of kidney function which is indicated by an acute rise in serum creatinine level.(1) Post-operative $\mathrm{AKI}$ is not an uncommon complication following coronary artery bypass grafting (CABG). About $2.3 \%$ of isolated $C A B G$ cases is vulnerable to $A K I$, and the incidence is higher (14\%-15\%) in patients with preoperative chronic kidney disease (CKD).(2) Studies have shown that even a small increase in serum creatinine, as a marker of $\mathrm{AKI}$, following $C A B G$ is an independent risk factor for increased mortality.(3),(4),(5) And in case of progression acute kidney injury to stage 3 most patients need renal replacement therapy/dialysis. Stage 3 AKI is associated with in-hospital mortality of $50-70 \%$. (6),(7)

That is why evaluation of renal pathophysiology during cardiac surgery interventions, looking at causes of kidney injury as well as methods of renal protection, stays an important question of clinical investigations.

The main objectives of the present study are

(I) to uncover the factors that contribute to acute kidney injury with particular reference to off-pump coronary bypass surgery (OP-CABG)

(II) to define any genetic predisposition to renal injury in OP-CABG

(III) to suggest renal protective strategies that may be applicable to OPCABG. 
CHAPTER 1

\section{Introduction}




\section{Renal Physiology and Cardiac Surgery:}

The kidneys contain approximately two million nephrons. Each of the nephron consists of a glomerulus and a tubule, which leads into a collecting duct. The microscopic anatomy of the nephron is presented at the Figure 1B. The nephron is a functional unit of the kidney that helps to maintain a remarkably stable internal environment despite large
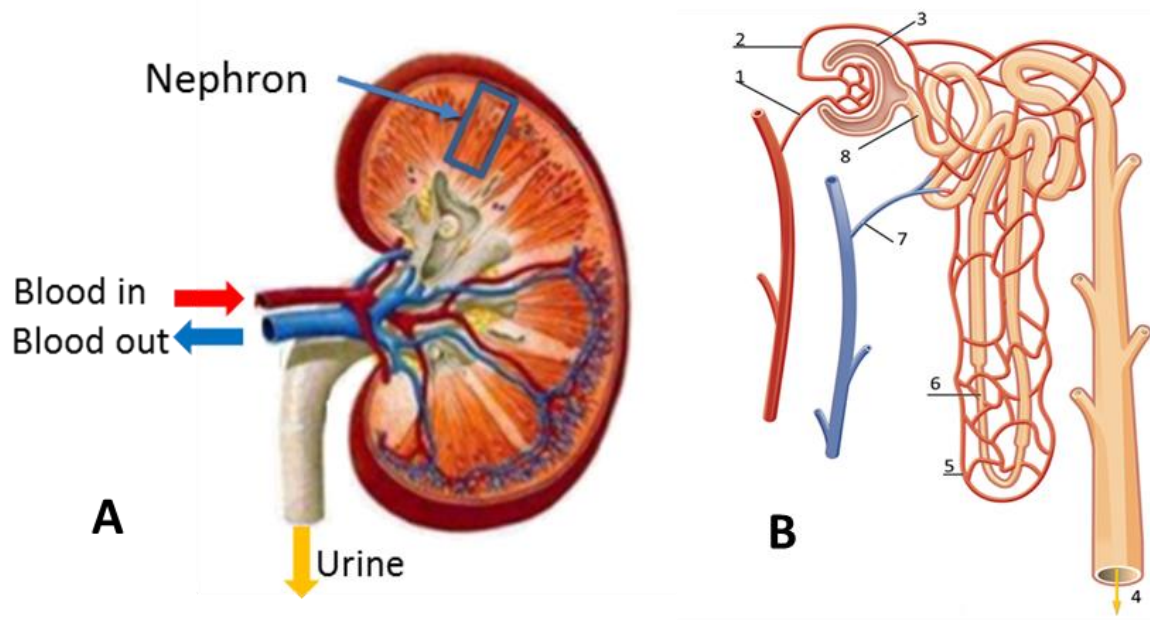

Figure 1. Kidney structure and function. A - Kidney cross section; B Nephron; B1 - afferent arteriole; B2 - efferent arteriole; B3 - glomerular capsule; B4 - urine outflow; B5 - peritubular capillary network; B6 - loop of nephron; B7 - venule; B8 - proximal convoluted tubule.

fluctuations

in fluid and solute intake. Kidneys not only excrete products of metabolism and drugs but also take active part in regulation of intravascular volume, osmolality, and acid-base and electrolyte balance. Three important functions of renal nephrons contribute to the formation of urine. These processes are glomerular ultrafiltration, tubular reabsorption and tubular secretion. In addition to the above functions, the 
kidney secretes renin, prostaglandins, kinins and erythropoietin and is involved in production of 125-dihydroxycholecalciferol which is important for bone metabolism. Renin, prostaglandins and kinins are hormones that contribute to fluid homeostasis. Erythropoietin acts directly on red blood cell (RBC) progenitors and precursors in the bone marrow to control proliferation, differentiation, and maturation of RBCs.

\section{The Glomerulus}

The glomerulus consists of at least five distinct components: capillary endothelium, glomerular basement membrane, visceral epithelium (which together make up the filtration barrier), parietal epithelium (Bowman capsule), and mesangium (interstitial cells).(8,9)The glomerular tuft is a highly convoluted series of capillary loops that is perfused by the afferent arteriole and drains into the efferent arteriole.

The parietal epithelial sac of the renal tubule is a blind pouch, and it surrounds the capillary tuft as Bowman capsule. It joins the visceral epithelium at the vascular pole of the glomerulus. Bowman space, between the visceral and parietal layers of the capsule, continues as the lumen of the proximal tubule at the urinary pole of the glomerulus, and the parietal endothelium unites with the cuboidal cells of the proximal tubule.

The cells in the interstitial mesangium are specialized pericytes equipped to perform numerous functions such as structural support, matrix elaboration, and phagocytosis. They possess threads of actin and myosin, which contract in response to vasoactive substances such as angiotensin II to restrict blood flow to fewer capillary loops. The mesangial cells control the glomerular permeability by regulation of the effective glomerular surface area for filtration. 


\section{Renal autoregulation}

The solute and water content of the organism maintained within the normal range despite wide fluctuations of arterial blood pressure by a process called 'autoregulation'. Urinary flow rate is determined by tubular water reabsorption and related to the hydrostatic pressure in the peritubular capillaries. A decrease in blood pressure, whether intentional or inadvertent, results in decreased urinary flow rate that improves only when the arterial blood pressure is restored. In 1951, Shipley and Study (10) demonstrated that the kidney maintains a constant renal blood flow and glomerular filtration rate (GFR) through an arterial pressure range of 80 to $180 \mathrm{~mm} \mathrm{Hg}$.

There are at least two important mechanisms for renal autoregulation namely the myogenic and the tubuloglomerular feedback. If the mean arterial pressure decreases, renal vascular resistance decreases and renal blood flow is maintained i.e., the arterioles dilate in response to decreased arterial pressure and vice versa. This is the myogenic response. Tubuloglomerular feedback via the juxtaglomerular apparatus acts as a negative feedback control mechanism. It uses information concerning distal tubular fluid flow rate to control the renal blood flow. This control mechanism plays a vital role by modulating blood flow and glomerular filtration rate in response to changes in blood pressure(11-13)

\section{Evaluation of renal function}

\section{Urine output}

The commonest and most easily available parameter that is in the clinical evaluation of renal function remains the urine output. In physiological conditions, urine output should be in a range of $0.5-1.5$ $\mathrm{mL} / \mathrm{kg} / \mathrm{h}$. However, in the perioperative period, oliguria - urine flow rate $<0.5 \mathrm{~mL} / \mathrm{kg} / \mathrm{h}$ is almost inevitable, whether induced by hypotension, or as a manifestation of the physiologic response to surgical stress(14). 
Normal urinary flow resumes when arterial blood pressure and intravascular volume are restored to normal levels at the end of surgery.

Currently, urinary flow rate together with changes in serum creatinine are included in the consensus definitions of AKI known as the RIFLE (risk, injury, failure, loss, end-stage renal disease) criteria(15) and the AKIN (Acute Kidney Injury Network) criteria(16). In both definitions, the first three stages of AKI (risk, injury, failure in RIFLE; stages 1, 2, and 3 in AKIN) are categorized based on oliguria $(<0.5$ or $<0.3 \mathrm{~mL} / \mathrm{kg} / \mathrm{h})$ of increasing duration.

\section{Blood Urea Nitrogen}

Urea is an end product of hepatic metabolism of ammonia. Urea is a small molecule that is uncharged and hence not protein bound; it is rapidly cleared from the blood by glomerular filtration. However, urea then undergoes reabsorption by the tubules. This explains why the blood urea nitrogen (BUN) does not correlate directly with glomerular filtration rate (GFR)(17). The normal values BUN ranges from 5 to $10 \mathrm{mg} / \mathrm{dL}$ (1.8 $3.6 \mathrm{mmol} / \mathrm{l})$. The normal ratio of BUN to serum creatinine is about 10:1. An increase in this ratio to $20: 1$ or higher implies the existence of a prerenal syndrome (prerenal azotemia). For example, elevation of BUN out of proportion to decreases in GFR occurs whenever there is increased protein catabolism and formation of urea nitrogen. This scenario occurs with absorption of blood from the gastrointestinal tract, steroid therapy, major trauma, and sepsis.

\section{Creatinine and Creatinine Clearance}

Creatinine, the endogenous end product of creatine phosphate metabolism, is normally generated from muscle at a very uniform rate and is handled by the kidney in a manner similar to that of inulin. Creatinine is soluble and freely distributed through the total body water. Creatinine production rate depends on muscle mass, physical activity, 
protein intake, and catabolism. In a steady state the serum creatinine concentration represents an equilibrium between creatinine generation rate, which is dependent on muscle mass and catabolic activity, and creatinine excretion, which is dependent on (and reflective of) the GFR.

Increases in serum creatinine from baseline are used to define the first three categories of the RIFLE and AKIN criteria for AKI (baseline $\times 1.5,2$ to 3 , and $>3$ respectively).(15,16) The importance of small increases in serum creatinine is recognized by the AKIN criteria, which define stage $1 \mathrm{AKI}$ by an increase of as little as $>0.3 \mathrm{mg} / \mathrm{dL}(\geq 26.4$ $\mu \mathrm{mol} / \mathrm{L})$. Indeed, there is evidence that this criterion alone predicts outcomes after AKI (hospital length of stay, dialysis, and mortality) as accurately as do the full AKIN criteria.(18)

Limitations to Serum Creatinine as a parameter for GFR are:

(a) Serum creatinine is usually measured by the Jaffé reaction, a chromogenic assay based on the red color of the creatinine complex with alkaline picrate. It also picks up other normally occurring chromogens, such as glucose, protein, ketones, and ascorbic acid, which represent about $14 \%$ of total creatinine when renal function is normal, although substantially less when serum creatinine is elevated (17) Similarly, ketoacidosis, barbiturates, and cephalosporin antibiotics cause false elevation of creatinine(19)

(b) $\mathrm{N}$-acetylcysteine, an antioxidant advocated by some as a renoprotective agent in contrast nephropathy, ${ }^{12}$ decreases serum creatinine levels, which may in part account for its apparently beneficial effect on renal function. ${ }^{13}$

(c) The relationship between serum creatinine and GFR as measured by creatinine clearance is reciprocal and exponential. Doubling of the serum creatinine corresponds to halving of the GFR.(17) Because these changes occur at a GFR $>50 \mathrm{~mL} /$ minute, the impairment induced by aging is not reflected by the serum 
creatinine. The implication is that a 20 -year-old and 80 -year-old patient may have an identical serum creatinine within the normal range, but compared with the younger, the older patient has half the GFR and renal reserve.

(d) The creatinine generation rate is relatively consistent in a given individual, but it varies with muscle mass, rate of catabolism, physical activity, and protein intake. ${ }^{14}$ In a cachectic patient with very low muscle mass, creatinine generation may be so feeble that the serum creatinine remains "normal" $(<0.9 \mathrm{mg} / \mathrm{dL})$ even in the face of a GFR $<25 \mathrm{~mL} /$ minute. ${ }^{15} \mathrm{The}$ GFR declines progressively and predictably with age, from about $125 \mathrm{~mL} /$ minute in a healthy 20-year-old to about $60 \mathrm{~mL} /$ minute in an 80-year-old .(17)

(e) The level of creatinine in plasma water is determined not only by its urinary clearance and by its rate of production but also by its volume of distribution in the body.(20) Creatinine level in plasma can decrease due to dilution by the $10 \%$ to $15 \%$ increases in total body water that occur with fluid administration and retention during major surgery. It is not uncommon for serum creatinine to be decreased from baseline on the first postoperative day. Subsequently, when total body water is decreased by fluid mobilization and diuresis, the serum creatinine increases. This change in creatinine concentration does not necessarily imply AKI, but may simply represent hemoconcentration and a re-equilibration to baseline.

The creatinine clearance is far more accurate in tracking rapid alterations in GFR than the serum creatinine alone. Creatinine clearance rate (CCR) provides a simple, inexpensive bedside estimate of GFR. A single blood sample is drawn at the midpoint of a carefully timed urine collection, and urine and plasma creatinine (UCR, PCR) with urinary flow rate in $\mathrm{mL} /$ minute $(\mathrm{V})$ are used to calculate GFR: 


$$
\mathrm{GFR}=\mathrm{CCR}=\mathrm{UCR} \times \mathrm{V} / \mathrm{PCR}
$$

where,

GFR - glomerular filtration rate; CCR - creatinine clearance; UCR - urine creatinine; PCR - plasma creatinine

It is clearly seen from the equation (1) that changes in GFR occur immediately after alterations in creatinine excretion rate, which is incorporated into the equation. However, this method has its own limitations. Bedside use of creatinine clearance was formerly restricted by the belief that a prolonged (12- to 24-hour) urine collection is necessary to eliminate errors induced by residual urine in the bladder neck after spontaneous voiding. This practice is tedious and cumbersome, and it is inaccurate when renal function is rapidly changing. For example, if serum creatinine increases from 1 to $2 \mathrm{mg} / \mathrm{dL}$ from the beginning to the end of a 24-hour urine collection, clearance calculated on a serum creatinine drawn at the midpoint of the collection would mask the rapid deterioration in true GFR.

\section{Assessment of Glomerular Filtration Rate/Estimated GFR}

The glomerular filtration rate (GFR) is the most accurate representation of renal function. However, estimating the GFR using a 24-h urine creatinine clearance test is troublesome and time-consuming in acute situations when immediate treatment decisions are needed. Thus, most recent definitions use urine output and serum creatinine levels as surrogates of renal function because of their easy-to-measure characteristics. However, as was mentioned above, the serum creatinine concentration affected by factors other than creatinine filtration. Appropriate interpretation of the estimated GFR (eGFR) requires understanding of the principles of physiology, laboratory medicine, epidemiology and biostatistics. 
Several formulas have been suggested to decrease the inaccuracy of GFR estimations. One of the most commonly used formula for estimation of GFR is one proposed by Cockcroft and Gault.(21)

$$
\mathrm{C}_{\mathrm{Cr}}=\{((\mid \text { 40-age) } \times \text { weight }) /(72 \times \mathrm{SCr})\} \times 0.85 \text { (if female) }
$$

Where,

$\mathrm{C}_{\mathrm{cr}}$ - creatinine clearance in $\mathrm{mL} /$ minute;

Age in years, weight in $\mathrm{kg}, \mathrm{SCr}$ (serum creatinine) in $\mathrm{mg} / \mathrm{dL}$.

In this equation, the body weight may substantially alter the derived GFR. In obese or edematous patients, the total body weight is much greater than the lean body mass from which creatinine derived. In this case, GFR is overestimated(22). Also in cachectic patients with depleted lean body mass, GFR could be overestimated if creatinine production is so low that serum creatinine is less than $1.0 \mathrm{mg} / \mathrm{dL}$ $(88.4 \mu \mathrm{mol} / \mathrm{L})$. Using ideal body weight and the corrected serum creatinine concentration in the Cockcroft-Gault equation results in more accurate predictions of glomerular filtration rate in critically ill patient.(23)

The 1999 MDRD Study equation was developed from data in the baseline period of the MDRD Study, a randomized trial studying the effects of dietary protein restriction and lower blood pressure on CKD progression. The original equation included 6 variables: serum creatinine level, age, sex, race (African American vs white and other), and serum urea nitrogen and albumin concentrations.(24) In 2006 the equation was re-expressed for use with standardized serum creatinine assays as a 4-variable MDRD equation(25)

eGFR $\left(\mathrm{mL} / \mathrm{min} / 1.73 \mathrm{~m}^{2}\right)=(175 \times \text { serum creatinine } \mathrm{mg} / \mathrm{dl})^{-1.154} \times$ age $^{-0.203} \times(0.742$ if female $) \times(1.210$ if African-American $)$ 
The 2006 MDRD Study equation was found to be more accurate compared to the Cockcroft-Gault equation (26) The MDRD-derived eGFR is the basis of the National Kidney Foundation classification of chronic kidney disease (CKD).(27)

The main limitations to the MDRD Study equation were a systematic bias to underestimate measured GFR at higher levels and imprecision throughout the range (28)

The 2009 CKD-EPI creatinine equation was developed to overcome the shortcomings of the 2006 MDRD equation(29).The final equation includes the same variables as those in the MDRD Study equation, but the form of the variables and the coefficients differ.

Evaluation in the validation population showed lesser bias of the CKD-EPI than the MDRD equation, especially at eGFR of 60 $\mathrm{mL} / \mathrm{min} / 1.73 \mathrm{~m}^{2}$, but only moderate improvement in overall accuracy and drug dosage adjustment. Importantly, the performance of both equations was not as good in regions outside North America, Europe, and Australia, presumably reflecting differences in creatinine generation due to racial, ethnic, and regional variations in muscle mass and diet that are not captured by the race coefficients (28). One more caveat is that in case of a rapid changing renal function, eGFR based on serum creatinine is subject to the same limitations as serum creatinine itself.

\section{Biomarkers of Renal Injury}

In contrast to serum creatinine, which is used as an indirect indicator of renal function or dysfunction (i.e., GFR), biomarkers are molecules or compounds that indicate direct tubular injury. Traditional biomarkers include $\beta 2$ Microglobulin and $N$-acetyl- $\beta$-d-glucosaminidase. Their widely acknowledged limitations in the early and accurate detection of evolving renal injury have fostered an increasing interest in a new generation of biomarkers. Functional genomics and proteomics have 
Table 1. List of biomarkers of renal injury/dysfunction.

\begin{tabular}{|c|c|c|c|}
\hline Filtration-Based & Biomarkers & Biomarkers & Biomarkers \\
\hline Markers of & Reflecting Renal & Reflecting Renal & Reflecting \\
\hline Renal & Tubular Cell & Tubular Cell & the Renal \\
\hline \multirow[t]{3}{*}{ Dysfunction } & Damage (Tubular & Dysfunction & Stress \\
\hline & Enzymuria) & (Tubular & Response \\
\hline & & Proteinuria) & \\
\hline \multirow{20}{*}{$\begin{array}{l}\text { Cystatin C } \\
\text { Proatrial } \\
\text { natriuretic } \\
\text { peptide (1-98) } \\
\text { Tryptophan } \\
\text { glycoconjugate }\end{array}$} & a-Glutathione S- & $\alpha_{1}$-Microglobulin, & Neutrophil \\
\hline & transferase, & $\beta_{2}$-Microglobulin, & gelatinase- \\
\hline & m-Glutathione S- & Albumin, & associated \\
\hline & transferase, & Adenosine & lipocalin, \\
\hline & $\beta-N$-Acetyl- $\beta$-D- & deaminase & Urinary \\
\hline & glucosaminidase, & binding protein, & interleukin- \\
\hline & v-Glutamyl & Renal tubular & 18 \\
\hline & transpeptidase, & epithelial & Platelet- \\
\hline & Alkaline & antigen-1, & activating \\
\hline & phosphatase, & Retinol binding & factor, \\
\hline & Lactate & protein, & Kidney \\
\hline & dehydrogenase, & Lysozyme, & injury \\
\hline & Ala-(Leu-Gly)- & Ribonuclease, & molecule-1, \\
\hline & aminopeptidase, & $\lg G$ & Cysteine- \\
\hline & Proximal renal & Transferrin, & rich protein \\
\hline & tubular epithelial & Ceruloplasmin, & 61 \\
\hline & antigen, & Lambda and & \\
\hline & Urinary sodium & kappa light & \\
\hline & hydrogen & chains, & \\
\hline & exchanger isoform. & $\begin{array}{l}\text { Urinary total } \\
\text { protein. }\end{array}$ & \\
\hline
\end{tabular}


created the possibility of identifying potential injury biomarkers with a precision and specificity not previously possible, and numerous candidate biomarkers are currently at various stages of clinical investigation. However, to replace serum creatinine in clinical practice, new biomarkers of renal injury must reliably identify patients at risk for adverse outcomes across a range of clinical populations, a goal that has not yet been achieved. The list of substances that have been put forward in the literature as markers of kidney injury is presented in Table 1.

\section{Cystatin C}

There is a great interest in defining endogenous plasma markers that provide a more reliable, early indicator of changing GFR; especially in AKI.(27)One that has received attention is cystatin C, a cysteineprotease inhibitor that is released into the circulation at a constant rate by all nucleated cells. Given the short half-life of cystatin $C$ (approximately 2 hours), it should be anticipated that it will increase more rapidly than serum creatinine after an acute change in GFR. $(30,31)$ Furthermore, cystatin $\mathrm{C}$ is completely filtered by the glomerulus and neither secreted nor resorbed by the tubular epithelium and its serum levels bear a close relationship to serum creatinine and GFR.(32)Also, serum cystatin $C$ is less subject to nonrenal variables such as muscle mass, age, or gender and in certain clinical situations appears to be a more accurate predictor of low GFR than serum creatinine. $(33,34)$ However, more recent studies suggest that the relationship between serum cystatin $C$ and GFR is affected by various factors. This relationship is affected by cigarette smoking, inflammation (elevated Creactive protein), corticosteroid use, and immunosuppressive therapy. $(35,36)$ As a consequence, cystatin $C$ remains an investigational marker that has no added information to serum creatinine as a marker of kidney dysfunction in clinical practice. 


\section{Beta-2 Microglobulin}

Microglobulin is present on the surface of almost all cells. It is a small protein component of the major histocompatibility complex. It is filtered by the glomerular apparatus and then is subjected to partial tubular reabsorption. The ratio of $\beta 2$-microglobulin between serum and urine may help distinguish glomerular from tubular injury, although the relationship between increased urinary $\beta 2$-microglobulin and subsequent acute tubular necrosis (ATN) has not been established. In glomerular injury, serum $\beta 2$-microglobulin levels increase and urine levels decrease. This assessment has been used as an early sign of rejection in renal transplantation.(37)

\section{Urinary $\mathrm{N}$-acetyl- $\beta$-d-glucosaminidase}

$N$-acetyl- $\beta$ - $d$-glucosaminidase (NAG) is a lysosomal enzyme, which is found abundantly in proximal tubular epithelial cells. NAG is a well-established method of detecting subclinical tubular injury. Urinary NAG levels, or the ratio of its isoenzymes, have been used in the early detection of rejection in transplant patients and to follow the course of chronic renal disease, such as lupus nephritis.(38) However, a relationship between elevations in urinary NAG and histopathologic changes, increasing serum creatinine, or adverse clinical outcomes has not been established. Therefore, the perioperative interpretation and clinical utility of NAG remains uncertain.(35)

\section{Neutrophil Gelatinase-Associated Lipocalin}

Neutrophil gelatinase-associated lipocalin (NGAL) is a small 25kDA polypeptide expressed in distal tubular cells and collecting ducts, whose mRNA undergoes dramatic up-regulation after ischemic tubular injury.(39)Up-regulation can be detected within minutes of ischemiareperfusion injury; it increases three- to fourfold within 2 to 3 hours and 
up to 10000 -fold by 24 hours (Fig-7). NGAL is protease resistant and is readily detected in tiny (nanogram $/ \mathrm{mL}$ ) amounts of urine almost immediately after renal injury, preceding the appearance of NAG and $\beta 2$ microglobulin. However, the diagnostic performance of NGAL for AKI has varied widely and dramatically across clinical studies for reasons that remain unclear.

\section{Interleukin-18 (IL-18)}

Synthesized as an inactive $23-\mathrm{kDa}$ precursor by several cell types, including proximal tubular epithelial cells, macrophages, and monocytes, IL-18 is a proinflammatory cytokine. Multiple studies demonstrate increased urinary IL-18 levels in association with acute kidney injury.(40-42)However, results have been inconsistent with limited data addressing a relationship with adverse clinical outcomes and its potential role as a diagnostic marker in clinical practice remains uncertain.

\section{Other Candidate Biomarkers}

Multiple other potential biomarkers of acute kidney injury have been identified. Liver fatty acid-binding protein (L-FABP), a component of the cytoplasm of proximal tubular cells, binds fatty acids for transport to mitochondria. It is released early into the urine following tubular injury, and there is some evidence that it may be more specific than NGAL.(43) In a study on 85 patients undergoing cardiac surgery, AKI was defined by stage 1 of the AKIN criteria. Urinary L-FABP was increased significantly earlier and to a greater extent than urinary NGAL.(44)

Hepcidin is a peptide hormone produced in the liver that regulates iron homeostasis. Its synthesis appears to be up-regulated by CPB and urinary hepcidin increases in patients with normal renal function. In the presence of AKI, 24-hour urinary hepcidin and hepcidinto-creatinine ratios decrease and provide high sensitivity and specificity 
for its diagnosis. $(3,45)$ The true role of the previously mentioned biomarkers, as well as others such as retinol-binding protein and multiple forms of glutathione-S-transferase, awaits larger multicenter studies to characterize their validity and potential clinical utility. It may be practical to consider a panel of biomarkers that together define the course of AKI over time.

An emerging approach is the integration of serum creatinine (an indicator of renal function) with biomarkers (evidence of tubular injury). But, at this point in time, an increased serum creatinine concentration, despite all the limitations enumerated earlier, remains the gold standard in the definition of AKI that is consistently and reliably associated with adverse clinical outcomes.(46-49)

\section{Etiology of acute kidney injury and Renal Protection during Cardiac Surgery.}

\section{Cardiac Surgery and Cardiopulmonary Bypass}

The incidence of acute renal failure requiring renal replacement therapy after uncomplicated cardiac surgery in patients with previously normal renal function is infrequent $(<2 \%)$. (50)However, the incidence of AKI defined by consensus definitions is much higher and about $20 \%$ to $30 \%$.(51,52)Furthermore, tubular enzymuria and microalbuminuria is consistently observed during cardiopulmonary bypass.(53) Urinary NGAL increases significantly within 2 hours of CPB in pediatric or adult patients. These patients develop a $50 \%$ increase in postoperative serum creatinine, with a peak delayed until 1 to 3 days after surgery. $(54,55)$

It is important that regardless of the pathogenesis, even milder forms of $\mathrm{AKI}$ are consistently associated with increased mortality, length of stay, and hospital costs. $(47,49,52)$ 
Multiple risk factors have been identified, including preoperative renal dysfunction, hypertension, diabetes, impaired cardiac function, preoperative anemia, perioperative erythrocyte transfusion, combined surgical procedures, prolonged cardiopulmonary bypass, and advanced age. $(56,57)$

Chronic kidney disease (CKD) is a major risk factor. In cardiac surgery, the odds ratio for perioperative mortality increases to $1.18,2.23$, and 4.39 for preexisting CKD stages 3, 4, and 5, respectively.(58)

Preoperative hypertension is recognized as another major risk factor for AKI after cardiac surgery. This risk is increased by preexisting systolic (wide pulse pressure) hypertension. The risk of $A K I$ increases by nearly $50 \%$ for every $20 \mathrm{~mm} \mathrm{Hg}$ in pulse pressure above $40 \mathrm{~mm} \mathrm{Hg.(59)}$

Several perioperative factors directly or indirectly are associated with the occurrence of $\mathrm{AKI}$ after cardiac surgery. Most patients before cardiac surgery will have undergone contrast angiography in preparation for surgery. The time interval between this contrast infusion and surgery has been suggested as a potential contributory factor to perioperative AKI.(60)

Cardiopulmonary bypass (CPB) and consequent changes in homeostasis are recognized as a main risk factor contributing to the development of $A K I$ in cardiac surgical patients. CPB is notorious to release particulate, gaseous, micro- or macroscopic emboli that may be involved in the genesis of $\mathrm{AKI}$ in some patients undergoing cardiac surgery. (17)

Acute anemia (hemoglobin $<9 \mathrm{~g} / \mathrm{dL}$ ) during cardiopulmonary bypass is associated with an increased risk of $\mathrm{AKI}$, but so is red cell transfusion when hemoglobin is $>8 \mathrm{~g} / \mathrm{dL}(61)$.

Although much effort has centered on the minimum arterial pressure needed to maintain renal perfusion during CPB, this tends to be contradictory. Animal studies of cardiopulmonary bypass have shown that renal blood flow (RBF) is dependent on renal perfusion pressure, 
and infusion of dopamine does not increase RBF during low pressure states.(15)This suggests that autoregulation may be impaired during cardiopulmonary bypass. Decreased mean arterial pressure during CPB appears to be well tolerated, unless it is associated with anemia.(51) Also, was demonstrated that maintaining a high level of MAP (on average) during normothermic CPB does not reduce the risk of postoperative AKI.(62)

On the other hand, it is recognized that systemic blood pressure has a major role in the maintenance of renal function. When MAP drops below the optimal autoregulation threshold renal blood flow is decreased.(63) Furthermore, the longer the period with MAP is below $50 \mathrm{mmHg}$ or $60 \mathrm{mmHg}$ during $\mathrm{CPB}$, the more likely acute renal injury (AKI) will arise(51)(64) Kanji and colleagues also found that a drop in MAP bigger than $26 \mathrm{mmHg}$ during CPB compared to pre-bypass MAP was associated with AKI.(65) Increased variability of intraoperative blood pressure also appears to be a risk factor of postoperative AKI.(66)

In animal and human studies, pulsatile perfusion during CPB enhances renal cortical blood flow and decreases circulating catecholamines, endothelin, and cytokine activation $(67,68)$ Plasma renin activity is suppressed by pulsatile perfusion; however, evidence of glomerular injury (in this case, $\beta 2$-microglobulinuria) persists.(69) The absence of an effect of pulsatile flow on the frequency of postoperative AKI was confirmed by a large (1820 patients) non-randomized observational study.(70)Also, in a randomized prospective study on 215 pediatric patients undergoing repair of congenital heart disease, the use of pulsatile flow during CPB was not associated with a difference in serum creatinine. However, pulsatile perfusion in this study resulted in decreased inotropic drug requirement, shorter ICU and hospital lengths of stay, and increased urine output.(71)There is evidence that pulsatile flow achieved with intra-aortic balloon counter pulsation attenuated the 
decline in GFR, but there was no difference in urine output or renal outcome.(72)

Overall, results of clinical studies of pulsatile perfusion on CPB are inconsistent and further complicated by the absence of a precise and widely accepted definition of what constitutes pulsatile flow on CPB. Current evidence appears to be insufficient to allow recommendations either for or against the routine use of pulsatile perfusion on CPB to decrease the risk of renal injury.

Acute renal failure has been associated with persistent elevation of plasma renin levels(73) leading to activation of renin-angiotensin system. Norepinephrine concentrations increase progressively during bypass(74)Activation of renin-angiotensin system as well as thromboxane, released from activated platelets, and vascular elaboration of endothelin could add to renal vasoconstriction during extracorporeal circulation.(17)

Inflammatory cascades initiated by surgery may be further amplified in response to CPB. Red blood cells in a CPB system, release free hemoglobin, an established nephrotoxin, into the plasma. ${ }^{63}$ Another consequence of hemolysis is the release of labile free iron that contributes to activation of reactive oxygen species, inflammation, and AKI.(75) A number of the tubular biomarkers released in AKI are associated with iron metabolism: NGAL participates in iron transport, LFABP is a high-affinity heme binding protein, and hepcidin (which appears to be protective) sequesters free iron.(76)This may be a causative factor for renal dysfunction in cardiac surgery. In a study specifically examining hemolysis during CPB for repair of thoracoabdominal aortic aneurysms, there was a direct association among peak plasma free hemoglobin, NAG, and perioperative AKI.(77)

The individual response to CPB varies greatly and may be also the consequence of variable genetic polymorphisms that regulate the response to inflammatory and vasomotor processes.(78) 
Unfortunately, despite all the putative mechanisms described above, it remains unclear how much CPB itself contributes exactly to AKI during cardiac surgery. In addition, the severity of postoperative AKI and its outcome correlated with the severity of cardiac dysfunction after cardiopulmonary bypass.(79)

It is important to realize the multi causal nature of postoperative $\mathrm{AKI}$ and that a combination of patients' and procedural factors may have a cumulative effect that results to postoperative AKI in cardiac surgical patients.

\section{Avoidance of CPB}

The benefit to renal function of off-pump coronary artery bypass (OPCAB) remains equivocal. Although OPCAB is associated with less evidence of acute kidney injury, as manifested by lower levels of serum creatinine, cystatin $\mathrm{C}$, microalbuminuria, and NAG, a clear benefit to renal outcome, morbidity, or mortality has not been demonstrated. $(80,81)$ In patients with a low risk, little difference has been observed in the incidence of acute kidney injury, regardless of whether CPB is used.(82) However, a recent meta-analysis of randomized trials, found evidence to support a reduction in AKI with off-pump surgery but with no demonstrable benefit in terms of reduction in requirement for dialysis or mortality (83).

We need additional high-quality evidence that addresses clinically relevant end points to clarify the potential renal benefit of offpump cardiac surgery.

\section{Dopaminergic and diuretic Drugs}

In a study comparing equipotent inotropic doses of dopamine and dobutamine after cardiac surgery, the two agents had similar effects on GFR, RBF, renal vascular resistance, and filtration fraction, but 
dopamine caused greater urine flow rate, natriuresis, fractional excretion of sodium, and potassium excretion, indicating a diuretic effect independent of changes in RBF and GFR.(84) However, there is no evidence that the prophylactic administration of low-dose dopamine has a protective role during CPB in patients with previously normal $(85,86)$ or impaired renal function.(87) Furthermore, in a study on normal volunteers, McGregor and colleagues found a 30-fold intersubject variability in plasma dopamine levels.(88) Some subjects, given an infusion of low-dose dopamine, had plasma levels consistent with those associated with doses in the high, $\alpha$-adrenergic range. Even at small doses it can cause unwanted tachycardia, and its postoperative infusion is associated with a more frequent incidence of supraventricular and ventricular arrhythmias.(89)

In contrast to dopamine, a renoprotective effect occurs from an infusion of low-dose fenoldopam infusion $(0.1-0.3 \mathrm{mcg} / \mathrm{kg} / \mathrm{minute})$ during cardiac surgery(90). Echocardiographic studies using the Doppler technique have demonstrated a dose-dependent increase in renal blood flow, especially in the cortical zones, when fenoldopam is administered in this dose range.(91) A meta-analysis of 13 randomized and casematched studies on 1059 patients found that fenoldopam infusion is associated with a significant decrease in dialysis requirement, ICU length of stay, and in-hospital mortality. However, most studies with fenoldopam have been relatively small and have identified improved serum creatinine and creatinine clearance rather than renal outcome(92,93). The most convincing evidence thus far comes from a randomized, double-blinded study in 193 high-risk patients by Cogliati and colleagues.(94) Patients who received fenoldopam had a decreased incidence of acute kidney injury (12.6 versus $27.6 \%, P=0.02)$ and requirement for dialysis $(0$ versus $8.2 \%, P=0.004)$.

It may be noted that prophylactic administration of diuretics during CPB may actually be harmful. $(70,95)$ 
Thus, there is no convincing evidence to demonstrate the benefit of dopaminergic or diuretic drugs for renal benefit in cardiac surgery.

\section{Natriuretic Peptides}

There has been considerable interest in the ability of infused anaritide to reverse established acute renal failure ("renal rescue"). Animal studies of ischemic and nephrotoxic acute tubular necrosis, $(96,97)$ as well as preliminary clinical studies,(98) indicate usefulness of atrial natriuretic peptide (ANP).

A large prospective study demonstrated significantly increased dialysis-free survival with anaritide infusion in oliguric acute renal failure, but in nonoliguric acute renal failure, survival actually worsened.(99)

Subsequently, a randomized, double-blind, placebo-controlled trial in 222 patients with oliguric acute renal failure found no differences in dialysis requirement, dialysis-free survival, or 60-day mortality between anaritide and placebo.(100) However, patients receiving anaritide had significantly more frequent incidence of hypotension during infusion of the study drug. Exogenous administration of anaritide (human recombinant atrial natriuretic peptide, ANP) decreases systemic arterial blood pressure through arterial and venous dilation.

Infusion of anaritide has been studied also during CPB.(101) Compared with control, patients who received anaritide had significantly lower plasma levels of renin, angiotensin II, and aldosterone and higher GFR and urine output. A recent Cochrane review of ANP therapy concluded that although there was some evidence supporting a beneficial effect of low-dose ANP as a preventive strategy to reduce the risk of $A K I$ requiring dialysis, the evidence is insufficient to make any strong recommendations.(102)

Nesiritide (human recombinant brain Natiuretic peptide, BNP) is approved by the FDA for the parenteral treatment of advanced decompensated congestive heart failure. It decreases increased cardiac 
preload and afterload, enhances cardiac function, and promotes diuresis and relieves symptoms related to pulmonary congestion and edema.(103) The major adverse effect is dose-related hypotension, which if excessive, can impair renal function.(104) A meta-analysis of studies of nesiritide infusion in patients with advanced decompensated heart failure indicated increasing serum creatinine levels.(105) However, a large prospective placebo-controlled study demonstrated no worsening of renal function in patients with advanced decompensated heart failure,(106) and similar results have been found when comparing nesiritide to nitroglycerin(98) or nitroprusside.(100) Perioperative infusion of low-dose $(0.01 \mathrm{mcg} / \mathrm{kg} /$ minute $)$ nesiritide in high-risk patients undergoing cardiac surgery may have a renoprotective effect.(101) In a prospective, randomized, blinded study of 279 patients with left ventricular dysfunction $(\mathrm{EF}<40 \%$ ) undergoing coronary revascularization or mitral valve surgery, patients who received nesiritide had increased urine output, an attenuated postoperative increase in serum creatinine, and improved survival 6 months after surgery. A meta-analysis of 15 trials of infusions of ANP or BNP in cardiovascular surgery found consistent benefits, including increased urine output and GFR, decreased diuretic use, decreased peak postoperative serum creatinine and requirement for dialysis, and decreased ICU and hospital length of stay.(102) These findings have yet to be confirmed by a large, multicenter, prospective randomized controlled trial.

\section{N-Acetylcysteine}

$\mathrm{N}$-acetylcysteine is an antioxidant that directly scavenges reactive oxygen species, and it has been widely used to prevent radiocontrast nephropathy. However, the data about effectivity of $\mathrm{N}$ acetylcysteine in prevention of postoperative kidney injury in cardiac surgery patients are contradictory. Along with studies that shows that intravenous infusion of NAC could prevent postoperative AKI especially 
in patients with preexisting renal failure(107)there are multiple studies which do not support perioperative NAC administration as a mean to reduce the risk of $\mathrm{AKI}(108-110)$ In two prospective, blinded, randomized studies, neither intermittent injection(103) nor continuous infusion(104) of $\mathrm{N}$-acetylcysteine had any impact on renal function or outcome after cardiac surgery. A study on 254 patients with chronic renal insufficiency (GFR $<60 \mathrm{~mL} /$ minute) was similarly unable to demonstrate any significant benefit from intermittent injection of $\mathrm{N}$-acetylcysteine.(105) Most recently, a randomized controlled study on more than 2300 patients undergoing coronary or peripheral vascular angiography failed to show any benefit associated with $\mathrm{N}$-acetylcysteine administration.(111)

Further research is required to identify CABG patients at risk for postoperative renal events who could possibly benefit from intravenous infusion of NAC for prevention of kidney injury during cardiac surgery.

\section{Urinary Alkalinization}

As described above, hemolysis is a common occurrence during $\mathrm{CPB}$, the release of labile free iron may play a role in inducing activation of reactive oxidation species, and $\mathrm{AKI}$ in this situation could be considered a form of pigment nephropathy.(112) Under these circumstances, urinary alkalinization could prevent formation of methemoglobin and tubular casts, decrease endocytic hemoglobin uptake, and attenuate proximal tubular necrosis; bicarbonate may scavenge free iron-mediated reactive oxygen species such as hydroxyl ions and peroxynitrite.(75) Indeed, in a small, randomized, double-blind trial in 100 patients undergoing cardiac surgery who were at increased risk of perioperative AKI, urinary alkalinization by a 24-hour infusion of sodium bicarbonate was beneficial: the infusion of sodium bicarbonate in this study decreased the incidence of postoperative increase in Serum Creatinine by $25 \%$ with a concomitant decreased urine NGAL.(106) 
These are preliminary observations and their impact on outcome remain to be confirmed by larger prospective studies. 


\section{References}

1. Kellum JA, Lameire N, Aspelin P, Barsoum RS, Burdmann EA, Goldstein SL, et al. Diagnosis, evaluation, and management of acute kidney injury: A KDIGO summary (Part 1). Crit Care. 2013 Feb 4;17(1).

2. O'Brien SM, Shahian DM, Filardo G, Ferraris VA, Haan CK, Rich JB, et al. The Society of Thoracic Surgeons 2008 cardiac surgery risk models: part 2--isolated valve surgery. Ann Thorac Surg [Internet]. 2009 Jul [cited 2019 Sep 18];88(1 Suppl):S23-42. Available from: http://www.ncbi.nlm.nih.gov/pubmed/19559823

3. Lassnigg A, Schmidlin D, Mouhieddine M, Bachmann LM, Druml $\mathrm{W}$, Bauer $\mathrm{P}$, et al. Minimal changes of serum creatinine predict prognosis in patients after cardiothoracic surgery: A prospective cohort study. J Am Soc Nephrol. 2004 Jun;15(6):1597-605.

4. Ryckwaert F, Boccara G, Frappier J-M, Colson PH. Incidence, risk factors, and prognosis of a moderate increase in plasma creatinine early after cardiac surgery. Crit Care Med [Internet]. 2002 Jul [cited 2019 Sep 18];30(7):1495-8. Available from: http://www.ncbi.nlm.nih.gov/pubmed/12130968

5. Brown JR, Cochran RP, Dacey LJ, Ross CS, Kunzelman KS, Dunton RF, et al. Perioperative increases in serum creatinine are predictive of increased 90-day mortality after coronary artery bypass graft surgery. Circulation [Internet]. 2006 Jul 4 [cited 2019 Sep 18];114(1 Suppl):I409-13. Available from: http://www.ncbi. nlm.nih.gov/pubmed/16820609

6. Lassnigg A, Schmidlin D, Mouhieddine M, Bachmann LM, Druml $\mathrm{W}$, Bauer $\mathrm{P}$, et al. Minimal changes of serum creatinine predict prognosis in patients after cardiothoracic surgery: a prospective cohort study. J Am Soc Nephrol [Internet]. 2004 Jun [cited 2019 Sep 18];15(6):1597-605. Available from: http://www.ncbi. 
nlm.nih.gov/pubmed/15153571

7. Rosner $\mathrm{MH}$, Okusa MD. Acute kidney injury associated with cardiac surgery. Clin J Am Soc Nephrol [Internet]. 2006 [cited 2019 Sep 18];1(1):19-32. Available from: http://www.ncbi. nlm.nih.gov/entrez/query.fcgi?cmd=Retrieve $\& \mathrm{db}=$ PubMed\&dopt $=$ Citation\&list_uids $=17699187$

8. Koeppen BM, Stanton BA. Renal physiology. 272 p.

9. Anatomy of the Kidney - Brenner and Rector's The Kidney, 8th ed [Internet]. [cited 2019 Sep 18]. Available from: https://doctorlib.info/nephrology/kidney/3.html

10. Aukland $\mathrm{K}$, Oien $\mathrm{AH}$. Renal autoregulation: models combining tubuloglomerular feedback and myogenic response. Am J Physiol [Internet]. 1987 Apr [cited 2019 Sep 18];252(4 Pt 2):F768-83. Available from: http://www.ncbi.nlm.nih.gov/pubmed/3565585

11. SHIPLEY RE, STUDY RS. Changes in renal blood flow, extraction of inulin, glomerular filtration rate, tissue pressure and urine flow with acute alterations of renal artery blood pressure. Am J Physiol. 1951 Dec 1;167(3):676-88.

12. Sladen RN. Oliguria in the ICU. Systematic approach to diagnosis and treatment. Anesthesiol Clin North America [Internet]. 2000 Dec [cited 2019 Sep 18];18(4):739-52, viii. Available from: http://www.ncbi.nlm.nih.gov/pubmed/11094688

13. Bellomo R, Ronco C, Kellum JA, Mehta RL, Palevsky P. Acute Renal Failure: Definition, Outcome Measures, Animal Models, Fluid Therapy and Information Technology Needs [Internet]. Vol. 8, Crit Care. 2004 [cited 2019 Sep 18]. p. r204-12. Available from: http://www.ncbi.nlm.nih.gov/pubmed/15312219\%0Ahttp://www.pu bmedcentral.nih.gov/articlerender.fcgi?artid=PMC522841\%0Ahttp ://ccforum.biomedcentral.com/articles/10.1186/cc2872

14. Tepel M, Zidek W. N-Acetylcysteine in nephrology; contrast nephropathy and beyond. Curr Opin Nephrol Hypertens [Internet]. 
2004 Nov [cited 2019 Sep 18];13(6):649-54. Available from: http://www.ncbi.nlm.nih.gov/pubmed/15483456

15. Hoffmann U, Fischereder M, Krüger B, Drobnik W, Krämer BK. The value of $\mathrm{N}$-acetylcysteine in the prevention of radiocontrast agent-induced nephropathy seems questionable. J Am Soc Nephrol [Internet]. 2004 Feb [cited 2019 Sep 18];15(2):407-10. Available from: http://www.ncbi.nlm.nih.gov/pubmed/14747387

16. Myers BD, Miller DC, Mehigan JT, Olcott IV CO, Golbetz H, Robertson CR, et al. Nature of the renal injury following total renal ischemia in man. J Clin Invest. 1984;73(2):329-41.

17. Miller RD, Cohen NH, Eriksson LI, Professor F, Chair A, WienerKronish JP. Miller's Anesthesia, 2-Volume Set. Elsevier; 2014. $3576 \mathrm{p}$.

18. Chertow GM, Burdick E, Honour M, Bonventre J V., Bates DW. Acute kidney injury, mortality, length of stay, and costs in hospitalized patients. J Am Soc Nephrol. 2005;16(11):3365-70.

19. Samra M, Abcar AC. False estimates of elevated creatinine. Perm J. 2012;16(2):51-2.

20. Moran SM, Myers BD. Course of acute renal failure studied by a model of creatinine kinetics. Kidney Int [Internet]. 1985 Jun [cited 2019 Sep 18];27(6):928-37. Available from: http://www.ncbi.nlm. nih.gov/pubmed/4021321

21. Cockcroft DW, Gault MH. Prediction of creatinine clearance from serum creatinine. Nephron. 1976;16(1):31-41.

22. Coresh J, Stevens LA. Kidney function estimating equations: Where do we stand? Vol. 15, Current Opinion in Nephrology and Hypertension. 2006. p. 276-84.

23. Robert S, Zarowitz BJ, Peterson EL, Dumler F. Predictability of creatinine clearance estimates in critically ill patients. Crit Care Med [Internet]. 1993 Oct [cited 2019 Sep 18];21(10):1487-95. Available from: http://www.ncbi.nlm.nih.gov/pubmed/8403957 
24. Levey AS, Bosch JP, Lewis JB, Greene T, Rogers N, Roth D. A more accurate method to estimate glomerular filtration rate from serum creatinine: a new prediction equation. Modification of Diet in Renal Disease Study Group. Ann Intern Med [Internet]. 1999 Mar 16 [cited 2019 Sep 18];130(6):461-70. Available from: http://www.ncbi.nlm.nih.gov/pubmed/10075613

25. Levey AS, Coresh J, Greene T, Stevens LA, Zhang Y, Hendriksen $S$, et al. Using standardized serum creatinine values in the modification of diet in renal disease study equation for estimating glomerular filtration rate. Ann Intern Med. 2006 Aug 15;145(4):247-54.

26. Stevens LA, Nolin TD, Richardson MM, Feldman HI, Lewis JB, Rodby $R$, et al. Comparison of drug dosing recommendations based on measured GFR and kidney function estimating equations. Am J Kidney Dis [Internet]. 2009 Jul [cited 2019 Oct 4];54(1):33-42. Available from: http://www.ncbi.nlm.nih.gov/ pubmed/19446939

27. Foundation NK, Intern A. National Kidney Foundation practice guidelines for chronic kidney disease : evaluation , classification , and stratification . PubMed Commons. 2004;2003-4.

28. Levey AS, Inker LA, Coresh J. GFR estimation: from physiology to public health. Am J Kidney Dis [Internet]. 2014 May [cited 2019 Oct 4];63(5):820-34. Available from: http://www.ncbi.nlm.nih.gov /pubmed/24485147

29. Levey AS, Stevens LA, Schmid CH, Zhang Y, Castro AF, Feldman $\mathrm{HI}$, et al. A new equation to estimate glomerular filtration rate. Ann Intern Med. 2009 May 5;150(9):604-12.

30. Uchida K, Gotoh A. Measurement of cystatin-C and creatinine in urine. Clin Chim Acta [Internet]. 2002 Sep [cited 2019 Sep 18];323(1-2):121-8. Available from: http://www.ncbi.nlm.nih.gov/ pubmed/12135813 
31. Hojs R, Bevc S, Ekart R, Gorenjak M, Puklavec L. Serum cystatin $\mathrm{C}$ as an endogenous marker of renal function in patients with mild to moderate impairment of kidney function. Nephrol Dial Transplant. 2006 Jul;21(7):1855-62.

32. Go AS, Chertow GM, Fan D, McCulloch CE, Hsu C. Chronic kidney disease and the risks of death, cardiovascular events, and hospitalization. N Engl J Med [Internet]. 2004 [cited 2019 Sep 18];351(13):1296-305. Available from: http://www.ncbi.nlm. nih.gov/pubmed/15385656

33. Yeo KK, Li Z, Yeun JY, Amsterdam E. Severity of chronic kidney disease as a risk factor for operative mortality in nonemergent patients in the California coronary artery bypass graft surgery outcomes reporting program. Am J Cardiol [Internet]. 2008 May 1 [cited 2019 Sep 18];101(9):1269-74. Available from: http://www.ncbi.nlm.nih.gov/pubmed/18435956

34. Trof RJ, Di Maggio F, Leemreis J, Groeneveld ABJ. Biomarkers of acute renal injury and renal failure. Vol. 26, Shock. 2006. p. 245-53.

35. Laterza OF, Price CP, Scott MG. Cystatin C: an improved estimator of glomerular filtration rate? Clin Chem [Internet]. 2002 May [cited 2019 Sep 18];48(5):699-707. Available from: http://www.ncbi.nlm.nih.gov/pubmed/11978596

36. Royakkers AANM, van Suijlen JDE, Hofstra LS, Kuiper MA, Bouman CSC, Spronk PE, et al. Serum cystatin C-A useful endogenous marker of renal function in intensive care unit patients at risk for or with acute renal failure? Curr Med Chem [Internet]. 2007 [cited 2019 Sep 18];14(21):2314-7. Available from: http://www.ncbi.nlm.nih.gov/pubmed/17896979

37. Parikh CR, Abraham E, Ancukiewicz M, Edelstein CL. Urine IL-18 is an early diagnostic marker for acute kidney injury and predicts mortality in the intensive care unit. J Am Soc Nephrol [Internet]. 
2005 Oct [cited 2019 Sep 20];16(10):3046-52. Available from: http://www.ncbi.nlm.nih.gov/pubmed/16148039

38. Negishi K, Noiri E, Doi K, Maeda-Mamiya R, Sugaya T, Portilla D, et al. Monitoring of urinary L-type fatty acid-binding protein predicts histological severity of acute kidney injury. Am J Pathol [Internet]. 2009 Apr [cited 2019 Sep 20];174(4):1154-9. Available from: http://www.ncbi.nlm.nih.gov/pubmed/19264903

39. Matsui K, Kamijo-lkemori A, Sugaya T, Yasuda T, Kimura K. Usefulness of urinary biomarkers in early detection of acute kidney injury after cardiac surgery in adults. Circ J [Internet]. 2012 [cited 2019 Sep 20];76(1):213-20. Available from: http://www.ncbi.nlm.nih.gov/pubmed/22094907

40. Englberger L, Suri RM, Li Z, Dearani JA, Park SJ, Sundt TM, et al. Validation of clinical scores predicting severe acute kidney injury after cardiac surgery. Am J Kidney Dis [Internet]. 2010 Oct [cited 2019 Sep 20];56(4):623-31. Available from: http://www.ncbi.nlm.nih.gov/pubmed/20630639

41. Ip-Yam PC, Murphy S, Baines M, Fox MA, Desmond MJ, Innes PA. Renal function and proteinuria after cardiopulmonary bypass: the effects of temperature and mannitol. Anesth Analg [Internet]. 1994 May [cited 2019 Sep 20];78(5):842-7. Available from: http://www.ncbi.nlm.nih.gov/pubmed/8160980

42. Mishra J, Dent C, Tarabishi R, Mitsnefes MM, Ma Q, Kelly C, et al. Neutrophil gelatinase-associated lipocalin (NGAL) as a biomarker for acute renal injury after cardiac surgery. Lancet (London, England) [Internet]. [cited 2019 Sep 20];365(9466):1231-8. Available from: http://www.ncbi.nlm. nih.gov/pubmed/15811456

43. Wagener G, Jan M, Kim M, Mori K, Ph D. Association between Increases in Urinary Neutrophil Gelatinase - associated Lipocalin and Acute Renal. Anesthesiology. 2006;105(3):485-91. 
44. Kuitunen A, Vento A, Suojaranta-Ylinen R, Pettiä V. Acute renal failure after cardiac surgery: evaluation of the RIFLE classification. Ann Thorac Surg [Internet]. 2006 Feb [cited 2019 Sep 20];81(2):542-6. Available from: http://www.ncbi.nlm.nih.gov/ pubmed/16427848

45. Robert AM, Kramer RS, Dacey LJ, Charlesworth DC, Leavitt BJ, Helm RE, et al. Cardiac surgery-associated acute kidney injury: a comparison of two consensus criteria. Ann Thorac Surg [Internet]. 2010 Dec [cited 2019 Sep 20];90(6):1939-43. Available from: http://www.ncbi.nlm.nih.gov/pubmed/21095340

46. Karkouti K, Wijeysundera DN, Yau TM, Callum JL, Cheng DC, Crowther $\mathrm{M}$, et al. Acute kidney injury after cardiac surgery: focus on modifiable risk factors. Circulation [Internet]. 2009 Feb 3 [cited 2019 Sep 20];119(4):495-502. Available from: http://www.ncbi .nlm.nih.gov/pubmed/19153273

47. Palomba H, De Castro I, Neto ALC, Lage S, Yu L. Acute kidney injury prediction following elective cardiac surgery: AKICS Score. Kidney Int. 2007 Sep;72(5):624-31.

48. Aronson S, Fontes ML, Miao Y, Mangano DT, Investigators of the Multicenter Study of Perioperative Ischemia Research Group, Ischemia Research and Education Foundation. Risk index for perioperative renal dysfunction/failure: critical dependence on pulse pressure hypertension. Circulation [Internet]. 2007 Feb 13 [cited 2019 Sep 20];115(6):733-42. Available from: http://www.ncbi.nlm.nih.gov/pubmed/17283267

49. Hilberman M, Maseda J, Stinson EB, Derby GC, Spencer RJ, Miller DC, et al. The diuretic properties of dopamine in patients after open-heart operation. Anesthesiology [Internet]. 1984 Nov [cited 2019 Sep 20];61(5):489-94. Available from: http://www.ncbi.nlm.nih.gov/pubmed/6496987

50. Mehta RH, Honeycutt E, Patel UD, Lopes RD, Williams JB, Shaw 
LK, et al. Relationship of the time interval between cardiac catheterization and elective coronary artery bypass surgery with postprocedural acute kidney injury. Circulation. 2011 Sep 13;124(11 SUPPL. 1).

51. Haase M, Bellomo R, Story D, Letis A, Klemz K, Matalanis G, et al. Effect of mean arterial pressure, haemoglobin and blood transfusion during cardiopulmonary bypass on post-operative acute kidney injury. Nephrol Dial Transplant [Internet]. 2012 Jan [cited 2019 Sep 20];27(1):153-60. Available from: http://www.ncbi.nlm.nih.gov/pubmed/21677302

52. Weir MR, Aronson S, Avery EG, Pollack C V. Acute kidney injury following cardiac surgery: role of perioperative blood pressure control. Am J Nephrol [Internet]. 2011 [cited 2019 Sep 20];33(5):438-52. Available from: http://www.ncbi.nlm.nih.gov/ pubmed/21508632

53. Canivet JL, Larbuisson R, Damas P, Blaffart F, Faymonville M, Limet $R$, et al. Plasma renin activity and urine beta 2microglobulin during and after cardiopulmonary bypass: pulsatile vs non-pulsatile perfusion. Eur Heart J [Internet]. 1990 Dec [cited 2019 Sep 20];11(12):1079-82. Available from: http://www.ncbi. nlm.nih.gov/pubmed/2292254

54. Haase-Fielitz A, Mertens PR, Plass M, Kuppe H, Hetzer R, Westerman $\mathrm{M}$, et al. Urine hepcidin has additive value in ruling out cardiopulmonary bypass-associated acute kidney injury: an observational cohort study. Crit Care [Internet]. 2011 Aug 4 [cited 2019 Sep 20];15(4):R186. Available from: http://www.ncbi. nlm.nih.gov/pubmed/21816077

55. Prowle JR, Ostland V, Calzavacca P, Licari E, Ligabo EV, Echeverri JE, et al. Greater increase in urinary hepcidin predicts protection from acute kidney injury after cardiopulmonary bypass. Nephrol Dial Transplant [Internet]. 2012 Feb [cited 2019 Sep 
20];27(2):595-602. Available from: http://www.ncbi.nlm.nih.gov /pubmed/21804084

56. Myers BD, Moran SM. Hemodynamically mediated acute renal failure. N Engl J Med [Internet]. 1986 Jan 9 [cited 2019 Sep 20];314(2):97-105. Available from: http://www.ncbi.nlm.nih.gov /pubmed/3510383

57. Haase M, Haase-Fielitz A, Bagshaw SM, Ronco C, Bellomo R. Cardiopulmonary bypass-associated acute kidney injury: a pigment nephropathy? Contrib Nephrol [Internet]. 2007 [cited 2019 Sep 20];156:340-53. Available from: http://www.ncbi.nlm. nih.gov/pubmed/17464145

58. Ling W, Zhaohui N, Ben H, Leyi G, Jianping L, Huili D, et al. Urinary IL-18 and NGAL as early predictive biomarkers in contrast-induced nephropathy after coronary angiography. Nephron Clin Pract [Internet]. 2008 [cited 2019 Sep 20];108(3):c176-81. Available from: http://www.ncbi.nlm.nih.gov/ pubmed/18287807

59. Haase M, Haase-Fielitz A, Bellomo R. Cardiopulmonary bypass, hemolysis, free iron, acute kidney injury and the impact of bicarbonate. Contrib Nephrol [Internet]. 2010 [cited 2019 Sep 20];165:28-32. Available from: http://www.ncbi.nlm.nih.gov/ pubmed/20427952

60. Vermeulen Windsant IC, Snoeijs MG, Hanssen SJ, Altintas S, Heijmans $\mathrm{JH}$, Koeppel TA, et al. Hemolysis is associated with acute kidney injury during major aortic surgery. Kidney Int [Internet]. 2010 May [cited 2019 Sep 20];77(10):913-20. Available from: http://www.ncbi.nlm.nih.gov/pubmed/20182411

61. Nakamura K, Harasaki H, Fukumura F, Fukamachi K, Whalen R. Comparison of pulsatile and non-pulsatile cardiopulmonary bypass on regional renal blood flow in sheep. Scand Cardiovasc J [Internet]. 2004 Mar [cited 2019 Sep 20];38(1):59-63. Available 
from: http://www.ncbi.nlm.nih.gov/pubmed/15204249

62. Azau A, Markowicz P, Corbeau JJ, Cottineau C, Moreau X, Baufreton $C$, et al. Increasing mean arterial pressure during cardiac surgery does not reduce the rate of postoperative acute kidney injury. Perfus (United Kingdom). 2014 Nov 27;29(6):496504.

63. Persson PB, Ehmke H, Nafz B, Kirchheim HR. Sympathetic modulation of renal autoregulation by carotid occlusion in conscious dogs. Am J Physiol [Internet]. 1990 Feb [cited 2019 Nov 18];258(2 Pt 2):F364-70. Available from: http://www.ncbi. nlm.nih.gov/pubmed/2309893

64. Fischer UM, Weissenberger WK, Warters RD, Geissler HJ, Allen SJ, Mehlhorn U. Impact of cardiopulmonary bypass management on postcardiac surgery renal function. Perfusion. 2002;17(6):4016.

65. Kanji HD, Schulze CJ, Hervas-Malo M, Wang P, Ross DB, Zibdawi $M$, et al. Difference between pre-operative and cardiopulmonary bypass mean arterial pressure is independently associated with early cardiac surgery-associated acute kidney injury. J Cardiothorac Surg. 2010 Sep 8;5(1).

66. Haase $M$, Bellomo $R$, Haase-Fielitz A. Novel biomarkers, oxidative stress, and the role of labile iron toxicity in cardiopulmonary bypass-associated acute kidney injury. J Am Coll Cardiol [Internet]. 2010 May 11 [cited 2019 Sep 20];55(19):2024-33. Available from: http://www.ncbi.nlm.nih.gov /pubmed/20447525

67. Hilberman M, Derby GC, Spencer RJ, Stinson EB. Sequential pathophysiological changes characterizing the progression from renal dysfunction to acute renal failure following cardiac operation. J Thorac Cardiovasc Surg [Internet]. 1980 Jun [cited 2019 Sep 20]; 79 (6):838-44. Available from: http://www.ncbi. 
nlm.nih.gov/pubmed/7374199

68. Abu-Omar Y, Mussa S, Naik MJ, MacCarthy N, Standing S, Taggart DP. Evaluation of Cystatin $\mathrm{C}$ as a marker of renal injury following on-pump and off-pump coronary surgery. Eur J Cardiothorac Surg [Internet]. 2005 May [cited 2019 Sep 20];27(5):893-8. Available from: http://www.ncbi.nlm.nih.gov/ pubmed/15848332

69. Parikh CR, Coca SG, Thiessen-Philbrook H, Shlipak MG, Koyner JL, Wang Z, et al. Postoperative biomarkers predict acute kidney injury and poor outcomes after adult cardiac surgery. J Am Soc Nephrol. 2011 Sep;22(9):1748-57.

70. Lassnigg A, Donner E, Grubhofer G, Presterl E, Druml W, Hiesmayr M. Lack of renoprotective effects of dopamine and furosemide during cardiac surgery. J Am Soc Nephrol [Internet]. 2000 Jan [cited 2019 Sep 20];11(1):97-104. Available from: http://www.ncbi.nlm.nih.gov/pubmed/10616845

71. Loef BG, Epema AH, Navis G, Ebels T, Van Oeveren W, Henning $\mathrm{RH}$. Off-pump coronary revascularization attenuates transient renal damage compared with on-pump coronary revascularization. Chest. 2002;121(4):1190-4.

72. Woo EBC, Tang ATM, el-Gamel A, Keevil B, Greenhalgh D, Patrick $M$, et al. Dopamine therapy for patients at risk of renal dysfunction following cardiac surgery: science or fiction? Eur $\mathrm{J}$ Cardiothorac Surg [Internet]. 2002 Jul [cited 2019 Sep 20];22(1):106-11. Available from: http://www.ncbi.nlm.nih.gov/ pubmed/12103382

73. Sezai $A$, Shiono $M$, Nakata $K$, Hata $M$, lida $M$, Saito $A$, et al. Effects of pulsatile CPB on interleukin- 8 and endothelin-1 levels. Artif Organs [Internet]. 2005 Sep [cited 2019 Sep 20];29(9):70813. Available from: http://www.ncbi.nlm.nih.gov /pubmed/16143012 
74. Downing SW, Edmunds LH. Release of vasoactive substances during cardiopulmonary bypass. Ann Thorac Surg [Internet]. 1992 Dec [cited 2019 Nov 18];54(6):1236-43. Available from: http://www.ncbi.nlm.nih.gov/pubmed/1340777

75. Abramov D, Tamariz M, Serrick Cl, Sharp E, Noel D, Harwood S, et al. The influence of cardiopulmonary bypass flow characteristics on the clinical outcome of 1820 coronary bypass patients. Can J Cardiol [Internet]. 2003 Mar 15 [cited 2019 Sep 20];19(3):237-43. Available from: http://www.ncbi.nlm.nih.gov/ pubmed/12677278

76. Onorati F, Presta P, Fuiano G, Mastroroberto P, Comi N, Pezzo $F$, et al. A Randomized Trial of Pulsatile Perfusion Using an IntraAortic Balloon Pump Versus Nonpulsatile Perfusion on ShortTerm Changes in Kidney Function During Cardiopulmonary Bypass During Myocardial Reperfusion. Am J Kidney Dis. 2007 Aug;50(2):229-38.

77. Hilberman M, Myers BD, Carrie BJ, Derby G, Jamison RL, Stinson EB. Acute renal failure following cardiac surgery. J Thorac Cardiovasc Surg [Internet]. 1979 Jun [cited 2019 Sep 20];77(6):880-8. Available from: http://www.ncbi.nlm.nih.gov/ pubmed/439924

78. Lu JCT, Coca SG, Patel UD, Cantley L, Parikh CR. Searching for Genes That Matter in Acute Kidney Injury: A Systematic Review for the Translational Research Investigating Biomarkers and Endpoints for Acute Kidney Injury (TRIBE-AKI) Consortium. Clin J Am Soc Nephrol. 2009;4:1020-31.

79. Meco M, Allaz MC, Cirri S. Effects of fenoldopam mesylate infusion on splanchnic perfusion after myocardial revascularization on cardiopulmonary bypass: an ultrasound Doppler study. J Cardiothorac Vasc Anesth [Internet]. 2011 Aug [cited 2019 Sep 23]; 25(4):642-6. Available from: 
http://www.ncbi.nlm.nih.gov/pubmed/21109463

80. Nigwekar SU, Navaneethan SD, Parikh CR, Hix JK. Atrial natriuretic peptide for management of acute kidney injury: A systematic review and meta-analysis. Clin J Am Soc Nephrol. 2009 Feb 1;4(2):261-72.

81. MacGregor DA, Smith TE, Prielipp RC, Butterworth JF, James $\mathrm{RL}$, Scuderi PE. Pharmacokinetics of dopamine in healthy male subjects. Anesthesiology [Internet]. 2000 Feb [cited 2019 Sep 23];92(2):338-46. Available from: http://www.ncbi.nlm.nih.gov/ pubmed/10691218

82. Myles PS, Buckland MR, Schenk N 1, Cannon GB, Langley M, Davis BB, et al. Anaesth Intens Care. Vol. 21. 1993.

83. Nigwekar SU, Kandula P, Hix JK, Thakar C V. Off-Pump Coronary Artery Bypass Surgery and Acute Kidney Injury: A Meta-analysis of Randomized and Observational Studies. Am J Kidney Dis. 2009 Sep;54(3):413-23.

84. Caimmi P-P, Pagani L, Micalizzi E, Fiume C, Guani S, Bernardi $\mathrm{M}$, et al. Fenoldopam for renal protection in patients undergoing cardiopulmonary bypass. J Cardiothorac Vasc Anesth [Internet]. 2003 Aug [cited 2019 Sep 23];17(4):491-4. Available from: http://www.ncbi.nlm.nih.gov/pubmed/12968238

85. Ranucci M, Soro G, Barzaghi N, Locatelli A, Giordano G, Vavassori $A$, et al. Fenoldopam prophylaxis of postoperative acute renal failure in high-risk cardiac surgery patients. Ann Thorac Surg [Internet]. 2004 Oct [cited 2019 Sep 23];78(4):13327; discussion 1337-8. Available from: http://www.ncbi.nlm. nih.gov/pubmed/15464494

86. Cogliati AA, Vellutini R, Nardini A, Urovi S, Hamdan M, Landoni $G$, et al. Fenoldopam infusion for renal protection in high-risk cardiac surgery patients: a randomized clinical study. J Cardiothorac Vasc Anesth [Internet]. 2007 Dec [cited 2019 Sep 
23];21(6):847-50. Available from: http://www.ncbi.nlm.nih.gov /pubmed/18068064

87. Conger JD. A controlled evaluation of prophylactic dialysis in post-traumatic acute renal failure. J Trauma [Internet]. 1975 Dec [cited 2019 Sep 23];15(12):1056-63. Available from: http://www.ncbi.nlm.nih.gov/pubmed/1202238

88. Seki G, Suzuki K, Nonaka T, Nosaka K, Taniguchi S, Aizawa C, et al. Effects of atrial natriuretic peptide on glycerol induced acute renal failure in the rat. Jpn Heart J [Internet]. 1992 May [cited 2019 Sep 23];33(3):383-93. Available from: http://www.ncbi. nIm.nih.gov/pubmed/1387917

89. Rahman SN, Kim GE, Mathew AS, Goldberg CA, Allgren R, Schrier RW, et al. Effects of atrial natriuretic peptide in clinical acute renal failure. Kidney Int. 1994;45(6):1731-8.

90. Lewis J, Salem MM, Chertow GM, Weisberg LS, McGrew F, Marbury TC, et al. Atrial natriuretic factor in oliguric acute renal failure. Anaritide Acute Renal Failure Study Group. Am J Kidney Dis [Internet]. 2000 Oct [cited 2019 Sep 23];36(4):767-74. Available from: http://www.ncbi.nlm.nih.gov/pubmed/11007679

91. Sezai A, Shiono M, Orime $\mathrm{Y}$, Hata $\mathrm{H}$, Hata M, Negishi N, et al. Low-dose continuous infusion of human atrial natriuretic peptide during and after cardiac surgery. Ann Thorac Surg [Internet]. 2000 Mar [cited 2019 Sep 23];69(3):732-8. Available from: http://www.ncbi.nlm.nih.gov/pubmed/10750752

92. Nigwekar SU, Navaneethan SD, Parikh CR, Hix JK. Atrial natriuretic peptide for preventing and treating acute kidney injury. Cochrane database Syst Rev [Internet]. 2009 Oct 7 [cited 2019 Sep 23];(4):CD006028. Available from: http://www.ncbi.nlm.nih. gov/pubmed/19821351

93. Mills RM, LeJemtel TH, Horton DP, Liang C, Lang R, Silver MA, et al. Sustained hemodynamic effects of an infusion of nesiritide 
(human b-type natriuretic peptide) in heart failure: a randomized, double-blind, placebo-controlled clinical trial. Natrecor Study Group. J Am Coll Cardiol [Internet]. 1999 Jul [cited 2019 Sep 23];34(1):155-62. Available from: http://www.ncbi.nlm.nih.gov /pubmed/10400005

94. Colucci WS. Nesiritide for the treatment of decompensated heart failure. J Card Fail [Internet]. 2001 Mar [cited 2019 Sep 23];7(1):92-100. Available from: http://www.ncbi.nlm.nih.gov /pubmed/11264555

95. Kumada Y, Yoshitani K, Shimabara Y, Ohnishi Y. Perioperative risk factors for acute kidney injury after off-pump coronary artery bypass grafting: a retrospective study. JA Clin Reports. 2017 Dec;3(1).

96. Sackner-Bernstein JD, Skopicki HA, Aaronson KD. Risk of worsening renal function with nesiritide in patients with acutely decompensated heart failure. Circulation [Internet]. 2005 Mar 29 [cited 2019 Sep 23];111(12):1487-91. Available from: http://www. ncbi.nlm.nih.gov/pubmed/15781736

97. O'Connor CM, Starling RC, Hernandez AF, Armstrong PW, Dickstein K, Hasselblad V, et al. Effect of nesiritide in patients with acute decompensated heart failure. N Engl J Med. 2011 Jul 7;365(1):32-43.

98. Chow SL, O'Barr SA, Peng J, Chew E, Pak F, Quist R, et al. Renal function and neurohormonal changes following intravenous infusions of nitroglycerin versus nesiritide in patients with acute decompensated heart failure. J Card Fail [Internet]. 2011 Mar [cited 2019 Sep 23];17(3):181-7. Available from:

http://www.ncbi.nlm.nih.gov/pubmed/21362524

99. Allgren RL, Marbury TC, Rahman SN, Weisberg LS, Fenves AZ, Lafayette RA, et al. Anaritide in acute tubular necrosis. N Engl J Med. 1997 Mar 20;336(12):828-34. 
100. Zhao Q, Wu T-G, Lin Y, Li B, Luo J-Y, Wang L-X. Low-dose nesiritide improves renal function in heart failure patients following acute myocardial infarction. Heart Vessels [Internet]. 2010 Mar [cited 2019 Sep 23];25(2):97-103. Available from: http://www.ncbi.nlm.nih.gov/pubmed/20339970

101. Mentzer RM, Oz MC, Sladen RN, Graeve AH, Hebeler RF, Luber $\mathrm{JM}$, et al. Effects of perioperative nesiritide in patients with left ventricular dysfunction undergoing cardiac surgery:the NAPA Trial. J Am Coll Cardiol [Internet]. 2007 Feb 13 [cited 2019 Sep 23];49(6):716-26. Available from: http://www.ncbi.nlm.nih.gov/ pubmed/17291938

102. Mitaka C, Kudo T, Haraguchi G, Tomita M. Cardiovascular and renal effects of carperitide and nesiritide in cardiovascular surgery patients: a systematic review and meta-analysis. Crit Care [Internet]. 2011 [cited 2019 Sep 23];15(5):R258. Available from: http://www.ncbi.nlm.nih.gov/pubmed/22032777

103. Burns KEA, Chu MWA, Novick RJ, Fox SA, Gallo K, Martin CM, et al. Perioperative $\mathrm{N}$-acetylcysteine to prevent renal dysfunction in high-risk patients undergoing cabg surgery: a randomized controlled trial. JAMA [Internet]. 2005 Jul 20 [cited 2019 Sep 23];294(3):342-50. Available from: http://www.ncbi.nlm.nih.gov/ pubmed/16030279

104. Haase M, Haase-Fielitz A, Bagshaw SM, Reade MC, Morgera S, Seevenayagam S, et al. Phase II, randomized, controlled trial of high-dose $\mathrm{N}$-acetylcysteine in high-risk cardiac surgery patients. Crit Care Med [Internet]. 2007 May [cited 2019 Sep 23];35(5):1324-31. Available from: http://www.ncbi.nlm.nih.gov/ pubmed/17414730

105. Sisillo E, Ceriani R, Bortone F, Juliano G, Salvi L, Veglia F, et al. $\mathrm{N}$-acetylcysteine for prevention of acute renal failure in patients with chronic renal insufficiency undergoing cardiac surgery: a 
prospective, randomized, clinical trial. Crit Care Med [Internet]. 2008 Jan [cited 2019 Sep 23];36(1):81-6. Available from: http://www.ncbi.nlm.nih.gov/pubmed/18090169

106. Haase M, Haase-Fielitz A, Bellomo R, Devarajan P, Story D, Matalanis $G$, et al. Sodium bicarbonate to prevent increases in serum creatinine after cardiac surgery: a pilot double-blind, randomized controlled trial. Crit Care Med [Internet]. 2009 Jan [cited 2019 Sep 23];37(1):39-47. Available from: http://www.ncbi.nlm.nih.gov/pubmed/19112278

107. He G, Li Q, Li W, Wang L, Yang J, Zeng F. N-Acetylcysteine for Preventing of Acute Kidney Injury in Chronic Kidney Disease Patients Undergoing Cardiac Surgery: A Metaanalysis. Heart Surg Forum. 2018 Dec 19;21(6):E513-21.

108. Mei M, Zhao HW, Pan QG, Pu YM, Tang MZ, Shen BB. Efficacy of N-Acetylcysteine in Preventing Acute Kidney Injury After Cardiac Surgery: A Meta-Analysis Study. J Investig Surg. 2017 Jan 6;1-10.

109. Ashworth A, Webb ST. Does the prophylactic administration of Nacetylcysteine prevent acute kidney injury following cardiac surgery? Interact Cardiovasc Thorac Surg. 2010 Sep 1;11(3):303-8.

110. Adabag AS, Ishani A, Koneswaran S, Johnson DJ, Kelly RF, Ward $\mathrm{HB}$, et al. Utility of $\mathrm{N}$-acetylcysteine to prevent acute kidney injury after cardiac surgery: A randomized controlled trial. Am Heart J. 2008 Jun;155(6):1143-9.

111. Berwanger $\mathrm{O}$. Acetylcysteine for prevention of renal outcomes in patients undergoing coronary and peripheral vascular angiography: Main results from the randomized acetylcysteine for contrast-induced nephropathy trial (ACT). Circulation. 2011 Sep 13;124(11):1250-9.

112. Alkan $T$, Akçevin A, Undar A, Türkoğlu H, Paker $T$, Aytaç A. 
Benefits of pulsatile perfusion on vital organ recovery during and after pediatric open heart surgery. ASAIO J [Internet]. [cited 2019 Sep 20];53(6):651-4. Available from: http://www.ncbi.nlm.nih.gov /pubmed/18043139 
Renal function following CABG: On-pump vs off-pump

K Pramodh, Vani MD, K Muralidhar MD

Published in: Indian Journal of Thoracic and Cardiovascular Surgery 2003; 19:169-73. https://doi.org/10.1007/s12055-003-0012-5. 


\section{Abstract}

Background: Despite the success of on-pump coronary artery bypass grafting (CABG), potential risk of renal dysfunction (RD) related to cardio pulmonary bypass (CPB) is well documented. Recently, several studies have demonstrated that off-pump CABG can be performed safely with results similar to on-pump CABG. Hence renal function in two groups was evaluated to aid in assessment and prevention of acute RD. Methods: Study group consisted of 60 patients (30 on-pump, mean age $51.9 \pm 8.9$ years and 30 off-pump, mean age $56.3 \pm 10.1$ years) who underwent elective primary CABG. Blood samples were collected preoperatively and at 6,24 and 48 hours post-operatively for estimation of serum creatinine and thereby assessment of creatinine clearance. Results: $46.66 \%$ and $20 \%$ of patients developed RD in on-pump and offpump CABG respectively. Creatinine clearance decreased from a preoperative value of $81 \pm 19.7 \mathrm{ml} / \mathrm{min}$ to a postoperative (24hours) value of $72.9 \pm 20.5 \mathrm{ml} / \mathrm{min}$ in off-pump and from preoperative value of $78.8 \pm 24.3$ $\mathrm{ml} / \mathrm{min}$ to a postoperative (24 hours) value of $62.7 \pm 18.2 \mathrm{ml} / \mathrm{min}$ in onpump. Creatinine clearance remained significantly depressed for 48 hours in on-pump group where as it was well preserved in the off-pump patients. Decrease in creatinine clearance in on-pump group was significant at 24 hours post-operatively $(p=0.045)$, thus suggesting that renal function was impaired in on-pump group. Hypertension, diabetes and ejection fraction $<40 \%$ have not influenced significantly in developing RD during on-pump or off-pump CABG. We also found that there was a negative correlation of creatinine clearance with age suggesting that increased age proves to be a risk factor for developing $\mathrm{RD}$ in on-pump group. Conclusions: Renal function is better preserved in patients undergoing off-pump CABG than on-pump CABG. Increased age proves to be a risk factor for patients undergoing on-pump CABG and hence elderly people have to be preferably allocated to off-pump than on-pump CABG.

\section{Keywords}

Renal dysfunction, CABG, Creatinine Clearance 


\section{Introduction}

Post-operative acute renal insufficiency continues to be a significant cause for morbidity and mortality after cardiac operations, despite advances and improvements in cardiopulmonary bypass (CPB) technology, anesthesia, intraoperative hemodynamic monitoring, intensive care and antibiotic therapy $y^{1,2,3}$. The etiology of this condition is multifactorial and includes factors relating to conduct and management of CPB, such as bypass time, use of vasopressors before CPB, systemic inflammatory response, hypoperfusion and loss of pulsatile perfusion ${ }^{4}$. Since CPB has pathophysiologic sequelae, recently there has been a revival of interest in performing coronary artery bypass grafting (CABG) on beating heart ${ }^{1}$, where, advocates of off-pump CABG have proposed that theoretical advantages of avoiding CPB are decreased incidence of neurologic dysfunction, postoperative myocardial infarction, bleeding, renal failure and respiratory failure ${ }^{5}$. Since no data is available suggestive of renal function following off-pump CABG from a prospective randomized study of patients who had elective operations, renal function in the two groups was evaluated to aid in assessment and prevention of acute renal dysfunction.

\section{Material and Methods}

\section{Patients}

A prospective study was performed in 60 patients (30 on-pump and 30 off-pump), undergoing elective primary CABG in an ultra-modern cardiac hospital. Patients were randomly allocated to either on-pump (group 1) or off-pump (group 0) group. Patients who were allocated to off-pump CABG were not crossed over to on-pump CABG at any time and thus the randomization sequence was strictly adhered to. Patients with serum creatinine levels $>1.3 \mathrm{mg} / \mathrm{dl}$, history of acute renal failure in past and any cardiac surgeries in the past were excluded from the study. 
Data collected includes age, gender, weight, history of diabetes, hypertension, ventricular ejection fraction.

\section{Anesthetic Technique}

Anesthesia was induced with pentothal sodium, fentanyl, midazolam and maintained with Isoflurane and Fentanyl as required. Muscle relaxation was achieved with pancuronium. Standard postoperative protocol for the patient management was employed.

\section{Surgical procedure}

For off-pump: Median sternotomy was performed with simultaneous harvesting of radial artery/saphenous vein and left internal mammary artery. Injection Heparin (200 units/kg) was administered. Heart was stabilized with an Octopus tissue-stabilizing device. During distal grafting, mean arterial pressure (MAP) was maintained above $70 \mathrm{~mm}$ of $\mathrm{Hg}$ using phenylephrine and inotropes (dopamine, dobutamine or adrenaline) when required. Heparin was neutralized with protamine after the grafting procedure. Hemostasis was attained. Sternotomy was repaired after placing one-mediastinal and left pleural drains.

For on-pump: Median sternotomy was performed with simultaneous harvesting of radial artery/saphenous vein and left internal mammary artery. Standard bypass techniques were employed. After systemic heparinization (heparin 400units $/ \mathrm{kg}$ ), CPB was instituted and patients were cooled to $28^{\circ} \mathrm{C}$. CPB was set up using two-stage right atrial cannulation with arterial return on to ascending aorta. Aorta was crossclamped and tepid blood cardioplegic arrest was achieved. Heparin was neutralized with protamine after the grafting procedure. While on CPB, MAP was maintained between $60-80 \mathrm{~mm}$ of $\mathrm{Hg}$ and an extracorporeal flow was maintained at 2.2-2.4 It $/ \mathrm{sq} . \mathrm{m} / \mathrm{min}$. All patients were cooled to $28^{\circ} \mathrm{C}$. Post CPB inotropes were used as required. Urine output was maintained $>1 \mathrm{ml} / \mathrm{kg} / \mathrm{hr}$ during CPB. 
In both the groups, during postoperative period, urine output was maintained more than $0.5 \mathrm{ml} / \mathrm{kg} / \mathrm{hr}$. Diuretics were used as necessary. Hemodynamic parameters like heart rate, mean arterial and central venous pressures were monitored and recorded intraoperatively and post-operatively.

\section{Sample collection}

Single arterial blood samples were collected for measurement of serum creatinine. It was done preoperatively and at 6, 24 and $48 \mathrm{hrs}$. post-operatively in the intensive care unit. All samples were analyzed immediately after collection.

\section{Laboratory Methods}

Serum creatinine values were determined with a commercial reagent kit (Creatinine Flex Ô reagent cartridge, Dimension clinical chemistry system, Dade Behring). Creatinine clearance was determined by using the standard formula - COCKROFT GAULT EQUATION ${ }^{10}$.

Creatinine clearance $=(140$-age in years $) \times$ Body weight in kgs. $/ 72 \times$ Serum creatinine in $\mathrm{mg} / \mathrm{dl}$

For females, the obtained result was multiplied by 0.85 .

\section{Statistical Analysis}

Data are presented as mean \pm standard deviation. To compare the means of 2 independent groups, the independent sample (Student's t- test) was employed. T-test with modified degrees of freedom (df) and 2-tailed $F$ max test were used whenever and wherever applicable. Comparison between the groups was performed with Mann-Whitney $U$ test, $Z$ corrected for ties. To compare the means of dependent variables whose values were obtained from the same individual at different points in time, repeated Measures Multivariate Analysis of Variance (RMANOVA) was used. Comparison of proportions of qualitative 
variables across 2 or more groups was affected using the Chi-square test with Yates' continuity correction. Correlations between quantitative variables were performed using Pearson's product moment correlation co-efficient. Differences were considered significant if $p<0.05$.

\section{Results}

The demographic characteristics of the patients studied are shown in table 1 . The groups 0 and 1 were compared with respect to

\section{Table 1. Demographic data of patient groups}

\begin{tabular}{llllll}
\hline Variable & $\begin{array}{l}\text { Off-pump } \\
\mathbf{N}=30\end{array}$ & $\begin{array}{l}\text { On-pump } \\
\mathbf{N}=30\end{array}$ & p Value & t Value & df \\
\hline Age(yrs) & $56.3 \pm 10.1$ & $51.9 \pm 8.9$ & 0.082 & 1.77 & 58 \\
Weight (kg) & $70.8 \pm 13.7$ & $65 \pm 9.9$ & 0.063 & 1.89 & 58 \\
Hypertension & 15 & 16 & 1 & & 1 \\
Diabetes & 12 & 14 & 0.79 & & 1 \\
Ejection fraction (\%) & $50.2 \pm 8$ & $50.3 \pm 9.4$ & 0.95 & 0.06 & 58 \\
Angiogram done & $30.6 \pm 41.5$ & $36.4 \pm 41.8$ & 0.2 & & $\mathrm{Z}=1.27$ \\
before surgery (days) & & & & & \\
CPB time (min) & & $99.1 \pm 24.1$ & & & \\
Aortic CCT time (min) & & $55.9 \pm 18.7$ & & & \\
\hline
\end{tabular}

Data are presented as mean \pm standard deviation

$\mathrm{CCT}=$ cross clamp time; $\mathrm{CPB}=$ cardiopulmonary bypass.

age, weight, number, hypertension, diabetes, ejection fraction, number of grafts, number of days angiogram was done before surgery, CPB time, and aortic cross clamping time. Hemodynamic parameters like heart rate, mean arterial and central venous pressures are presented in table2.

In our studies, overall incidence of renal dysfunction was $33.33 \%$. $46.66 \%$ of patients developed renal dysfunction in on-pump group and $20 \%$ of patients developed renal dysfunction in off-pump group. Serial serum creatinine levels of patients are presented in table 3 . 
Analysis of creatinine levels with respect to time in 2 groups was made. Serum creatinine levels increased progressively in both groups from preoperatively to $24 \mathrm{hrs}$ post-operatively and thereafter decreased

\section{Table 2. Hemodynamic parameters}

\begin{tabular}{llllll}
\hline Time & Off-pump & On-pump & p Value & t Value & df \\
\hline H.R $(\mathrm{bpm})$ & & & & & \\
I.P. & $76 \pm 9$ & $80 \pm 8$ & 0.07 & 1.81 & 58 \\
6hrs.P.O & $88 \pm 6$ & $86 \pm 6$ & 0.20 & 1.29 & 58 \\
24hrs.P.O & $94 \pm 6$ & $96 \pm 6$ & 0.20 & 1.29 & 58 \\
48hrs.P.O & $92 \pm 4$ & $90 \pm 6$ & 0.13 & 1.51 & 58 \\
MAP (mm Hg) & & & & & \\
I.P. & $82 \pm 7$ & $80 \pm 7$ & 0.27 & 1.10 & 58 \\
6hrs.P.O & $85 \pm 8.9$ & $82.4 \pm 10.3$ & 0.31 & 1.03 & 58 \\
24hrs.P.O & $86.9 \pm 7.5$ & $82 \pm 8.4$ & 0.021 & 2.38 & 58 \\
48hrs.P.O & $86.8 \pm 8.1$ & $86.1 \pm 10.6$ & 0.76 & 0.3 & 58 \\
CVP (mm Hg) & & & & & \\
I.P. & $8 \pm 2$ & $7 \pm 3$ & 0.13 & 1.51 & 58 \\
6hrs.PO & $9 \pm 2$ & $8.5 \pm 2$ & 0.34 & 0.97 & 58 \\
24hrs.PO & $9.2 \pm 2.2$ & $10.1 \pm 2.4$ & 0.16 & 1.42 & 58 \\
48hrs.PO & $9.5 \pm 1.9$ & $10.6 \pm 2.5$ & 0.047 & 2.03 & 58 \\
\hline
\end{tabular}

$\mathrm{CVP}=$ central venous pressure; $\mathrm{HR}=$ heart rate; $\mathrm{IP}=$ intra-operatively;

$\mathrm{MAP}=$ mean arterial pressure; $\mathrm{PO}=$ post-operatively.

by $48 \mathrm{hrs}$ post-operatively. The 2 groups did not differ statistically with respect to the changes in serum creatinine values. Serial serum creatinine clearance is presented in table 4. Creatinine clearance decreased in both groups from preoperatively to 24 hours postoperatively. At 24 hours post operatively the creatinine clearance in onpump group was significantly lower than the off-pump group. After 24 hours an increase in creatinine clearance was seen in both groups. The creatinine clearance reached towards preoperative levels in off-pump, but did not reach to preoperative levels in on-pump group. Overall there was a significant decrease in creatinine clearance across time from pre- 
operatively to 24 hours post-operatively followed by a small increase to $48 \mathrm{hrs}$ postoperatively.

Table 4. Serial creatinine clearance $(\mathrm{ml} / \mathrm{min})$ values

\begin{tabular}{lcclll}
\hline Time & Off-pump & On-pump & p Value & t Value & df \\
\hline Pr.O & $81 \pm 19.7$ & $78.8 \pm 24.3$ & 0.71 & 0.38 & 58 \\
6hrs.P.O & $80.4 \pm 24.7$ & $70.8 \pm 25.3$ & 0.14 & 1.49 & 58 \\
24hrs.P.O & $72.9 \pm 20.5$ & $62.7 \pm 18.2$ & 0.045 & 2.05 & 58 \\
48hrs.P.O & $78.9 \pm 27.2$ & $67.1 \pm 20.7$ & 0.062 & 1.9 & 58 \\
\hline
\end{tabular}

$\mathrm{PO}=$ post-operatively; $\mathrm{PrO}=$ pre-operatively

Analysis of renal function among patients with hypertension and diabetes (isolated and combined) was assessed using 4-way repeated measures multivariate analysis of variance (Table 5). Age as a risk factor for renal dysfunction was analyzed. By applying Pearson's product moment correlation co-efficient, comparison between 2 groups were made. A negative correlation with age was found, which was stronger in group 1 than in group 0 . Renal function in patients whose ejection fraction was less than $40 \%$ and more than $40 \%$ was compared. Renal function was equally preserved in both the groups.

\section{Discussion}

Post-operative renal dysfunction is a known complication following cardiac surgeries, the cause for which is multi-factorial, but primarily attributed to factors relating to renal hypoperfusion, occurring due to insult to the kidney before, during or after $\mathrm{CPB}^{7}$. The other factors contributing to it are bypass time, infection, low cardiac output, use of IABP, excessive blood loss, use of vasopressors before CPB, perioperative myocardial infarction, emergency operation, excessive transfusion, chronic renal disease. Free plasma haemoglobin, elastase \& 
endothelin. Free radicals including superoxide, hydrogen peroxide and the hydroxyl radicals can be generated during CPB \& can induce injury in the renal brush border membrane ${ }^{1}$. An inadequate flow during CPB is associated with sympathetic \& hormonal mediation of vasomotor activity which may adversely influence postoperative cardiac \& renal function?

Despite the success of CABG with CPB, the deleterious effects

Table 5. Creatinine and creatinine clearance of patients having diabetes, hypertension in isolation and combined and normal patients without diabetes and /or hypertension in two groups.

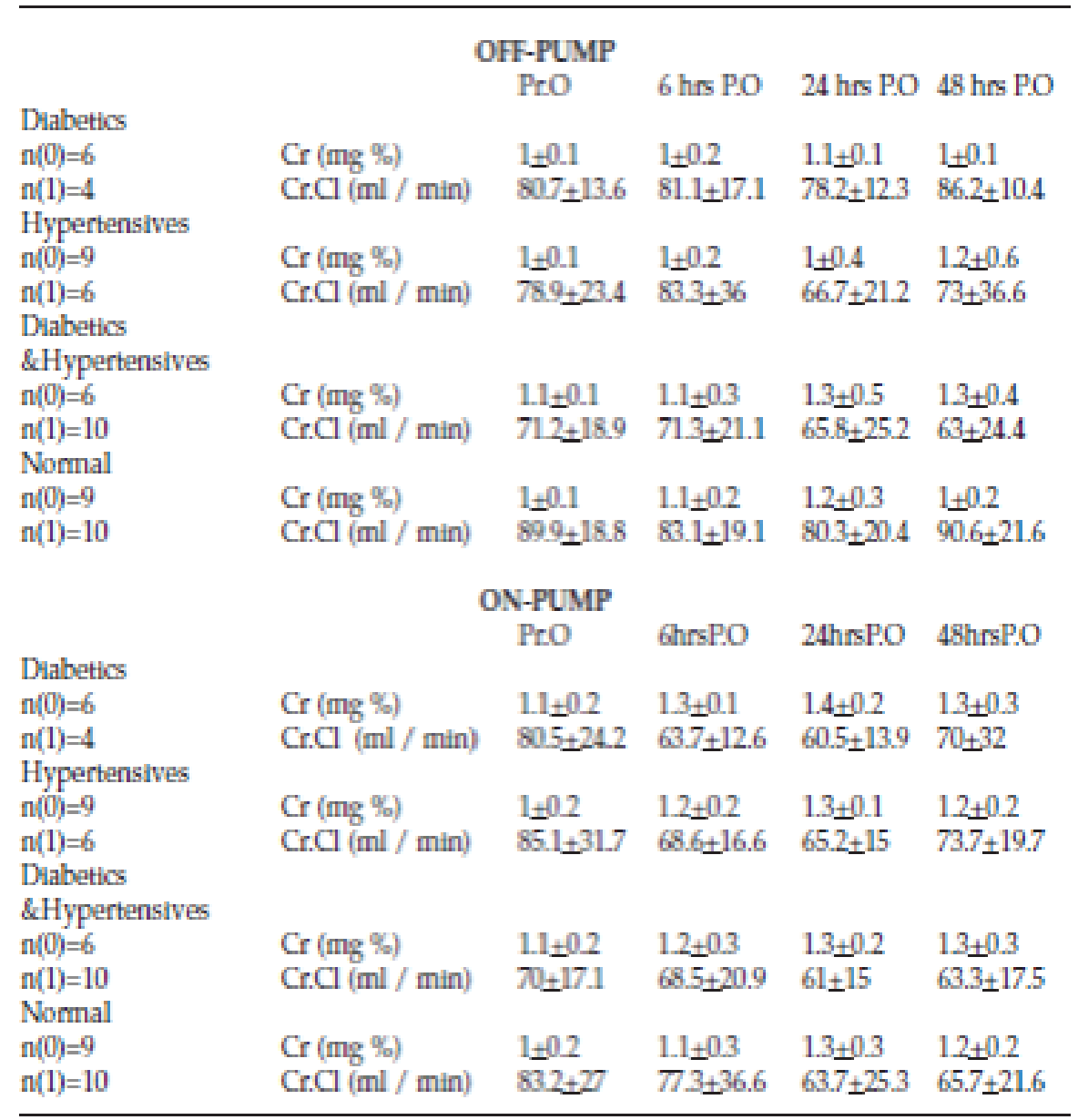

$\mathrm{n}(0)$ - number of patients in off-pump; n(1)- number of parknts in on-pump,

IO- post-operatively, $\mathrm{PrO}$ - pre-aperatively 
of CPB are well documented because of the following hazards it produces -i) Stroke and neurocognitive effects ii) immunosuppression iii) systemic inflammatory response with bleeding complications secondary to platelet dysfunction, renal insufficiency and pulmonary insufficiency. Hence the newly introduced surgical procedure off-pump CABG can be considered the best model of pulsatile perfusion and also which avoids the use of CPB and its side effects. Recent study by Omerglu et al has shown that, $C A B G$, which provides good long term graft patency can be performed on the beating heart as a viable alternative to conventional CABG i.e. on-pump ${ }^{8}$. Multiple side effects on every organ system including brain, lungs, liver and kidney which are mainly because of CPB can be avoided, by applying off-pump CABG which is its important advantage.

According to Howard et al, severe acute renal insufficiency occurs in $2 \%$ to $5 \%$ of patients whereas mild acute renal insufficiency may be seen in as many as $25 \%$ of patients undergoing cardiac surgeries $^{9}$. In our studies the incidence of acute renal insufficiency defined as serum creatinine $>1.3 \mathrm{mg} / \mathrm{dl}$, was $46.66 \%$ \& $20 \%$ in on-pump and off-pump groups respectively but since we wanted to assess the renal function accurately, we calculated the creatinine clearance by Cockroft-Gault equation. Ideally creatinine clearance should have been calculated by the formula- creatinine clearance=U.V/P (U=urine creatinine concentration, $\mathrm{V}=$ urine volume, $\mathrm{P}=$ plasma creatinine concentration). Here the $P$ value is inversely proportional to the creatinine clearance, which implies that a small rise in value of $P$, leads to a great decrease in creatinine clearance. Hence, although we actually did not find any significant difference in creatinine values in between onpump and off-pump statistically over time, we have got a significant difference in the creatinine clearance values over time in both the groups. This is substantiated by our observation as follows: - 
There was a significant decrease in the creatinine clearance in the on-pump group from pre-operatively to 24 hours post-operatively and further there was a gradual increase from 24 to $48 \mathrm{hrs}$. post-operatively, which did not reach the preoperative levels in the on-pump group while, the creatinine clearance values decreased progressively from preoperatively to $24 \mathrm{hrs}$. post-operatively which reached almost to the normal preoperative values by 48 hours post-operatively in the off-pump group. We also found that, there was a statistical significance of serial creatinine clearance values between the two groups at $24 \mathrm{hrs}$. postoperatively $(p=0.045)$. Though there was no difference in creatinine levels, the creatinine clearance decreased significantly in the on-pump group, which indicates renal dysfunction in on-pump group and there was a significant difference between the 2 groups. Hence on pump group is more prone to develop renal dysfunction after CABG.

We did not find any significance with diabetics and non-diabetics differing wholly in their creatinine and creatinine clearance. Even diabetics did not produce different results in groups 0 and 1. By the results obtained by applying Pillai's test and Fisher's test, diabetes did not influence change in creatinine and creatinine clearance across time and also in the effect of group on creatinine and creatinine clearance values across time. The same result was obtained in patients having only hypertension and in patients having both diabetes and hypertension, producing no significant changes. 
According to the previous studies done by Abel et al and Bhat

Table 6. Pearson's moment correlation co-efficients.

\begin{tabular}{lll}
\hline & Gp 0 (age) & Gp 1 (age) \\
\hline Cr.Pr.O & 0.41 & 0.14 \\
Cr.6 hrs. P.O & 0.13 & 0.14 \\
Cr.24 hrs. P.O & 0.28 & 0.14 \\
Cr.48 hrs. P.O & 0.34 & 0.34 \\
Cr.Cl.Pr.O & -0.46 & -0.61 \\
Cr.Cl.6 hrs P.O & -0.33 & -0.54 \\
Cr.Cl.24 hrs P.O & -0.46 & -0.63 \\
Cr.Cl.48 hrs P.O & -0.54 & -0.67
\end{tabular}

Cr.Pr.O=pre-operative creatinine ( $\mathrm{mg} \%$ )

$\mathrm{CrPO}=$ post-operative creatinine $(\mathrm{mg} \%)$

$\mathrm{Cr} . \mathrm{Cl} . \mathrm{Pr} . \mathrm{O}=$ pre-operative creatinine clearance $(\mathrm{ml} / \mathrm{min})$

$\mathrm{Cr} . \mathrm{Cl} . \mathrm{PO}=$ post-operative creatinine clearance $(\mathrm{ml} / \mathrm{min})$

Gp $0=$ group off-pump; Gp 1=group onpump.

JG et al, age seems to be a risk factor for acute renal insufficiency after open heart surgeries. In our study, we found that there was negative correlation of creatinine clearance with age (table-6); Statistically, creatinine clearance correlation seems to be stronger in group 1 than group 0 with respect to age, which indicates that the elderly people under going on-pump CABG are more prone to develop acute renal dysfunction.

We also compared the group of patients; whose ejection fraction was $\leq 40 \%$ and whose ejection fraction was $>40 \%$ as to know whether the group with ejection fraction $\leq 40 \%$ varied significantly from the other with respect to creatinine and creatinine clearance values. But it was not statistically significant. Hence according to our study, the group with ejection fraction $\leq 40 \%$ fared equally well as the group with ejection fraction $>40 \%$. Contrast material used for angiogram has significant importance in causing renal insufficiency. However, in our study there were no patients who had undergone angiogram within 2 - 3 days, prior 
to surgery. Hence, it is unlikely that contrast material has influenced the results.

\section{Conclusion}

By our study, we conclude that, renal function is better preserved in patients undergoing off-pump coronary revascularisation when compared to patients undergoing on-pump coronary revascularisation. Increased age proves to be a risk factor for patients undergoing on-pump CABG \& hence elderly people have to be preferably allocated to offpump than on-pump coronary revascularisation. However, it should be noted that the investigated groups are relatively small and prospective randomized studies involving larger groups will be necessary to clarify whether off-pump CABG is to be recommended preferentially in the elderly group to prevent renal dysfunction or not. 


\section{References}

1. Raimondo Ascione, Clinton T. Lloyd, Malcom J. Underwood, Walter J. Gomes and Gianni D. Angelini. Onpump versus off-pump coronary revascularisation: Evaluation of renal function. Ann Thorac Surg 1999; 68: 493-98.

2. Novis, Bruce K, Roizen, Michael F, Aronson, Solomon Aronson, et al. A. Association of preoperative risk factors with postoperative acute renal failure. Anasth \& Analg 1994; 78: 143-49.

3. Kellen, Mark, Aronson, Solomon, Roizen, Michael F, et al. A. Predictive and diagnostic tests of renal failure. Anasth \& Analg 1994; 78: 134-42.

4. Idriss A, Regragui, Mohammad Bashar Izzat, Inderpaul Birdi, Marta Lapsley, Alan J. Bryan, Gianni D. Angelini. Cardiopulmonary bypass perfusion temperature does not influence perioperative renal function. Ann Thorac Surg 1995; 60: 160-64.

5. Minoo N. Kavarana, Alain S. Asher, Alessandro Barbone, Mathew R. Williams, Joseph M. Faber, Alan D. Weinberg, et al. A comparison of consecutive off-pump versus conventional coronary artery bypass. The Heart Surgery Forum-a cardiothoracic multimedia journal. 2000-68905, December 19, 2000.

6. Andersson, Lars-Goran, Jeppsson, Anders, Lars-Eric, Ekroth, et al. Renal function during cardiopulmonary bypass: Influence of calcium entry blocker Felodipine. Anasth \& Analg 1996; 83: 34-40.

7. P.C. Ip-Yam, S. Murphy, M. Baines, M. A. Fox, M. J. Desmond, P. A. Innes. Renal function and proteinuria after cardiopulmonary bypass: The effects of temperature and mannitol. Anasth \& Analg 1994; 78: 842-47. 
8. Omerglu-SN, Kirali-K, Guler-M, Toker-ME, Ipek-G, Isik-O, et al. Midterm angiographic assessment of coronary artery bypass grafting without cardiopulmonary bypass. Ann Thoracic Surg 2000; 70: 844-50.

9. Howard L. Corwin, Stuart M. Sprague, Giacomo A. Delaria, Marija J. Norusis. Acute renal failure associated with cardiac operations. J Thorac Cardiovascular Surg 1989; 98: 1107-12.

10. Cockroft DW, Gault MH. Nephron 1976; 16: 31-41. 


\section{CHAPTER 3}

\section{Determinants of renal replacement therapy after adult cardiac surgery}

Kanchi Muralidhar, Bhagyashri Kakade, Guptha Ratan, Hegde Nitin, Ahmed Isthiaq, Vincent Lloyd.

Published in: Asian cardiovascular \& thoracic annals. 2013; 21(5):533-8. $10.1177 / 0218492312461638$. 


\begin{abstract}
Background: Acute renal injury requiring renal replacement therapy after cardiac surgery develops in $1 \%-5 \%$ of patients, and is strongly associated with perioperative morbidity and mortality. The prognostic risk factors for development acute renal injury requiring renal replacement therapy are identified in this study. Methods: 2585 adult patients who underwent cardiac surgery during a 1-year period (November 2010 to October 2011) were studied. The patients who developed acute renal injury requiring renal replacement therapy were compared with matched controls. Logistic regression analysis was applied to determine the predictors of acute renal injury requiring renal replacement therapy. Results: 44 patients developed acute renal injury requiring renal replacement therapy following cardiac surgery. On multivariate logistic analysis, the following factors independently predicted acute renal injury requiring renal replacement therapy $(p<0.05)$ : preoperative critical state, pre-existing renal dysfunction, preoperative diastolic dysfunction, and combined cardiac surgery. Conclusion: The risk of acute renal injury requiring renal replacement therapy can be fairly accurately predicted and quantified on the basis of available preoperative and intraoperative data. These predictors may be used by physicians to estimate the risk and target high-risk groups for interventions that prevent, reduce, or ameliorate the occurrence of renal failure needing acute renal replacement therapy.
\end{abstract}

\title{
Keywords
}

Acute kidney injury, cardiac surgical procedures, postoperative complications, renal dialysis, risk assessment 


\section{Introduction}

Acute renal failure after cardiac surgery continues to be a devastating complication that is associated with multiorgan dysfunction, increased resource utilization, high cost, and increased morbidity. Annually, one million patients worldwide undergo coronary revascularization with the use of cardiopulmonary bypass (CPB), and approximately 77,000 patients a year develop postoperative acute kidney injury (AKI), of which 14,000 require renal dialysis for the first time. Of the $1 \%$ to $3 \%$ of patients sustaining $A K I$ severe enough to require renal replacement therapy (RRT) or dialysis after cardiac surgery, up to $60 \%$ die before hospital discharge, and many of the survivors require continuing dialysis or are left with chronic kidney disease.(1) Although acute tubular necrosis is a potentially reversible illness, most patients who develop renal dysfunction requiring RRT, succumb before recovery as a result of complications of acute tubular necrosis, underlying pathology, or multiorgan failure. Even during cardiac procedures involving the use of $\mathrm{CPB}$, in which there is no evidence of $\mathrm{AKI}$ by serum creatinine, more subtle markers often demonstrate renal tubular injury.(2) Greater degrees of AKI after cardiac surgery are associated with poorer outcomes, increased costs, and more short- and long-term resource utilization(3-5)The degree of AKI also predicts poorer long-term survival in patients discharged home.(6-8) Notably, the long-term risk of mortality and other adverse outcomes is strongly linked to the magnitude of the injury; incomplete return of renal function occurs in up to one-third of these patients. (6-8) We analyzed the outcome of patients undergoing cardiac surgery in terms of the incidence of AKI requiring RRT.

\section{Patients and methods}

We reviewed data collected from 2585 adult patients who underwent cardiac surgery at this institution from November 2010 to 
October 2011. Of these, 44 developed acute renal failure needing RRT, and their data were analyzed. Patients who were on maintenance dialysis prior to surgery were excluded from the analysis. The study group was compared with randomly selected controls of same number,

Table I. Preoperative data of 44 patients who developed postoperative acute renal injury, and 44 controls.

\begin{tabular}{llll}
\hline Variable & $\begin{array}{l}\text { Study } \\
\text { group }\end{array}$ & $\begin{array}{l}\text { Control } \\
\text { group }\end{array}$ & p value \\
\hline Age (years) & $56.5 \pm 12.5$ & $52 \pm 14.0$ & 0.06 \\
Sex (male/female) & $36 / 8$ & $30 / 14$ & 0.140 \\
COPD & 8 & 9 & 1.0 \\
Extracardiac arteriopathy & 5 & 3 & 0.7 \\
Neurologic dysfunction & 4 & 0 & 0.116 \\
Previous cardiac surgery & 8 & 1 & 0.03 \\
Active endocarditis & 1 & 0 & 1.0 \\
Critical preoperative state & 13 & 0 & $<0.001$ \\
Diabetes mellitus & 24 & 18 & 0.2 \\
Acute coronary syndrome & 13 & 9 & 0.46 \\
LV dysfunction & 23 & 16 & 0.198 \\
Recent MI & 4 & 3 & 1.000 \\
PA hypertension & 19 & 15 & 0.512 \\
surgery on thoracic aorta & 2 & 0 & 0.494 \\
Post-MI septal rupture & 3 & 0 & 0.241 \\
Diastolic dysfunction & 19 & 7 & 0.005 \\
\hline CO & & &
\end{tabular}

COPD: chronic obstructive pulmonary disease; LV: left ventricular;

MI: myocardial infarction; PA: pulmonary arterial.

who did not develop renal failure during the same period. Table 1 shows the demographic and preoperative data of the RRT and the control groups. The incidences of diabetes mellitus, acute coronary syndrome, left ventricular dysfunction, 
and diastolic dysfunction were significantly higher in patients who developed AKI needing RRT. Definitions of the terminology are given in Table 2. Anesthetic premedication consisted of an anxiolytic and preoperative cardiac medication, with the exception of angiotensinconverting-enzyme inhibitors.

Anesthesia was induced with a combination of midazolam, fentanyl, and propofol. Endotracheal intubation was performed using pancuronium bromide. Anesthesia was maintained with isoflurane in an air oxygen mixture. Hemodynamics were maintained within $20 \%$ of baseline values. Anticoagulation was achieved using heparin to maintain the activated coagulation time at $5480 \mathrm{~s}$ during CPB. A standardized

Table 2. Definitions of terminology.

\begin{tabular}{|c|c|}
\hline Term & Definition \\
\hline Unstable angina & Rest angina requiring IV nitrates until arrival in the anesthetic room \\
\hline Left ventricular dysfunction & Moderate (LVEF $30 \%-50 \%$ ) or poor (LVEF < $30 \%$ ) \\
\hline Recent myocardial infarction & Acute myocardial infarction $<90$ days \\
\hline Pulmonary hypertension & Systolic pulmonary artery pressure $>60 \mathrm{~mm} \mathrm{Hg}$ \\
\hline Emergency operation & Carried out on referral before the next working day \\
\hline Diabetes mellitus & Needing oral hypoglycemic agents or insulin \\
\hline Major cardiac surgery & Major cardiac procedure other than or in addition to CABG \\
\hline Post-infarction septal rupture & Ventricular septal defect following acute myocardial infarction \\
\hline \multirow[t]{3}{*}{ Diastolic dysfunction } & Grade I (impaired relaxation) \\
\hline & Grade II (pseudo-normal) \\
\hline & Grade III (restrictive) \\
\hline \multirow[t]{2}{*}{ Chronic pulmonary disease } & Long-term use of bronchodilators/steroids \\
\hline & History of chronic bronchitis or emphysema \\
\hline Extracardiac arteriopathy & $\begin{array}{l}\text { Claudication, carotid occlusion, }>50 \% \text { stenosis, previous or } \\
\text { planned intervention on abdominal aorta, limb or carotids arteries }\end{array}$ \\
\hline Neurological dysfunction & Severely affecting ambulation or day-to-day functioning \\
\hline Previous cardiac surgery & Previous surgery that required opening the pericardium \\
\hline Renal dysfunction & Serum creatinine $>1.5 \mathrm{mg} \cdot \mathrm{dL}^{-1}$ or estimated GFR $<60 \mathrm{~mL} \cdot \mathrm{min}^{-1}$ \\
\hline Active endocarditis & Under antibiotic treatment for endocarditis at time of surgery \\
\hline \multirow[t]{5}{*}{ Critical preoperative state } & Ventricular tachycardia or fibrillation or aborted sudden death \\
\hline & Preoperative cardiac massage \\
\hline & Preoperative ventilation before arrival in the anesthetic room \\
\hline & Preoperative inotropic or intraaortic balloon pump support \\
\hline & Preoperative acute renal failure (anuria or oliguria) \\
\hline
\end{tabular}

CABG: coronary artery bypass grafting; GFR: glomerular filtration rate; N: intravenous; LVEF. left ventricular ejection fraction. 
perfusion protocol was employed, which included nonpulsatile CPB and maintenance of mean arterial pressure at $60-80 \mathrm{mmHg}$ during CPB. Heparin was neutralized with protamine after separation from CPB. Patients were electively ventilated after surgery until the criteria for tracheal extubation were met. Data recorded included demographic information, preoperative clinical variables, operation-related factors, and postoperative variables. The preoperative clinical variables were cardiacrelated factors (unstable angina, left ventricular ejection fraction, previous cardiac surgery, active endocarditis, diastolic dysfunction, critical preoperative state, post-infarction septal rupture), history of chronic pulmonary disease, extracardiac arteriopathy, neurological dysfunction, renal dysfunction, diabetes mellitus, and pulmonary hypertension.

Operation-related factors recorded were emergency status, a major cardiac procedure other than or in addition to coronary artery bypass grafting, operations on the ascending, arch, or descending aorta; number of grafts; coronary artery bypass grafting; CPB time; aortic cross clamp time; deep hypothermic circulatory arrest time; inotropics used during surgery; and usage of blood and blood products. Postoperative data recorded were duration of inotropic infusion, incidence of arrhythmias, time to extubation, use of an intraaortic balloon pump (IABP), need for pacing, reexploration for bleeding, perioperative myocardial infarction, sternal or leg wound infection, septicemia, cerebrovascular accident, tracheostomy, bed sore, renal dysfunction needing dialysis, psychological complications, multiorgan dysfunction, duration of intensive care unit and hospital stay, and hospital death. Criteria for the initiation of RRT were 2 or more of the following: oliguria (urine output $<200 \mathrm{~mL}$ per $12 \mathrm{~h}$ ), anuria (urine output: $0-50 \mathrm{~mL}$ per $12 \mathrm{~h}$ ), blood urea $>200 \mathrm{mg} \cdot \mathrm{dL}^{-1}$, creatinine $>3.6 \mathrm{mg}^{-\mathrm{dL}^{-1}}, \mathrm{Kp}>6.5 \mathrm{mmol} . \mathrm{L}^{-1}$ or rapidly rising, pulmonary edema unresponsive to diuretics, 
uncompensated metabolic acidosis $(\mathrm{pH}<7.1), \quad \mathrm{Nap}<110$ and $>160$ mmol. $\mathrm{L}^{-1}$, temperature $>40^{\circ} \mathrm{C}$, and uremic encephalopathy.

The statistical software SAS version 9.2, SPSS 15.0, Stat 10.1, Medical 9.0.1, Systat 12.0, and Renvironment 2.11.1 were used for analyses of the data. The results of continuous measurements are presented as mean \pm standard deviation, and categorical measurements are given in number and percentage. Significance was assessed the $5 \%$ level. The various tests used were Student's $t$ test (2-tailed and independent) to find the significance of study parameters on continuous scales or between 2 group on metric parameters, the test for homogeneity of variance, the chi-squared test, or Fisher's exact test to find the significance of study parameters on categorical scales among 2 or more groups, and multivariate logistic regression analysis. The goal of logistic regression was to predict the category of outcome for individual cases, using the most parsimonious model. To accomplish this goal, a model was created that included all predictor variables; stepwise regression was analyzed. A $p$ valve of $<0.05$ was considered significant.

\section{Results}

Of the 2585 patients who underwent cardiac surgery during one year, 44 developed acute renal failure of sufficient severity to indicate the institution of RRT; thus, the observed overall frequency of AKI requiring RRT in the study was $1.7 \%$. Table 3 shows the intraoperative and postoperative data. Using univariate analysis, the duration of postoperative ventilator support, inotropic support, use of IABP, temporary pacing, and re-exploration for bleeding were significantly higher in the RRT group. The requirement for IABP support and duration of inotrope usage are indicators of low cardiac output status in the RRT group. Obviously, prolonged postoperative ventilator support and requirement for tracheostomy were responsible for longer intensive care unit and hospital stays in the RRT group. Similarly, the incidence of 
septicemia, bed sores, neuropsychiatric complications, and multiorgan dysfunction were significantly higher in the RRT group. Hospital mortality (within 30 days of surgery) in the study group was $61.4 \%(n=27)$, which

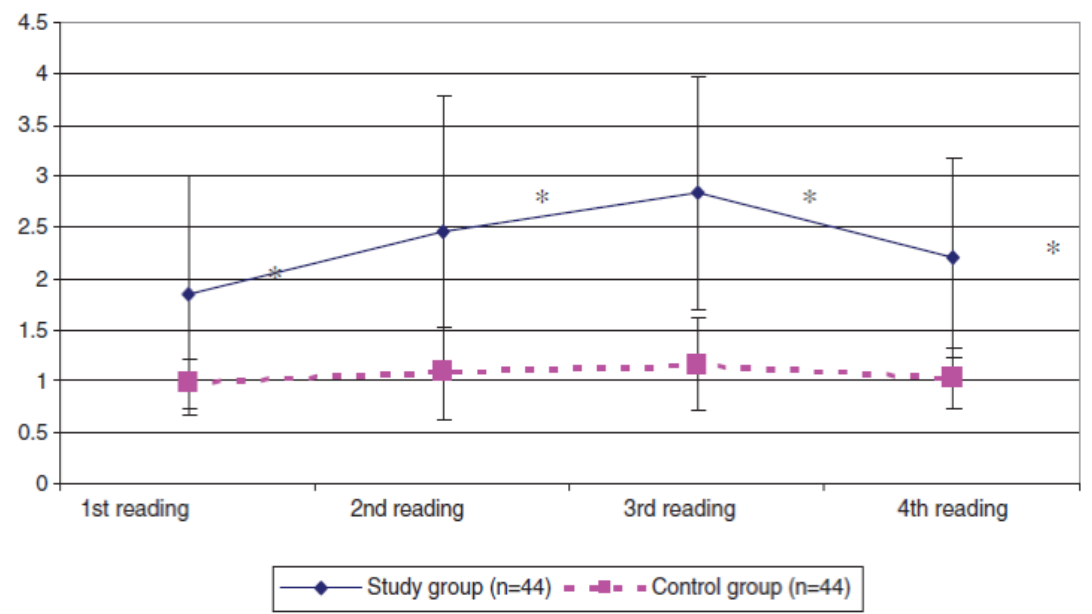

Figure I. Comparison of serum creatinine in the 2 groups. Ist reading=preoperative, 2 nd reading $=$ end of surgery, $3 \mathrm{rd}$ reading $=24 \mathrm{~h}$ after surgery, 4 th reading $=$ before intensive care unit discharge.

was highly significant. Figure 1 shows the values of serum creatinine in the 2 groups; the values were $>1.5 \mathrm{mg}^{-\mathrm{dL}^{-1}}$ throughout in the study group, whereas they were $<1.2 \mathrm{mg} \cdot \mathrm{dL}^{-1}$ in the control group. On multivariate logistic regression analysis, the factors that were highly predictive of renal dysfunction and requirement for RRT after cardiac surgery were preoperative critical status, preoperative renal dysfunction, preoperative diastolic dysfunction (grades 1,2 and 3), and major cardiac surgery with or without coronary artery bypass grafting. 
Table 3. Intraoperative and postoperative data.

\begin{tabular}{|c|c|c|c|}
\hline Variable & Study group & Control group & $p$ value \\
\hline Duration of inotropic support (h) & $11.05 \pm 9.67$ & $3.69 \pm 4.29$ & $<0.001$ \\
\hline Time to extubation (h) & $12.16 \pm 10.32$ & $2.37 \pm 4.06$ & $<0.001$ \\
\hline Intraaortic balloon pump & 17 & 2 & 0.001 \\
\hline Temporary pacing & 16 & 6 & 0.025 \\
\hline Reexploration for bleeding & 14 & 3 & 0.006 \\
\hline Perioperative myocardial infarction & 2 & 0 & 0.494 \\
\hline Sternal infection & 5 & 2 & 0.434 \\
\hline Leg wound infection & 4 & I & 0.360 \\
\hline Septicemia & 10 & I & 0.007 \\
\hline Stroke & 3 & 0 & 0.241 \\
\hline Tracheostomy & 15 & 1 & $<0.001$ \\
\hline Bed sore & 14 & 2 & 0.002 \\
\hline Renal dysfunction & 43 & I & $<0.001$ \\
\hline Neuropsychiatric complication & 5 & I & 0.202 \\
\hline Multiorgan dysfunction & 14 & 0 & $<0.001$ \\
\hline Death & 27 & 2 & $<0.001$ \\
\hline
\end{tabular}

\section{Discussion}

Acute kidney injury after cardiac surgery is a recognized complication that becomes devastating if RRT is required. RRT strikingly increases the risk of postoperative death. Despite improvements in surgical and anesthetic techniques and advances in dialysis, the risk of death due to renal failure persists. Preoperative renal risk stratification provides an opportunity to develop strategies for early diagnosis and

Table 4. Multivariate logistic regression analysis of predictors of renal replacement therapy.

\begin{tabular}{|c|c|c|c|c|c|}
\hline \multirow[b]{2}{*}{ Predictors } & \multicolumn{2}{|c|}{ Renal replacement therapy } & \multirow[b]{2}{*}{$p$ value } & \multirow[b]{2}{*}{ OR } & \multirow[b]{2}{*}{$95 \% \mathrm{Cl}$} \\
\hline & No & Yes & & & \\
\hline Preop critical status & 0 & $13(29.5 \%)$ & $<0.001$ & & \\
\hline Preop creatinine $>1.2 \mathrm{mg} \cdot \mathrm{dL}^{-1}$ & $5(11.4 \%)$ & $25(56.8 \%)$ & $<0.001$ & 13.23 & $3.83-45.69$ \\
\hline Diastolic dysfunction & 7 (I5.9\%) & $19(43.2 \%)$ & 0.006 & 6.97 & $1.75-27.73$ \\
\hline Major cardiac surgery \pm CABG & I $(2.3 \%)$ & $8(18.2 \%)$ & 0.006 & 31.09 & $2.65-365.08$ \\
\hline Intraoperative CPB $>140 \mathrm{~min}$ & $12(27.3 \%)$ & $17(38.6 \%)$ & 0.728 & 1.43 & $0.19-10.89$ \\
\hline Crossclamping $>90 \mathrm{~min}$ & $13(29.5 \%)$ & $16(36.4 \%)$ & 0.276 & 0.32 & $0.04-2.52$ \\
\hline
\end{tabular}

CABG: coronary artery bypass grafting; $\mathrm{Cl}$ : confidence interval; CPB: cardiopulmonary bypass; OR: odds ratio.

intervention. In this 
report, preoperative correlates of AKI necessitating RRT included baseline renal dysfunction, diastolic dysfunction, combined or major cardiac surgery, and preoperative critical status in the form of a need for ventilation or inotropic or IABP support, and prolonged ICU stay.

Various studies have looked into patient factors associated with the development of AKI following cardiac surgery. In a multivariable model, the preoperative patient characteristics most strongly associated with postoperative severe renal insufficiency included advanced age, female sex, white blood cell count $>12,000 / \mathrm{mm}^{3}$, previous coronary artery bypass, history of or ongoing congestive heart failure, peripheral vascular disease, hypertension, diabetes, and preoperative IABP.(9) In our study, all factors of a preoperative critical state (defined in Table 2) were significant risk factors for development of AKI requiring RRT after cardiac surgery. Such patients invariably have decreased renal perfusion as a result of systemic and renal vasoconstriction, which is worsened by the impact of surgery and anesthesia. In another study, multivariable predictors of RRT were preoperative estimated glomerular filtration rate, diabetes mellitus requiring medication, left ventricular ejection fraction, previous cardiac surgery, urgency of surgery, and preoperative IABP.(10) The incidence of postoperative renal compromise was $4.8 \%$; independent and significant risk factors were age $>75$ years, preoperative congestive heart failure, prior myocardial infarction, preexisting renal disease, intraoperative use of multiple inotropics, intraoperative IABP insertion, cardiopulmonary bypass $>2 \mathrm{~h}$, and preoperative pulse pressure such that for every additional $20-\mathrm{mm} \mathrm{Hg}$ increment in pulse pressure $>40 \mathrm{mmHg}$, there was a measurable risk of renal failure. Patients with pulse pressure hypertension $>80 \mathrm{mmHg}$ were 3-times more likely to suffer a renal-related death compared to those without these complications (3.7\% vs. $1.1 \%) .(11)$ 
Despite concern for almost half a century over the gravity of renal dysfunction as a complication,(3,12-14) AKI persists as a prevalent and major predictor of early mortality after cardiac surgery.(15) Although some of the damage associated with AKI simply reflects its association of other serious complications (e.g. sepsis) as an "epiphenomenon", there is also compelling evidence that $A K I$ itself contributes to unfavorable outcome.(16-21) Accumulation of uremic toxins other than urea and creatinine have widespread adverse effects on most organ systems.(16,17,22)Although mostly studied in chronic renal disease, inadequate clearance of uremic toxins adversely affect survival.(23) Even when postoperative dialysis is avoided, the powerful relationship of AKI with adverse outcome continues to stimulate the search for treatment options to protect the kidney. Although we practice avoidance of the numerous recognized renal insults, and follow well established protocols to reduce $\mathrm{AKI}$ rates, the search for renoprotective strategies have been somewhat disappointing. Lack of progress in this area has fueled strategic research into the pathogenesis of AKI, with a consensus that serum creatinine is the only marker commonly employed, but accumulation takes $48-72 \mathrm{~h}$. This is in contrast to conditions such as acute myocardial infarction in which advances have been made in terms of biomarkers of cellular injury.

Acute renal failure necessitating the use of RRT is a rare but serious complication after cardiopulmonary bypass. Multivariate regression analysis reveals that predictors of $\mathrm{AKI}$ after cardiac surgery include prior renal dysfunction, a critical preoperative state, diastolic dysfunction, and combined or major cardiac surgery. The therapeutic strategy may be directed towards preventing the occurrence or worsening of renal function in this group of patients. 


\section{REFERENCES}

1. Schiffl $H$. Renal recovery from acute tubular necrosis requiring renal replacement therapy: A prospective study in critically ill patients. Nephrol Dial Transplant. 2006 May;21(5):1248-52.

2. Mazzarella V, Gallucci MT, Tozzo C, Elli M, Chiavarelli R, Marino $\mathrm{B}$, et al. Renal function in patients undergoing cardiopulmonary bypass operations. J Thorac Cardiovasc Surg [Internet]. 1992 Dec [cited 2019 Dec 11];104(6):1625-7. Available from: http://www.ncbi.nlm.nih.gov/pubmed/1453727

3. Conlon PJ, Stafford-Smith M, White WD, Newman MF, King S, Winn MP, et al. Acute renal failure following cardiac surgery. Nephrol Dial Transplant. 1999;14(5):1158-62.

4. Mangano CM, Diamondstone LS, Ramsay JG, Aggarwal A, Herskowitz A, Mangano DT. Renal dysfunction after myocardial revascularization: risk factors, adverse outcomes, and hospital resource utilization. The Multicenter Study of Perioperative Ischemia Research Group. Ann Intern Med [Internet]. 1998 Feb 1 [cited 2019 Dec 11];128(3):194-203. Available from: http://www.ncbi.nlm.nih.gov/pubmed/9454527

5. Page US, Washburn T. Using tracking data to find complications that physicians miss: the case of renal failure in cardiac surgery. Jt Comm J Qual Improv [Internet]. 1997 Oct [cited 2019 Nov 20];23(10):511-20. Available from: http://www.ncbi.nlm.nih.gov /pubmed/9383670

6. Coca SG, Yusuf B, Shlipak MG, Garg AX, Parikh CR. Long-term Risk of Mortality and Other Adverse Outcomes After Acute Kidney Injury: A Systematic Review and Meta-analysis. Am J Kidney Dis. 2009 Jun;53(6):961-73. 
7. Swaminathan M, Hudson CCC, Phillips-Bute BG, Patel UD, Mathew JP, Newman MF, et al. Impact of early renal recovery on survival after cardiac surgery-associated acute kidney injury. Ann Thorac Surg [Internet]. 2010 Apr [cited 2019 Oct 15];89(4):1098104. Available from: http://www.ncbi.nlm.nih.gov /pubmed/20338313

8. Bihorac A, Yavas S, Subbiah S, Hobson CE, Schold JD, Gabrielli $A$, et al. Long-term risk of mortality and acute kidney injury during hospitalization after major surgery. Ann Surg [Internet]. 2009 May [cited 2019 Sep 20];249(5):851-8. Available from: http://www.ncbi.nlm.nih.gov/pubmed/19387314

9. Brown JR, Cochran RP, Leavitt BJ, Dacey LJ, Ross CS, MacKenzie TA, et al. Multivariable prediction of renal insufficiency developing after cardiac surgery. Circulation. 2007 Sep;116(11 SUPPL. 1).

10. Wijeysundera DN, Karkouti K, Dupuis JY, Rao V, Chan CT, Granton JT, et al. Derivation and validation of a simplified predictive index for renal replacement therapy after cardiac surgery. J Am Med Assoc. 2007 Apr 25;297(16):1801-9.

11. Aronson S, Fontes ML, Miao Y, Mangano DT, Investigators of the Multicenter Study of Perioperative Ischemia Research Group, Ischemia Research and Education Foundation. Risk index for perioperative renal dysfunction/failure: critical dependence on pulse pressure hypertension. Circulation [Internet]. 2007 Feb 13 [cited 2019 Sep 20];115(6):733-42. Available from: http://www.ncbi.nlm.nih.gov/pubmed/17283267

12. Doberneck RC, Reiser MP, Lillehei CW. Acute renal failure after open-heart surgery utilizing extracorporeal circulation and total body perfusion. Analysis of 1000 patients. J Thorac Cardiovasc 
Surg [Internet]. 1962 Apr [cited 2019 Nov 20];43:441-52. Available from: http://www.ncbi.nlm.nih.gov/pubmed/13886739

13. Abel RM, Beck CH, Buckley MJ, Austen WG. Renal Dysfunction Following Open-Heart Operations. Arch Surg. 1974;108(2):1757.

14. Yeh TJ, Brackney EL, Hall DP, Ellison RG. Renal Complications Of Open-Heart Surgery: Predisposing Factors, Prevention, And Management. J Thorac Cardiovasc Surg [Internet]. 1964 Jan [cited 2019 Nov 20];47:79-97. Available from: http://www.ncbi. nlm.nih.gov/pubmed/14113178

15. Lu JCT, Coca SG, Patel UD, Cantley L, Parikh CR. Searching for Genes That Matter in Acute Kidney Injury: A Systematic Review for the Translational Research Investigating Biomarkers and Endpoints for Acute Kidney Injury (TRIBE-AKI) Consortium. Clin J Am Soc Nephrol. 2009;4:1020-31.

16. Kelly KJ. Distant effects of experimental renal ischemia/reperfusion injury. J Am Soc Nephrol [Internet]. 2003 Jun [cited 2019 Nov 20];14(6):1549-58. Available from: http://www.ncbi.nlm.nih.gov/pubmed/12761255

17. Rabb H, Wang Z, Nemoto T, Hotchkiss J, Yokota N, Soleimani M. Acute renal failure leads to dysregulation of lung salt and water channels. Kidney Int. 2003;63(2):600-6.

18. Deng J, Hu X, Yuen PST, Star RA. Alpha-melanocyte-stimulating hormone inhibits lung injury after renal ischemia/reperfusion. Am J Respir Crit Care Med [Internet]. 2004 Mar 15 [cited 2019 Nov 20];169(6):749-56. Available from: http://www.ncbi.nlm.nih.gov /pubmed/14711793

19. Kramer AA, Postler G, Salhab KF, Mendez C, Carey LC, Rabb H. Renal ischemia/reperfusion leads to macrophage-mediated 
increase in pulmonary vascular permeability. Kidney Int. 1999;55(6):2362-7.

20. Meldrum KK, Meldrum DR, Meng X, Ao L, Harken AH. TNF- $\alpha-$ dependent bilateral renal injury is induced by unilateral renal ischemia-reperfusion. Am J Physiol - Hear Circ Physiol. 2002;282(2 51-2).

21. Serteser M, Koken T, Kahraman A, Yilmaz K, Akbulut G, Dilek ON. Changes in hepatic TNF- $\alpha$ levels, antioxidant status, and oxidation products after renal ischemia/reperfusion injury in mice. J Surg Res. 2002;107(2):234-40.

22. Cohen G, Hörl WH. Retinol binding protein isolated from acute renal failure patients inhibits polymorphonuclear leucocyte functions. Eur J Clin Invest. 2004 Nov;34(11):774-81.

23. Vanholder R, De Smet R, Glorieux G, Dhondt A. Survival of hemodialysis patients and uremic toxin removal. In: Artificial Organs. 2003. p. 218-23. 


\section{CHAPTER 4}

Genetic factors predisposing to acute kidney injury in patients undergoing offPump Coronary artery Bypass Graft (OPCABG) Surgery

Muralidhar Kanchi, Aditya Chaubey, VL Ramprasad, Sanghamitra Mishra, Kumar Belani, Varun Shetty, J Maessen.

Presented at the ASA meeting October 2018 at San Francisco, USA 


\section{Introduction}

Acute kidney injury (AKI) is not an uncommon clinical consequence in patients undergoing coronary artery bypass graft (CABG) surgery(1) occurring between $5-30 \%$ in hospitals around the world(2-4) AKI is one of major causes of the hospital morbidity and mortality following CABG. Mortality is up to $60 \%$ when renal replacement therapy is needed post cardiac surgery. Previous genome wide association studies (GWAS) done in Caucasians have identified up to 9 genetic polymorphisms in CABG patients developing AKI(5). In this study we evaluated the genetic predisposition to AKI using GWAS in patients from the Indian subcontinent undergoing elective off-pump CABG.

\section{Objectives of the Study:}

This study aims to explore the genetic predisposition(s) to Acute Kidney Injury (AKI) in patients undergoing off-Pump coronary artery bypass graft in the Indian subcontinent population, leading to the identification of the genetic polymorphism that have an impact on the disease.

\section{Specific objectives:}

1. To identify genomic profile (genomic-biomarkers) that will help to assess/predict the pre-operative risk to acute kidney injury

2. To identify genomic variations that make our population predisposed to pre-mature renal dysfunction.

3. To identify genomic variants associated with Coronary Artery Disease.

\section{Methods}

After ethical clearance, consenting patients/healthy controls presenting to a tertiary care cardiac hospital were recruited. Study participants were categorized into four cohorts as follows: $(A)$ patients with normal renal function undergoing off-pump CABG ( serum creatinine 
$<1.3 \mathrm{mg} / \mathrm{dl}$ and $/$ or eGFR $>60 \mathrm{ml} / \mathrm{min} / \mathrm{m} 2$ ); (B) patients with renal dysfunction ( serum creatinine $>1.3 \mathrm{mg} / \mathrm{dl}$ and $/$ or eGFR $<60 \mathrm{ml} / \mathrm{min} / \mathrm{m} 2$; not needing dialysis) undergoing off-pump CABG; (C) patients with renal dysfunction with no symptomatic/known heart disease (D) age-matched healthy control population (with normal kidney function, without symptomatic/known heart disease). Informed consent was obtained from the patients participating in the study. Peripheral blood samples were collected from these patients before the surgery. A detailed clinical history including information about nativity, mother tongue, body weight, height, serum creatinine, GFR, clinical diagnosis, family history was obtained from each of the participants. DNA was isolated from these blood samples and quantified to check the purity and integrity.

\section{Table 1: AKI Categories in the study}

\begin{tabular}{|c|c|}
\hline Categories & Description \\
\hline A & $\begin{array}{l}\text { Patients with normal renal function pre-surgery undergoing } \\
\text { off-pump CABG. }\end{array}$ \\
\hline B & $\begin{array}{l}\text { Patient with renal dysfunction (not needing dialysis) } \\
\text { undergoing off-pump CABG. }\end{array}$ \\
\hline C & $\begin{array}{l}\text { Patients with renal dysfunction with no symptomatic heart } \\
\text { disease }\end{array}$ \\
\hline D & $\begin{array}{l}\text { Patient with renal dysfunction with diabetes only and no } \\
\text { symptomatic heart disease }\end{array}$ \\
\hline
\end{tabular}

\section{Global Screening Array (GSA):}

The Infinium Global Screening Array (GSA) BeadChip is an advanced genotyping array that provides a cost-effective solution for population-scale genetic studies, variant screening, and precision medicine research. Using the proven iScan ${ }^{\mathrm{TM}}$ System, integrated 
analysis software, and Infinium high-throughput screening (HTS) Assay, this high-density, 24-sample BeadChip provides optimized content for a broad range of applications. The number of common markers between Infinium GSA chip version 1 and version 2 is 613,467.

\section{Figure 1: Flowchart of AKI association analysis}

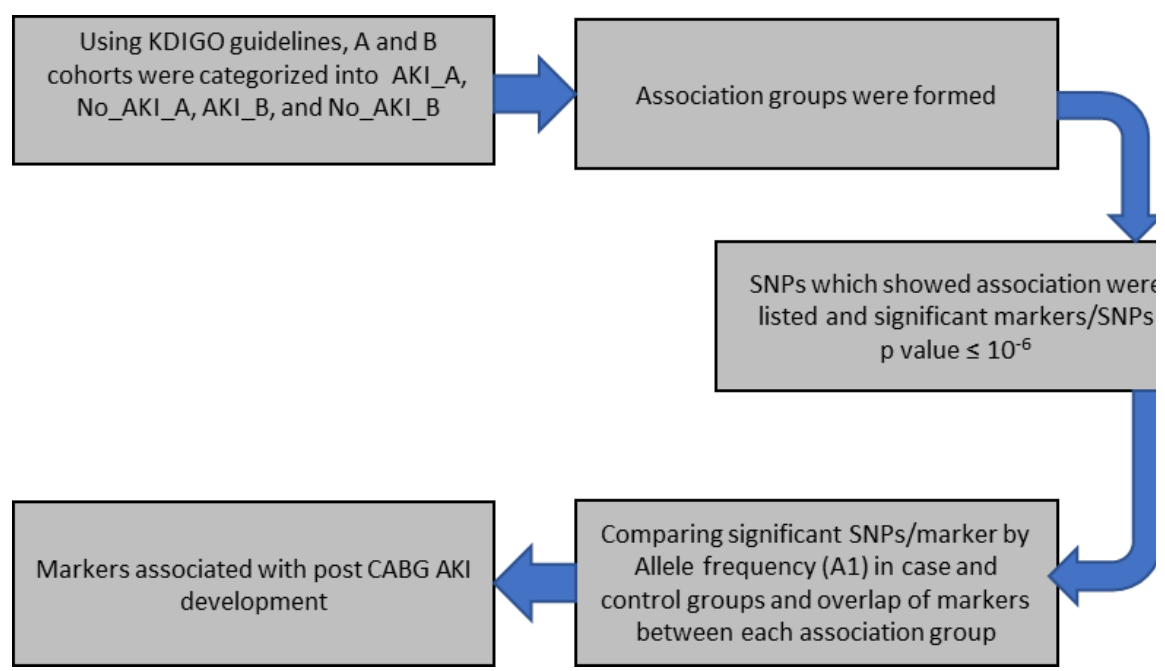

${ }^{*}$ Kidney Disease Improving Global Outcomes.

The Infinium Global Screening Array product files were taken from http://sapac.support.illumina.com/array/array_kits/infinium-global-

screening-array/downloads.html

SNP Genotyping was performed for each of the samples using Infinium Global Screening Array (GSA), Illumina. A summary of the markers is given in Table 2. The GSA process involves amplification, fragmentation, precipitation, and resuspension of the DNA. The resuspended DNA is hybridized to the bead chips. These chips are then stained after singlebase extension and scanned using iScan system. The resulting raw data files were analyzed using Genome studio 2.0 software. Automated genotype calling was done using Genome Studio v2.0. The data generated thereafter was stored and then exported using Plink 1.9. Quality check of the exported GSA data was done through custom 
Bioinformatics Pipeline using Vcftools v0.1.13, R packages ( $R$ version 3.3.2), gdsfmt 1.1 .0 and SNPRelate 1.12.2. Principal Components Analysis (PCA) was performed to analyze genome-wide singlenucleotide polymorphism (SNP) data, for detecting population structure and potential outliers.

A total of 493 individuals were genotyped using Illimuna Infinium GSA v1 \& v2 platforms (in part). The raw images were exported from the Illumina iScan machine and the IDAT files were converted to genotypes using methods recommended by Illumina Inc. Further common positions between GSA v1 and v2 were extracted (610780 markers) and performed QC. The sample level genotyping rate thresholds was set to 0.95 and removed one sample, which was below the threshold. Further 5 samples were found to have extreme low heterozygosity rate, and were removed from subsequent analysis. The overall genotyping rate post-QC is found to be 0.994 .

Table 2: Common markers in Infinium version 1 and 2 beadchips:

\begin{tabular}{|l|c|}
\hline \multicolumn{1}{|c|}{ Feature } & Description \\
\hline No. of markers in Version 1 & 642,824 \\
\hline No. of markers in Version 2 & 665,608 \\
\hline No. of markers common between V1 and V2 & 613,467 \\
\hline Capacity for Custom Markers & \\
\hline Number of Samples per Bead Chip & 50,000 \\
\hline DNA Input Requirement & 24 \\
\hline Assay & $200 n g$ \\
\hline Instrument Support & Infinium HTS \\
\hline
\end{tabular}


Genotype association was assessed between groups given in Table 1. These categories were based on the post-operative serum creatinine. Patients under AKI_A were those of Category $A$ who developed kidney dysfunction after CABG, while those under No_AKI_A did not develop any kidney dysfunction after CABG. So was for AKI_B and No_AKI_B. Association were tested using plink tool (version 1.9) in between the groups: Association groups given in Table 1 were formed and association analysis was performed using 610780 markers with Bonferroni corrected p.value threshold of 0.05 . The results of association analysis is summarized in Attached Excel file.

\section{Results}

Sample collection and clinical details

Table 3: Demographics and clinical details

\begin{tabular}{|l|c|c|c|c|}
\hline & $\begin{array}{c}\mathrm{A} \\
(\mathrm{n}=108)\end{array}$ & $\begin{array}{c}\mathrm{B} \\
(\mathrm{n}=111)\end{array}$ & $\begin{array}{c}\mathrm{C} \\
(\mathrm{n}=72)\end{array}$ & $\begin{array}{c}\mathrm{D} \\
(\mathrm{n}=201)\end{array}$ \\
\hline $\begin{array}{l}\text { Age (Mean } \pm \\
\text { STD })\end{array}$ & $55.14 \pm 9.76$ & $\begin{array}{c}61.03 \pm 8.1 \\
7\end{array}$ & $51.75 \pm 9.49$ & $54.17 \pm 6.87$ \\
\hline $\begin{array}{l}\text { Sex(M/F) } \\
\text { Body Weight } \\
\text { (Mean } \pm \text { STD) }\end{array}$ & $67.20 \pm 10.62$ & $66.52 \pm 8.5$ & $71.60 \pm 14.77$ & $70.70 \pm 13.11$ \\
\hline $\begin{array}{l}\text { BMI } \\
\text { (Mean } \pm \text { STD) }\end{array}$ & $24.59 \pm 3.22$ & $25.25 \pm 3.0$ & $26.26 \pm 4.52$ & $27.04 \pm 4.22$ \\
\hline DM & $0.51 \pm 0.50$ & $0.64 \pm 0.48$ & $0.31 \pm 0.46$ & $0.36 \pm 0.48$ \\
\hline HTN & $0.61 \pm 0.49$ & $0.72 \pm 0.45$ & $0.61 \pm 0.49$ & $0.29 \pm 0.46$ \\
\hline COPD & 0 & 0 & 0 & 0 \\
\hline PVD & 0 & 0 & 0 & 0 \\
\hline $\begin{array}{l}\text { CVA/ } \\
\text { neurological }\end{array}$ & 0 & 0 & 0 & 0 \\
disease & & & & 0 \\
\hline
\end{tabular}




\begin{tabular}{|l|c|c|c|c|}
\hline $\begin{array}{l}\text { previous } \\
\text { cardiac surgery }\end{array}$ & 0 & 0 & 0 & 0 \\
\hline $\begin{array}{l}\text { Serum } \\
\text { creatinine } \\
\text { (Mean } \pm \text { STD) }\end{array}$ & $0.96 \pm 0.14$ & $1.43 \pm 0.29$ & $2.49 \pm 2.38$ & $0.82 \pm 0.15$ \\
\hline $\begin{array}{l}\text { eGFR (Mean } \pm \\
\text { STD) }\end{array}$ & $81.96 \pm 14.22$ & $\begin{array}{c}51.33 \pm 9.3 \\
1\end{array}$ & $47.37 \pm 23.40$ & $102.34 \pm 23.49$ \\
\hline $\begin{array}{l}\text { Recent MI } \\
\text { LVEF }\end{array}$ & $40.50 \pm 4.20$ & $43.33 \pm 2.3$ & $57.50 \pm 2.50$ & 0 \\
\hline $\begin{array}{l}\text { Euroscore } \\
\text { (Average) }\end{array}$ & $\sim 2$ & $\sim 3$ & 0 & 0 \\
\hline
\end{tabular}

Table 4: Sample summary

\begin{tabular}{cc}
\hline Categories & Number of samples \\
\hline A & 108 \\
Post CABG-AKI- A & 8 \\
Post CABG NO AKI A & 100 \\
B & 111 \\
Post CABG-AKI B & 9 \\
Post CABG NO AKI B & 102 \\
C & 72 \\
D & 201 \\
\hline
\end{tabular}


Table 5: Results of association analysis

\begin{tabular}{|c|c|c|c|c|}
\hline Comparison & Group I & Group II & $\begin{array}{l}\text { Number } \\
\text { of } \\
\text { markers }\end{array}$ & $\begin{array}{l}\text { List of significant } \\
\text { markers identified }\end{array}$ \\
\hline 1 & AKI_A+AKI_B & $\begin{array}{l}\text { NoAKI_A + } \\
\text { NoAKI_B }\end{array}$ & 38 & $\begin{array}{l}\text { JHU_X.111764052, } \\
\text { GSA-rs78432535, } \\
\text { JHU_X.4629846, } \\
\text { JHU_X.33249089, } \\
\text { GSA-rs115265748, } \\
\text { rs76603121, } \\
\text { JHU_X.2948039, } \\
\text { rs4149859, GSA- } \\
\text { rs11799888, GSA- } \\
\text { rs62296417, GSA- } \\
\text { rs62346589, GSA- } \\
\text { rs72861264, GSA- } \\
\text { rs10056406, GSA- } \\
\text { rs111834033, GSA- } \\
\text { rs118025773, GSA- } \\
\text { rs1592079, GSA- } \\
\text { rs17821532, GSA- } \\
\text { rs624777650, GSA- } \\
\text { rs71534672, GSA- } \\
\text { rs76740047, GSA- } \\
\text { rs139883763, } \\
\text { rs5935359, GSA- } \\
\text { rs62344594, GSA- } \\
\text { rs78775059, } \\
\text { rs73192445, GSA- } \\
\text { rs73184486, } \\
\text { rs7049535, GSA- } \\
\text { rs12894624, GSA- } \\
\text { rs34163134, GSA- } \\
\text { rs115203545, GSA- } \\
\text { rs6575881, } \\
\text { rs12600453, GSA- } \\
\text { rs4251959, GSA- } \\
\text { rs74722110, GSA- } \\
\text { rs74758155, GSA- } \\
\text { rs78913616, } \\
\text { rs76748392, GSA- } \\
\text { rs62290342 }\end{array}$ \\
\hline 3 & A & B & 1 & JHU_X.122359432 \\
\hline 4 & $\begin{array}{l}\text { AKI_B + } \\
\text { AKI_A }\end{array}$ & $\mathrm{C}$ & 3 & JHU_X.43887938 \\
\hline
\end{tabular}




\begin{tabular}{|c|c|c|c|c|}
\hline \multirow{9}{*}{5} & \multirow{9}{*}{$A+B+C$} & \multirow{9}{*}{$\mathrm{D}$} & \multirow{9}{*}{7} & rs5935359 \\
\hline & & & & JHU_X.111764052 \\
\hline & & & & JHU_X.128495449 \\
\hline & & & & JHU_X.122359432 \\
\hline & & & & JHU_X.93803894 \\
\hline & & & & JHU_X.141720852 \\
\hline & & & & kgp22817822 \\
\hline & & & & rs16990116 \\
\hline & & & & rs16990114 \\
\hline
\end{tabular}

\section{Discussion}

Cardiovascular disease is a leading cause of morbidity and mortality in India causing over $25 \%$ of all deaths. Annually 1 million patients worldwide undergo coronary artery bypass graft (CABG) surgery as a major intervention for coronary artery disease. Approximately 77,000, develop postoperative acute kidney injury, out of which 14,000 require renal dialysis. This increases morbidity, mortality, hospital costs and consumes precious resources. Although the exact mechanism of postoperative AKI development is still unknown, clinical predictors and biomarkers of $A K I$ may be used to assess the risk of $A K I$ in $C A B G$ but identification of genetic factors may influence the therapeutic strategy in dealing with these patients at high risk of developing AKI. A systematic review of TRIBE-AKI consortium screened 7273 citations that concluded that the polymorphism of APO-E had a significant impact on incidence of $A K I$ in CABG(5). Isbir et al. have shown that ACE I/D bar and APO-E gene polymorphism to be associated with development of $\mathrm{AKI}$ in cardiac surgery(6). All reports in cardiac surgery and AKI relate to the use of cardiopulmonary bypass during CABG. Our study was aimed to determine influence of genetic polymorphism in patients undergoing offpump CABG. We found 18 genes associated with patients who developed AKI post CABG when compared to those who did not. We find markers associated with the $X$ chromosome. However, female to male ratios varies largely across groups. This may lead to false identification 
of marker, especially in sex chromosome which may not be true association with AKI. These findings have to be confirmed in a larger population to make a definitive conclusion. 


\section{References}

1. Rydén L, Sartipy U, Evans M, Holzmann MJ. Acute kidney injury after coronary artery bypass grafting and long-term risk of endstage renal disease. Circulation [Internet]. 2014 Dec 2 [cited 2019 Oct 15];130(23):2005-11. Available from: http://www.ncbi.nlm.nih.gov/pubmed/25239439

2. Loef BG, Epema AH, Smilde TD, Henning RH, Ebels $T$, Navis G, et al. Immediate postoperative renal function deterioration in cardiac surgical patients predicts in-hospital mortality and longterm survival. J Am Soc Nephrol [Internet]. 2005 Jan [cited 2019 Oct 15];16(1):195-200. Available from: http://www.ncbi.nlm.nih.gov/pubmed/15563558

3. Swaminathan M, Hudson CCC, Phillips-Bute BG, Patel UD, Mathew JP, Newman MF, et al. Impact of early renal recovery on survival after cardiac surgery-associated acute kidney injury. Ann Thorac Surg [Internet]. 2010 Apr [cited 2019 Oct 15];89(4):1098104. Available from:

http://www.ncbi.nlm.nih.gov/pubmed/20338313

4. Lassnigg A, Schmidlin D, Mouhieddine M, Bachmann LM, Druml $\mathrm{W}$, Bauer $\mathrm{P}$, et al. Minimal changes of serum creatinine predict prognosis in patients after cardiothoracic surgery: a prospective cohort study. J Am Soc Nephrol [Internet]. 2004 Jun [cited 2019 Oct 15];15(6):1597-605. Available from: http://www.ncbi.nlm.nih.gov/pubmed/15153571

5. Lu JCT, Coca SG, Patel UD, Cantley L, Parikh CR. Searching for Genes That Matter in Acute Kidney Injury: A Systematic Review for the Translational Research Investigating Biomarkers and Endpoints for Acute Kidney Injury (TRIBE-AKI) Consortium. Clin J Am Soc Nephrol. 2009;4:1020-31.

6. Isbir SC, Tekeli A, Ergen A, Yilmaz H, Ak K, Civelek A, et al. 
Genetic polymorphisms contribute to acute kidney injury after coronary artery bypass grafting. Heart Surg Forum [Internet]. 2007 [cited 2019 Oct 15];10(6):E439-44. Available from:

http://www.ncbi.nlm.nih.gov/pubmed/17921131 


\section{CHAPTER 5}

\section{Neutrophil Gelatinase-associated Lipocalin as a Biomarker for Predicting Acute Kidney Injury during Off-pump Coronary Artery Bypass Grafting}

Muralidhar Kanchi, R Manjunath, Jos Massen, Lloyd Vincen, Kumar Belani

Published in: Annals of Cardiac Anaesthesia 2017; 20:297-302. 


\begin{abstract}
Background: Acute kidney injury (AKI) following cardiac surgery is a major complication resulting in increased morbidity, mortality and economic burden. In this present study, we assessed the usefulness of estimating serum neutrophil gelatinase-associated lipocalin (NGAL) as a biomarker in predicting acute kidney injury (AKI) in patients with stable chronic kidney disease (CKD) and undergoing off-pump coronary artery bypass grafting (OP-CABG).
\end{abstract}

Materials and Methods: We prospectively studied 60 non-dialysis dependent CKD patients with estimated glomerular filtration rate (eGFR) $<60 \mathrm{ml} / \mathrm{min} / 1.73 \mathrm{~m}^{2}$ who required elective OP-CABG. Patients were randomized into two groups, group-D received dopamine infusion at 2 $\mu \mathrm{g} / \mathrm{kg} / \mathrm{min}$ following anesthesia induction till the end of the surgery, group-P did not receive any intervention. Serum creatinine, NGAL, brain natriuretic peptide (BNP) and troponin-I were estimated at specified intervals before, during and after surgery. The results of the study patients were also compared to a simultaneous matched cohort control of 30 patients (group-A) without renal dysfunction who underwent OPCABG.

Results: No patient required renal replacement therapy and no mortality was observed during perioperative and hospitalization period. Six patients from control group $(n=30), 10$ patients from placebo group $(n=30)$ and 12 patients from dopamine group $(n=30)$ developed stage- 1 AKI. However, we did not observe any stage-2 and stage-3 AKI among all the groups. There was a significant increase in serum NGAL levels at the end of surgery and $24 \mathrm{~h}$ postoperatively in placebo and dopamine groups as compared to the control.

Conclusion: The measurement of NGAL appears to predict the occurrence of AKI after OP-CAB surgery. However, large multicentric studies may be required to confirm the findings of this study.

Keywords: Acute kidney injury, Coronary artery bypass grafting, Cardiac surgery, Neutrophil gelatinase-associated lipocalin (NGAL), Creatinine, Dopamine. 


\section{Introduction}

Acute kidney injury (AKI) after cardiac surgery continues to be a major devastating complication because it can result in multi-organ dysfunction, death, increased resource utilization and high cost.(1) Globally 800,000 patients undergo coronary revascularization annually with the use of cardiopulmonary bypass (CPB). Approximately 77,000 patients in a year develop postoperative AKI, among which 14,000 require dialysis for the first time(2)Up to $30 \%$ of patients undergoing coronary artery bypass grafting (CABG) sustain sufficient renal injury to meet the threshold criteria, i.e., a creatinine increase of $>0.3 \mathrm{mg} \%$ or by $50 \%$ of the baseline value within $48 \mathrm{~h}$ of surgery. The reported incidence of AKI after cardiac surgery varies according to the definition of kidney injury as well as the institution reporting the results. Additionally, the current models poorly predict the likelihood of AKI. As many as $3 \%$ of patients sustaining $\mathrm{AKI}$ following $\mathrm{CABG}$ require dialysis and as many as $60 \%$ of these patients die before hospital discharge and the survivors continue with chronic renal disease with or without the need for dialysis.

Serum creatinine reflects the balance between the synthesis of creatinine and its excretion by the kidney. Creatinine production in the body varies with muscle mass, physical activity, protein intake and catabolism while creatinine excretion is dependent on the glomerular filtration rate (GFR). The serum creatinine and GFR are inversely and exponentially related. Halving of GFR implies that there will be doubling of creatinine concentration.(2)There are several limitations for creatinine as a marker of kidney injury in acute perioperative situations. However, it has a poor, predictive accuracy for kidney injury, particularly in the early stages of AKI.(3)

Neutrophil gelatinase-associated lipocalin (NGAL) is an irontransporting glycoprotein which accumulates in the kidney tubules and urine after nephrotoxic and ischemic insults.(4) This glycoprotein increases 3-4-fold within 2-3 $\mathrm{h}$ and up to 10,000 -fold by $24 \mathrm{~h}$ of renal 
insult. NGAL has been proposed as an early, sensitive, noninvasive biomarker for AKI. NGAL measured in the immediate postoperative period is an excellent predictor of AKI following pediatric cardiac surgery (5) and adult cardiac surgery.(6) To the best of our knowledge, there is scant literature looking at NGAL as a biomarker for predicting AKI in OPCABG receiving dopamine infusion. In this study, we measured both NGAL and serum creatinine to predict renal adverse outcomes in patients with stable chronic kidney disease (CKD) and not on dialysis undergoing elective OP-CABG. In addition, we also studied whether dopamine infusion during OP-CABG is beneficial in reducing renal injury in this group of patients.

\section{Patients and Methods}

After an approval from the institutional ethical committee and review board, we prospectively enrolled 60 patients who underwent an elective off pump CABG at Narayana Institute of Cardiac Sciences, Bangalore, between January-2012 and October-2016. The eligibility criteria included the presence of stable CKD (not on dialysis) and estimated glomerular filtration rate (eGFR) $\leq 60 \mathrm{ml} / \mathrm{min} / 1.73 \mathrm{~m}^{2}$ or creatinine $\geq 1.4 \mathrm{mg} \%$ prior to the surgery. Preoperative eGFR was estimated by using modification of diet in renal disease (MDRD) formula, eGFR of $<60 \mathrm{ml} / \mathrm{min} / 1.73 \mathrm{~m}^{2}$ was taken as indicative of renal impairment. Patients scheduled for OP-CABG were examined a day before the surgery, and all the base line investigation were noted. Demographic data (age, sex, height and weight), preoperative risk factors and preoperative surgical and anesthetic management were recorded for all the patients.

Patients scheduled for on-pump CABG, emergency surgery, redo operations, end-stage renal disease, chronic inflammatory disease/immune-suppression, corticosteroid therapy, age $<18$ years, 
enrolled in a conflicting research study, patients on renal replacement therapy (RRT) and renal transplanted patients were excluded from the study. All patients received a standard anesthetic which consisted of midazolam, propofol, isoflurane, fentanyl, vecuronium or atracurium, endotracheal intubation and mechanical ventilation to achieve normocarbia. Following median sternotomy and heparinization, the surgeons conducted distal coronary anastomosis on the beating-heart using 'octopus' (Medtronic Inc, Minneapolis, MA, USA) suction device tissue stabilizer for immobilization of the local heart muscle.

Hemodynamic care included a targeted mean arterial pressure of at least $70 \mathrm{mmHg}$, central venous pressure of $8-12 \mathrm{mmHg}$, stroke volume variation (SVV) of $\leq 12 \%$ using either Flotrac (Vigileo,I PX 1 , Edward Lifesciences, Irvine, USA) or Lidco rapid (model POC-125, ADVANTECH, Taiwan) and cardiac index of $\geq 2.5 \mathrm{~L} / \mathrm{min} / \mathrm{m}^{2}$. Epinephrine at $0.01-0.05 \mu \mathrm{g} / \mathrm{kg} / \mathrm{min}$ and nitroglycerine $0.05-0.1 \mu \mathrm{g} / \mathrm{kg} / \mathrm{min}$ were used as an inotrope / vasodilator at the discretion of the anesthesia care team. All patients were electively ventilated postoperatively until the criteria for separation from ventilator and tracheal extubation were met. Postoperative analgesia was provided with fentanyl infusion at 0.5-1.0 $\mu \mathrm{g} / \mathrm{kg} / \mathrm{hr}$ until removal of chest tubes and then a combination of oral tramadol and paracetamol. No nephrotoxic agents were used and nonsteroidal anti-inflammatory drugs were avoided in all patients.

The identified 60 patients with impaired renal function not requiring dialysis were scheduled for elective OP-CABG. We randomly allotted the patients to two groups. Group-D; received dopamine 2 $\mu \mathrm{g} / \mathrm{kg} / \mathrm{min}$ following anesthesia induction till the end of the surgery and standard care. Group-P; this was the placebo group that received $0.9 \%$ sodium chloride infusion and standard care. In addition, there was an age-matched control group of 30 patients (group-A) who had no renal dysfunction (preoperative serum creatinine of $\leq 1.4 \mathrm{mg} / \mathrm{dl}$ and eGFR $\geq 60 \mathrm{ml} / \mathrm{min} / 1.73 \mathrm{~m}^{2}$ ). Anesthesia and surgery were similar in all 
groups, mean arterial pressure and intravascular volume status was maintained with appropriate clinical measures during the course of surgery in all patients. Serum creatinine, NGAL, brain natriuretic peptide (BNP) and troponin-I were measured at specified intervals i.e. at the beginning of surgery after anesthetic induction, at the end of surgery, and $24 \mathrm{~h}$ after surgery. Thereafter, serum creatinine was estimated at 24 $\mathrm{h}$ intervals until $96 \mathrm{~h}$. The rationale for inclusion of estimation of BNP was based on the GALLANT trial which looked into prognostic utility of plasma NGAL in patients with acute heart failure assessed utility of NGAL alone and in combination with BNP as an aid to risk assessment of heart failure related adverse outcomes. ${ }^{[8]}$ The study demonstrated that NGAL is a powerful predictor of outcomes and this was stronger than BNP. Additionally, combination of high BNP/ high NGAL had the worst outcomes. While risk in low BNP/ high NGAL was significant, high BNP/ low NGAL group had outcomes similar to when both markers were low. This was explained by the fact that even though BNP was high, it represented 'dry' but not the 'wet' BNP.

The diagnosis of AKI postoperatively was made using 'kidney disease improving global outcomes' (KDIGO) criteria in terms of increase in serum creatinine on any of the first 3 postoperative days. Stage 1 AKI was defined as rise in serum creatinine by $0.3 \mathrm{mg} / \mathrm{dL}$ or by an increase $\geq 1.5$ fold from the reference value, stage 2 AKI classified by a 2 -2.9-fold increase in serum creatinine and stage $3 \mathrm{AKI}$ by $\geq 3$.0-fold increase in serum creatinine.

CABG related myocardial infarction was defined by elevation of cardiac biomarker troponin-I values ( $\geq 10 \times 99^{\text {th }}$ percentile $\left.U R L\right)$ in patients with normal baseline cardiac troponin (cTn) values along with either (i) new pathological $Q$ waves or new left bundle branch block (LBBB) or (ii) angiographic documented new graft or new native coronary artery occlusion, or (iii) imaging evidence of new loss of viable myocardium or new regional wall motion abnormality. 


\section{Results}

In a total of 90 patients who underwent OP-CABG, 60 patients suffered from stable CKD prior to surgery and 30 patients had normal renal function. Basic demographics and baseline clinical details of patients are given in Table 1. The numerical Euroscore was higher in the group-D and

Table-1: Basic demographics and clinical data of patients undergoing off-pump coronary artery bypass grafting

\begin{tabular}{|c|c|c|c|}
\hline Variable & $\begin{array}{c}\text { Group -A } \\
\text { Control }(n=29)\end{array}$ & $\begin{array}{l}\text { Group -P } \\
\text { Placebo } \\
(n=30)\end{array}$ & $\begin{array}{c}\text { Group-D } \\
\text { Dopamine } \\
(n=30)\end{array}$ \\
\hline Age in Years (mean \pm )SD & $57.1 \pm 9.5$ & $61.1 \pm 7.6$ & $60.7 \pm 5.9$ \\
\hline Male/Female & $27 / 3$ & $27 / 3$ & $30 / 0$ \\
\hline Diabetes mellitus & $17(56 \%)$ & $20(66 \%)$ & $24(80 \%)$ \\
\hline Hypertension & $17(56 \%)$ & $22(73 \%)$ & $26(87 \%)$ \\
\hline Euro Score & $2.30 \pm 1.9$ & $4.48 \pm 2.4^{\star *}$ & $6.27 \pm 1.8^{\star *}$ \\
\hline $\begin{array}{l}\text { Pre-operative eGFR } \\
\left(\mathrm{ml} / \mathrm{min} / 1.73 \mathrm{~m}^{2}\right)\end{array}$ & $84.65 \pm 16.6$ & $49.05 \pm 10.9^{* *}$ & $43.20 \pm 10.4^{* *}$ \\
\hline $\begin{array}{l}\text { Pre-operative Creatinine } \\
(\mathrm{mg} \%)\end{array}$ & $0.99 \pm 0.2$ & $1.32 \pm 0.2^{* *}$ & $1.81 \pm 0.5^{\star \star}$ \\
\hline $\begin{array}{l}{ }^{{ }^{2} \mathrm{p}<0.05 ;}{ }^{* *} \mathrm{p}<0.001 \text { compa } \\
\text { glomerular filtration rate; }\end{array}$ & etween grc & GFR= estim & \\
\hline
\end{tabular}


were excluded in the final analysis. There was a significant increase in serum NGAL and BNP levels at the end of surgery and at $24 \mathrm{~h}$ after surgery in placebo and dopamine groups compared to normal group. One patient from each group needed intra-aortic balloon pump (IABP) for cardiac support. The details of renal function postoperatively are displayed in Table 2 and Figure 1. Neither stage-3 nor stage-2 AKI was observed from our

Table 2: Serum creatinine, NGAL, troponin and BNP levels

\begin{tabular}{|c|c|c|c|c|}
\hline & $\begin{array}{l}\text { Group-A } \\
\text { Control }(n=29)\end{array}$ & $\begin{array}{l}\text { Group-P } \\
\text { Placebo } \\
(n=30)\end{array}$ & $\begin{array}{l}\text { Group-D } \\
\text { Dopamine } \\
(n=30)\end{array}$ & $p$ value \\
\hline \multicolumn{5}{|c|}{ Serum Creatinine $(\mathrm{mg} \%)($ mean $\pm S D)$} \\
\hline $\begin{array}{l}\text { Immediate Pre- } \\
\text { operative }\end{array}$ & $0.99 \pm 0.16$ & $1.56 \pm 0.43^{\star \star}$ & $1.69 \pm 0.61^{\star \star}$ & $<0.001$ \\
\hline $\begin{array}{l}\text { Immediate } \\
\text { Post-operative }\end{array}$ & $1.01 \pm 0.27$ & $1.60 \pm 0.47^{\star \star}$ & $1.67 \pm 0.58^{\star *}$ & $<0.001$ \\
\hline $\begin{array}{l}\text { Post operative } \\
24 \mathrm{~h}\end{array}$ & $1.04 \pm 0.16$ & $1.62 \pm 0.52^{\star *}$ & $1.76 \pm 0.51^{* *}$ & $<0.001$ \\
\hline $\begin{array}{l}\text { Post operative } \\
48 \mathrm{~h}\end{array}$ & $1.03 \pm 0.17$ & $1.64 \pm 0.52^{* *}$ & $1.78 \pm 0.54^{\star *}$ & $<0.001$ \\
\hline $\begin{array}{l}\text { Post operative } \\
72 \mathrm{~h}\end{array}$ & $0.96 \pm 0.15$ & $1.53 \pm 0.35^{\star}$ & $1.89 \pm 0.64^{\star \star}$ & $<0.001$ \\
\hline
\end{tabular}

NGAL $(\mathrm{ng} / \mathrm{mL})($ mean $\pm S D)$

$\begin{array}{lllll}\text { Pre-operative } & 84.4 \pm 35 & 183.5 \pm & 156.3 \pm 99^{*} & 0.011 \\ & & 250^{* *} & & \\ \text { Immediate } & 91.2 \pm 52 & 168.4 \pm 132 & 203.4 \pm 148^{*} & <0.001\end{array}$


Post-operative

Post operative

$24 \mathrm{~h}$

$\begin{array}{llll}135.2 \pm 90 & 249.95 \pm & 274.7 \pm & 0.002 \\ 262^{* *} \neq & 223^{* *} \neq & \end{array}$

Troponin (ng/mL) (mean $\pm S D)$

$\begin{array}{lllll}\text { Pre-operative } & 0.04 \pm 0.1 & 0.18 \pm 0.4 & 0.03 \pm 0.1 & 0.605\end{array}$

Immediate

Post-operative

$2.15 \pm 6.2 \quad 5.69 \pm 12.5 \quad 29.6 \pm 74.2 \quad 0.006$

Post operative

$24 \mathrm{~h}$
$6.71 \pm 15.2$
$3.69 \pm 5.6$
$12.1 \pm 17.2$
0.017

Brain Natriuretic Peptide $(\mathrm{pg} / \mathrm{mL})(\mathrm{mean} \pm S D)$

$\begin{array}{lllll}\text { Pre-operative } & 89.8 \pm 85 & 121.0 \pm 137 & 91.4 \pm 88 & 0.875 \\ \text { Immediate } & 105.3 \pm 166 & 202.7 \pm & & \\ \text { Post-operative } & & 243^{\star *} & 85.4 \pm 67 & 0.226 \\ & & 250.8 \pm & 547.5 \pm & \\ \text { Post operative } & 349.9 \pm 483 \neq & 234 \neq & 466^{\star *} \neq \neq & 0.062 \\ 24 \mathrm{~h} & & 234\end{array}$

${ }^{*} \mathrm{p}<0.05 ;{ }^{* *}<0.001$ comparison between groups; $\neq p<0.05, \neq \neq<0.001$ comparison within groups. NGAL- neutrophil gelatinase associated lipocalin; BNP- brain natriuretic peptide;

study groups. However 6 patients from control group had an elevation of serum creatinine by $0.3 \mathrm{mg} \%$ from pre-operative to post-operative $(1.0 \pm 0.12 \mathrm{mg} \%$ vs $1.44 \pm 2.4 \mathrm{mg} \%)$ with corresponding increase in the NGAL from $108 \pm 46 \mathrm{ng} / \mathrm{ml}$ to $212 \pm 95 \mathrm{ng} / \mathrm{ml}$. Ten out of 30 patients in placebo group had an elevation of serum creatinine from $1.45 \pm 0.15 \mathrm{mg} \%$ to $2.16+0.49 \mathrm{mg} \%$ with a corresponding increase in NGAL $141.7 \pm 55$ $\mathrm{ng} / \mathrm{ml}$ to $349 \pm 350 \mathrm{ng} / \mathrm{ml}$. Twelve patients in dopamine group (out of 30 patients) showed an elevation of serum creatinine from $1.7 \pm 0.61 \mathrm{mg} \%$ to 
$2.4 \pm 0.65 / \mathrm{mg} \%$ preoperative and postoperative respectively with corresponding NGAL value of $179 \pm 116 \mathrm{ng} / \mathrm{ml}$ to $390 \pm 291 \mathrm{ng} / \mathrm{ml}$. There was no difference in other variables with infusion of dopamine as compared to non-intervention group (ANOVA p>0.05 for all variables) (Table 3). There was no requirement for RRT and no mortality in any of the groups.
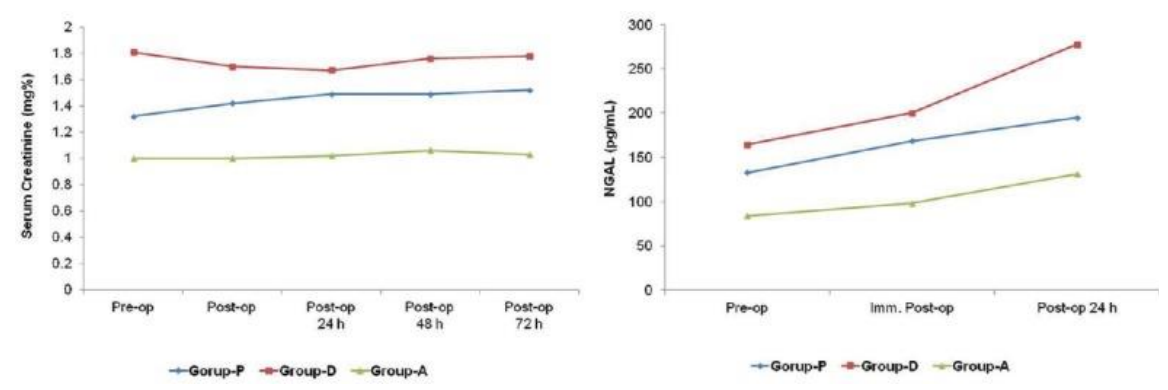

Figure 1. Comparison of serum creatinine and neutrophil gelatinaseassociated lipocalin between study groups

Table 3: Renal function following OP-CABG ( $p \geq 0.05$ by ANOVA between groups)

\begin{tabular}{lccc}
\hline Group & $\begin{array}{c}\text { Group-P } \\
\text { Placebo(n=30) }\end{array}$ & $\begin{array}{c}\text { Group-D } \\
\text { Dopamine }(\mathrm{n}=30)\end{array}$ & $\begin{array}{c}\text { Group-A } \\
\text { Normal }(\mathrm{n}=29)\end{array}$ \\
\hline $\begin{array}{c}\text { Need for } \\
\text { tRRT }\end{array}$ & 0 & 0 & 0 \\
${ }^{* * *}$ Stage 3 AKI & 0 & 0 & 0 \\
${ }^{* *}$ Stage 2 AKI & 0 & 0 & 0 \\
${ }^{*}$ Stage 1 AKI & 10 & 12 & 6 \\
& Postoperative & Urine output (ml) & \\
Day 1 & $2510 \pm 569$ & $2183.86 \pm 659$ & $2069.76 \pm 679$ \\
Day 2 & $2845.70 \pm 904$ & $3184.77 \pm 787$ & $3350 \pm 466$
\end{tabular}


$\mathrm{P} \geq 0.05$ by ANOVA between groups. *serum creatinine elevation by $0.3 \mathrm{mg} \%$; "*t serum creatinine increase by more than 2-2.9 fold; " creatinine elevation of $>3.0$ fold; ${ }^{\dagger} R R T=$ renal replacement therapy

\section{Discussion}

The present study was designed to evaluate the usefulness of NGAL measurement during OP-CABG for predicting AKI in patients with stable CKD. In addition, we examined the possible beneficial effects of dopamine infusion during OP-CABG in the same group of patients. AKI after cardiac surgery is not an uncommon complication, and $A K I$ is associated with increased morbidity, mortality and hospital costs. Even when renal replacement therapy is avoided, milder forms of $\mathrm{AKI}$ are associated with adverse outcomes and degree of AKI correlates negatively with long term survival despite successful hospital discharge. Renal dysfunction after cardiac surgery is multi-factorial in origin and there are multiple risk factors that contribute to the development of AKI. Serum creatinine was used as a marker of renal function; despite the fact that it is not completely reliable and delayed indicator of renal injury in acute setting. Biomarkers such as NGAL are detectable in urine and blood within 2-4 hours of injury and proven to be better indicator of renal insult in acute settings. Initial studies reported a strong relationship between NGAL and renal outcomes.(5-7) However, recent studies found a variable relationship between NGAL and renal outcomes.(8-12)Recent insights into the molecular nature of NGAL suggest that it might be released not only by tubular renal cells but also by neutrophils activated by systemic inflammatory triggers, such as cardio pulmonary bypass (CPB).(13-17)These studies were performed on patients who underwent OP-CABG to determine if NGAL is a marker of renal injury in this form of 
cardiac surgery. In our study, there was no incidence of stage 2 and stage $3 \mathrm{AKI}$ in all the three groups. However, stage $1 \mathrm{AKI}$ was seen in all the 3 groups. Six (20\%) patients in the normal group, 10 (33\%) patients in placebo group and $12(40 \%)$ patients in dopamine group had elevation of serum creatinine post operatively compared to preoperative values. Correspondingly NGAL values also increased in all these patients.

In a study published on 2004, there was a significant reduction in postoperative renal failure (17\% vs $9 \% ; P=0.022)$ and need for new dialysis ( $10 \%$ vs $3 \% ; P=0.022$ ) when CPB was eliminated for coronary revascularization strategy (OP-CABG) in patients with preexisting renal dysfunction. Avoidance of $\mathrm{CPB}$ results in (i) a reduction in the incidence of postoperative renal failure, (ii) a reduction in the need for new dialysis and (iii) improved in-hospital and midterm survival.(18)

In a meta-analysis of 22 randomized controlled trials (4819 patients), the weighted incidence of AKI in the on-pump CABG group was $4.0 \%$ (95\% confidence interval [Cl] 1.8\%, 8.5\%), dialysis requirement $2.4 \%(95 \% \mathrm{Cl} 1.6 \%, 3.7 \%)$, and mortality $2.6 \%(95 \% \mathrm{Cl}$ $1.6 \%, 4.0 \%$ ). But off-pump CABG was associated with $40 \%$ lower odds of postoperative AKI (OR 0.60; 95\% Cl 0.43, 0.84; $\mathrm{P}=0.003$ ) and a nonsignificant $33 \%$ lower odds for dialysis requirement (OR $0.67 ; 95 \% \mathrm{Cl}$ $0.40,1.12 ; P=0.12$ ). Within the selected trials, off-pump $C A B G$ was not associated with a significant decrease in mortality. The authors concluded that off-pump CABG may be associated with a lower incidence of postoperative AKI but may not affect dialysis requirement, a serious complication of cardiac surgery. (19) This meta-analysis did not evaluate the usefulness of NGAL measurement in predicting AKI after OP-CABG.

NGAL has good sensitivity and specificity for diagnosis of AKI, with a significantly earlier rise following injury when compared to creatinine. NGAL began to rise within two hours after renal insult, while creatinine rise occurred over a period of one to three days.(20) Our study 
also demonstrated the similar findings. NGAL values rose before the creatinine climb up. Hence, NGAL can be used as an early biomarker for detection of post-reparative AKI. NGAL value at $4 \mathrm{~h}$ in patients who developed AKI was significantly higher than in those patients who did not develop AKI $(P<0.05)$. It was not clear whether the degree of rise in NGAL levels was associated with more severe form of AKI or not. Furthermore, the rise in urine NGAL levels at $4 \mathrm{~h}$ in these patients was not uniform. One patient who developed AKI had 100-fold rise in urine NGAL levels at $4 \mathrm{~h}$ while the other six had a lesser degree of elevation of urine NGAL at $4 \mathrm{~h}$. Six patients who developed AKI had a normal serum creatinine value at $4 \mathrm{~h}$ postoperatively. Serum creatinine levels rose only at $24 \mathrm{~h}$ or more in all these six patients. However, urine NGAL levels at 4 $h$ were significantly high in the patients who developed AKI. They concluded that urine NGAL as an early biomarker of acute kidney injury in patients undergoing OP-CABG surgeries.(4) In our study, we have noted significant increase $(p<0.05)$ in NGAL values immediately after surgery in dopamine and placebo groups (Table 4).

A meta-analysis of 58 studies including 17 randomized clinical trials, showed that dopamine did not prevent mortality, (relative risk, 0.90 [0.44-1.83]; $p=0.92$ ), onset of acute renal failure (relative risk, 0.81 [0.55-1.19]; $p=0.34$ ), or need for dialysis, (relative risk, 0.83 [0.55-1.24]; $p=0.42$ ). There was sufficient statistical power to exclude any large $(>50 \%$ ) effect of dopamine on the risk of acute renal failure or need for dialysis. They concluded that the use of low-dose dopamine for the treatment or prevention of acute renal failure cannot be justified on the basis of available evidence and should be eliminated from routine clinical use.(21) Our findings were also similar to that of existing study. We did not find any improved outcome with the use of dopamine in the patients with underlying renal dysfunction undergoing OP-CABG. Both the study groups (placebo and dopamine) had pre-existing renal dysfunction. None of the patients required renal replacement therapy and none 
demonstrated stage 2 or stage $3 \mathrm{AKI}$ following surgery. There was an increase in serum creatinine from $1.45 \pm 0.15$ to $21.6 \pm 0.49$ and $1.77 \pm 0.61$ to $2.45 \pm 0.65$ in placebo and dopamine group respectively in the occurrence of stage $1 \mathrm{AKI}$, which was statistically not significant, and the group without preexisting renal dysfunction had a lesser incidence of stage I AKI. Use of dopamine at $2 \mu / \mathrm{kg}$ did not decrease the incidence of stage $1 \mathrm{AKI}$ in patient with stable CKD undergoing OP-CABG.

Dopamine may be particularly useful in patients with compromised systolic function but causes more tachycardia and may be more arrhythmogenic than norepinephrine.(22) It may also influence the endocrine response via the hypothalamic pituitary axis and have immunosuppressive effects. However, information from five randomized trials ( $n=1993$; patients with septic shock) comparing norepinephrine to dopamine does not support the routine use of dopamine in the management of septic shock.(23-25)

Table 4: Highest serum creatinine (mean \pm SD) and highest NGAL (mean $\pm \mathrm{SD}$ ) values of patients who developed stage $1 \mathrm{AKI}$ in three groups.

\begin{tabular}{|c|c|c|c|c|}
\hline \multirow[b]{2}{*}{ Group } & \multicolumn{2}{|c|}{ Creatinine (mg \%) } & \multicolumn{2}{|c|}{ NGAL (ng/ml) } \\
\hline & Base line & $\begin{array}{c}\text { Maximum } \\
\text { post- } \\
\text { operative } \\
\text { value }\end{array}$ & Base line & $\begin{array}{c}\text { Maximum } \\
\text { post- } \\
\text { operative } \\
\text { value }\end{array}$ \\
\hline
\end{tabular}

Group-A

Six patients $\quad 1.0 \pm 0.12 \quad 1.35 \pm 0.24^{*} \quad 108.5 \pm 46.5 \quad 202 \pm 95.32^{*}$ $(n=29)$ 
Group-P

Ten patients $\quad 1.45 \pm 0.15 \quad 2.16 \pm 0.49^{*} \quad 141.7 \pm 55.18 \quad 340.2 \pm 350.3^{*}$ $(n=30)$

Group-D

Twelve patients $(\mathrm{n}=30)$

${ }^{*} P>0.05$. Figures in parenthesis represent the total number in that group.

A large randomized trial and meta-analysis comparing low-dose dopamine to placebo found no difference in either primary outcomes (peak serum creatinine, need for renal replacement, urine output, time to recovery of normal renal function) or secondary outcomes (survival to either ICU or hospital discharge, ICU stay, hospital stay, arrhythmias).(21,26)Thus, the available data do not support administration of low doses of dopamine solely for the purpose of maintaining renal function.

\section{Conclusion}

Our study findings suggest that, the monitoring of neutrophil gelatinase associated lipocalin values could be beneficial for predicting AKI in patients with stable CKD and undergoing off-pump coronary artery bypass grafting. The use of dopamine during off-pump coronary artery bypass grafting is controversial, since our study did not show any reduction in the risk of acute kidney injury in patients with pre-existing renal dysfunction. We do not support administration of low doses of dopamine solely for renal preservation on OP-CABG. However, large multicentric studies may be needed to strengthen our findings. 


\section{Limitations of the study}

One of the important limitations of our study is small number of patients $(\mathrm{n}=90)$ tested. 


\section{References}

1. Mangano CM, Diamondstone LS, Ramsay JG, Aggarwal A, Herskowitz A, Mangano DT. Renal dysfunction after myocardial revascularization: risk factors, adverse outcomes, and hospital resource utilization. The Multicenter Study of Perioperative Ischemia Research Group. Ann Intern Med [Internet]. 1998 Feb 1 [cited 2019 Dec 11];128(3):194-203. Available from: http://www.ncbi.nlm.nih.gov/pubmed/9454527

2. Miller RD, Cohen NH, Eriksson LI, Professor F, Chair A, WienerKronish JP. Miller's Anesthesia, 2-Volume Set. Elsevier; 2014. $3576 \mathrm{p}$.

3. Waikar SS, Betensky RA, Bonventre J V. Creatinine as the gold standard for kidney injury biomarker studies? Nephrol Dial Transplant [Internet]. 2009 Nov [cited 2019 Sep 20];24(11):32635. Available from: http://www.ncbi.nlm.nih.gov/pubmed/19736243

4. Jain V, Mehta Y, Gupta A, Sharma R, Raizada A, Trehan N. The role of neutrophil gelatinase-associated lipocalin in predicting acute kidney injury in patients undergoing off-pump coronary artery bypass graft: A pilot study. Ann Card Anaesth. 2016 Apr 1;19(2):225-30.

5. Mishra J, Dent C, Tarabishi R, Mitsnefes MM, Ma Q, Kelly C, et al. Neutrophil gelatinase-associated lipocalin (NGAL) as a biomarker for acute renal injury after cardiac surgery. Lancet (London, England) [Internet]. [cited 2019 Sep 20];365(9466):1231-8. Available http://www.ncbi.nlm.nih.gov/pubmed/15811456

6. Wagener G, Jan M, Kim M, Mori K, Ph D. Association between Increases in Urinary Neutrophil Gelatinase - associated Lipocalin and Acute Renal. Anesthesiology. 2006;105(3):485-91.

7. Bennett M, Dent CL, Ma Q, Dastrala S, Grenier F, Workman R, et 
al. Urine NGAL predicts severity of acute kidney injury after cardiac surgery: A prospective study. Clin J Am Soc Nephrol. 2008 May;3(3):665-73.

8. Han WK, Wagener G, Zhu Y, Wang S, Lee HT. Urinary biomarkers in the early detection of acute kidney injury after cardiac surgery. Clin J Am Soc Nephrol. 2009 May 1;4(5):87382.

9. Wagener G, Gubitosa G, Wang S, Borregaard N, Kim M, Lee HT. Urinary Neutrophil Gelatinase-Associated Lipocalin and Acute Kidney Injury After Cardiac Surgery. Am J Kidney Dis. 2008;52(3):425-33.

10. Haase M, Bellomo R, Devarajan P, Schlattmann P, Haase-Fielitz A, Bagshaw SM, et al. Accuracy of Neutrophil GelatinaseAssociated Lipocalin (NGAL) in Diagnosis and Prognosis in Acute Kidney Injury: A Systematic Review and Meta-analysis. Am J Kidney Dis. 2009 Dec;54(6):1012-24.

11. Koyner JL, Vaidya VS, Bennett MR, Ma Q, Worcester E, Akhter $\mathrm{SA}$, et al. Urinary biomarkers in the clinical prognosis and early detection of acute kidney injury. Clin J Am Soc Nephrol. 2010 Dec 1;5(12):2154-65.

12. Parikh CR, Coca SG, Thiessen-Philbrook H, Shlipak MG, Koyner JL, Wang Z, et al. Postoperative biomarkers predict acute kidney injury and poor outcomes after adult cardiac surgery. J Am Soc Nephrol. 2011 Sep;22(9):1748-57.

13. Cai L, Borowiec J, Xu S, Han W, Venge P. Assays of urine levels of $\mathrm{HNL} / \mathrm{NGAL}$ in patients undergoing cardiac surgery and the impact of antibody configuration on their clinical performances. Clin Chim Acta. 2009 May;403(1-2):121-5.

14. Cai L, Rubin J, Han W, Venge P, Xu S. The origin of multiple molecular forms in urine of HNL/NGAL. Clin J Am Soc Nephrol. 2010 Dec 1;5(12):2229-35. 
15. Mårtensson J, Bell $\mathrm{M}$, Oldner $\mathrm{A}, \mathrm{Xu} \mathrm{S}$, Venge $\mathrm{P}$, Martling $\mathrm{CR}$. Neutrophil gelatinase-associated lipocalin in adult septic patients with and without acute kidney injury. Intensive Care Med. 2010 Aug;36(8):1333-40.

16. Glassford NJ, Schneider AG, Xu S, Eastwood GM, Young H, Peck $L$, et al. The nature and discriminatory value of urinary neutrophil gelatinase-associated lipocalin in critically ill patients at risk of acute kidney injury. Intensive Care Med. 2013 Oct;39(10):1714-24.

17. Mårtensson J, Bellomo RR. The rise and fall of NGAL in acute kidney injury. Vol. 37, Blood Purification. S. Karger AG; 2014. p. 304-10.

18. Beauford RB, Saunders CR, Niemeier LA, Lunceford TA, Karanam $R$, Prendergast $T$, et al. Is off-pump revascularization better for patients with non-dialysis-dependent renal insufficiency? Heart Surg Forum. 2004;7(2):84-9.

19. Seabra VF, Alobaidi S, Balk EM, Poon AH, Jaber BL. Off-pump coronary artery bypass surgery and acute kidney injury: a metaanalysis of randomized controlled trials. Clin J Am Soc Nephrol [Internet]. 2010 Oct [cited 2019 Sep 20];5(10):1734-44. Available from: http://www.ncbi.nlm.nih.gov/pubmed/20671222

20. Moss E, Lamarche Y. Acute Kidney Injury Following Cardiac Surgery: Prevention, Diagnosis, and Management. In: Renal Failure - The Facts. InTech; 2012.

21. Kellum JA, Decker JM. Use of dopamine in acute renal failure: A meta-analysis. Crit Care Med. 2001;29(8):1526-31.

22. Regnier B, Rapin M, Gory G, Lemaire F, Teisseire B, Harari A. Haemodynamic effects of dopamine in septic shock. Intensive Care Med. 1977;3(2):47-53.

23. Martin C, Viviand X, Leone M, Thirion X. Effect of norepinephrine on the outcome of septic shock. Crit Care Med. 2000;28(8):2758- 
65.

24. Ruokonen E, Takala J, Kari A, Saxen H, Mertsola J, Hansen EJ. Regional blood flow and oxygen transport in septic shock. Crit Care Med. 1993;21(9):1296-303.

25. De Backer D, Biston P, Devriendt J, Madl C, Chochrad D, Aldecoa $\mathrm{C}$, et al. Comparison of Dopamine and Norepinephrine in the Treatment of Shock. N Engl J Med [Internet]. 2010 Mar 4 [cited 2019 Dec 11];362(9):779-89. Available from: http://www.nejm.org/doi/abs/10.1056/NEJMoa0907118

26. Bellomo R, Chapman M, Finfer $S$, et al: Low-dose dopamine in patients with early renal dysfunction: A placebo-controlled randomised trial. Australian and New Zealand Intensive Care Society (ANZICS) Clinical Trials Groups. J Cardiothorac Vasc Anesth. 2001 Aug;15(4):531. 


\section{CHAPTER 6}

\section{$\mathrm{N}$-Acetylcysteine does not prevent renal dysfunction after off-pump coronary artery bypass surgery}

Prasad Apoorva, Banakal Sanjaykumar, Muralidhar Kanchi Published in: European Journal of Anaesthesiology 2010 Nov;27(11):973-7.

Doi: 10.1097/EJA.0b013e3283383506. 


\section{Abstract}

Background and Objective: Coronary artery bypass graft surgery in high-risk patients may be associated with postoperative renal dysfunction. N-Acetylcysteine is a powerful antioxidant and has been used to prevent contrast-induced renal dysfunction. The efficacy of $\mathrm{N}$-acetylcysteine in preventing postoperative renal dysfunction following off-pump coronary artery bypass graft surgery was studied. Methods: A prospective, randomized, controlled study was conducted in patients undergoing off-pump coronary artery bypass graft. The study group (37 patients) received $\mathrm{N}$ acetylcysteine in the perioperative period, whereas the control group (37 patients) did not. The data obtained were analyzed using the independent sample t-test (Student's t-test) and X-test. Results: There was no significant difference in the incidence of renal dysfunction between the two groups. Three patients $(8.6 \%)$ in the $\mathrm{N}$-acetylcysteine group and four (11.4\%) in the control group developed renal dysfunction ( $P$ value was 1.00 ). Conclusion: $\mathrm{N}$-Acetylcysteine does not have any beneficial effect on renal function in high-risk patients undergoing offpump coronary artery bypass graft.

Keywords: cardiovascular; complications; failure; kidney; renal; surgery 


\section{Introduction}

Renal dysfunction is one of the important postoperative complications following coronary artery bypass grafting.(1) The potential risk factors are advanced age and presence of comorbid conditions such as hypertension, diabetes mellitus, cardiac failure and preexisting renal disease. $(2,3)$ These factors may collectively contribute to renal hypoxia and ischemia. Hypoxic ischemic insults result in direct toxic effects within renal tubular epithelial cells with depletion of local antioxidants and the formation of reactive oxygen species (ROS). Off-pump coronary artery bypass grafting (OP-CABG) has revolutionized the surgical approach for the treatment of coronary artery disease by avoiding extracorporeal circulation.

Recently, several meta analyses and randomized controlled trials have demonstrated that $\mathrm{N}$-acetylcysteine (NAC) attenuates contrast-induced declines in renal function because of its antioxidant and ROS scavenger properties.(4-6) If NAC proves to be effective in preventing the deterioration of renal function following OP-CABG, it would be a highly cost-effective strategy, as NAC is inexpensive and rarely associated with any toxicity.

\section{Methods}

This was a randomized, prospective, open-label study with two parallel groups. The study was carried out between January 2006 and June 2007. After approval by the ethics committee of the hospital, patients admitted for elective OP-CABG surgery and deemed high risk (as defined by the presence of one or more of the criteria listed for inclusion) for postoperative renal dysfunction were included in the study. 
The inclusion and exclusion criteria are as follows.

1. Inclusion criteria:

1. age older than 70 years,

2. diabetes mellitus,

3. Hypertension,

4. baseline serum creatinine level higher than $133 \mu \mathrm{mol}$ $\mathrm{I}^{-1}\left(1.5 \mathrm{mg} \mathrm{dl}^{-1}\right)$ and

5. Ejection fraction less than $35 \%$.

2. Exclusion criteria:

1. known allergy or hypersensitivity to NAC,

2. use of nephrotoxic drugs and nonsteroidal antiinflammatory drugs,

3. history of current or previous dialysis,

4. prior renal transplant,

5. conversion to cardiopulmonary bypass during surgery,

6. patients needing intra-aortic balloon pump (IABP),

7. patients on large doses of inotropes and

8. Pregnancy.

Seventy-four patients were enrolled after obtaining written informed consent. This study was confined to patients undergoing OPCABG and hence four patients were excluded from the study because of conversion to on-pump coronary artery bypass surgery. These patients were followed up in the postoperative period. Random numbers were generated from a random number of table and patients were assigned to either the NAC group or the control group according to the numbers. The NAC group (37 patients) received oral NAC $600 \mathrm{mg}$ twice a day on the 
preoperative day and intravenous NAC $600 \mathrm{mg}$ prior to the induction of anaesthesia on the day of surgery. This was followed by intravenous NAC $600 \mathrm{mg}$ twice a day until the second postoperative day (total dose of NAC administered was $4.8 \mathrm{~g}$ ). The control group comprising 37 patients did not receive NAC or placebo. All the patients were assessed preoperatively and baseline parameters (Table 1) were collected by the first author.

Table 1 Perioperative characteristics of the $\mathrm{N}$-acetylcysteine and control group

\begin{tabular}{|c|c|c|}
\hline & NAC $(n=35)$ & $\begin{array}{l}\text { Control } \\
(n=35)\end{array}$ \\
\hline \multicolumn{3}{|l|}{ Demographic variables } \\
\hline Age (years) & $55.60(10.24)$ & $57.77(9.36)$ \\
\hline Sex, male $[\mathrm{n}(\%)]$ & $25(71)$ & $28(80)$ \\
\hline Height $[\mathrm{cm}$, mean (SD)] & $161.34(8.56)$ & $\begin{array}{l}161.09 \\
(10.33)\end{array}$ \\
\hline Weight $[\mathrm{cm}$, mean (SD)] & $67.71(11.81)$ & $64.57(10.46)$ \\
\hline \multicolumn{3}{|l|}{ Medical variables } \\
\hline \multicolumn{3}{|l|}{ Comorbid diseases } \\
\hline Diabetes mellitus [ $n(\%)]$ & $9(28)$ & $12(34)$ \\
\hline Hypertension [ $\mathrm{n}(\%)]$ & $5(14)$ & $7(20)^{\prime}$ \\
\hline $\begin{array}{l}\text { Diabetes mellitus and hypertension } \\
\text { [ } \mathrm{n}(\%)]\end{array}$ & $14(40)$ & $13(37)$ \\
\hline $\begin{array}{l}\text { Chronic obstructive pulmonary } \\
\text { disease }[\mathrm{n}(\%)]\end{array}$ & - & $2(6)$ \\
\hline DM + COPD + hypertension [ $\mathrm{n}(\%)]$ & $1(3)$ & - \\
\hline None $[\mathrm{n}(\%)]$ & $6(17)$ & $1(3)$ \\
\hline History of smoking [ $\mathrm{n}(\%)]$ & $12(34)$ & $11(31)$ \\
\hline $\begin{array}{l}\text { Left ventricular ejection fraction [\%, } \\
\text { mean (SD)] }\end{array}$ & $50.54(9.47)$ & $49.43(9.34)$ \\
\hline \multicolumn{3}{|l|}{ Coronary disease [ $\mathrm{n}(\%)]$} \\
\hline 1 vessel & $1(3)$ & $2(6)$ \\
\hline 2 vessel & $9(26)$ & $8(23)$ \\
\hline 3 vessel & $25(71)$ & $25(71)$ \\
\hline Previous myocardial infarction [ $n(\%)]$ & $17(51)$ & $18(51)$ \\
\hline \multicolumn{3}{|l|}{ Intraoperative variable } \\
\hline \multicolumn{3}{|l|}{ Number of grafts [ $n(\%)]$} \\
\hline One & $8(23)$ & $6(17)$ \\
\hline Two & $13(37)$ & $15(43)$ \\
\hline Three & $14(40)$ & $14(40)$ \\
\hline Blood/blood products transfused [ $\mathrm{n}$ & $10(29)$ & $14(40)$ \\
\hline
\end{tabular}



(\%)]
Intravenous fluids infused [I, mean
(SD)]
Urine output [ml, mean (SD)]
$2.10(0.67)$
$2.19(0.63)$
Postoperative variables
419.71
(219.52)
Elective ventilation [h, mean (SD)]
Intensive care unit stay [days, mean
(SD)]
Hospital stay [days, mean (SD)]
$14.83(4.88)$
$2.83(1.04)$
419.29
(170.37)
14.54 (2.92) 13.91 (2.59)
COPD - chronic obstructive pulmonary disease; DM - diabetes mellitus; $\mathrm{NAC}$ - $\mathrm{N}$-acetylcysteine

Patients underwent coronary artery bypass surgery under general anaesthesia. On the day of surgery, the patients with normal ejection fraction were premedicated with diazepam $10 \mathrm{mg}$ and atenolol $50 \mathrm{mg}$ orally. Atenolol $12.5 \mathrm{mg}$ was administered to patients with an ejection fraction less than $35 \%$. Induction was done using a combination of intravenous midazolam $\left(0.1 \mathrm{mg} \cdot \mathrm{kg}^{-1}\right)$ and fentanyl $\left(5-10 \mu \mathrm{g} \cdot \mathrm{kg}^{-1}\right)$, followed by paralysis with intravenous pancuronium $\left(0.1 \mathrm{mg} \cdot \mathrm{kg}^{-1}\right)$. Anaesthesia was maintained with a gas mixture of isoflurane (1-2\%) in oxygen. The five-lead electrocardiogram, peripheral oxygen saturation, end-tidal carbon dioxide, intra-arterial pressure, central venous pressure, nasopharyngeal temperature and urine output were continuously monitored. The patients were anticoagulated using intravenous heparin to maintain the activated clotting time (ACT) of more than $420 \mathrm{~s}$ during grafting as per the institutional protocol. At the end of the procedure, anticoagulation was reversed using protamine. The heart was stabilized with an 'OCTOPUS' suction device (Medtronic Inc., Minneapolis, Minnesota, USA, 2001; model-28400) to perform OP-CABG. Administration of intravenous fluids, blood products, inotropes and vasodilators were left to the discretion of the attending anaesthesiologist. Postoperatively patients were sedated and ventilated in the intensive care unit. 
A postoperative increase in the serum creatinine level of more than $44 \mu$ mol.l-1 $(0.5 \mathrm{mg} . \mathrm{dl}-1)$ or a rise in the creatinine level by $25 \%$ from the basal level was taken as the criterion for deterioration of renal function.

Serum creatinine level and glomerular filtration rate (GFR) were measured preoperatively and postoperatively on the first, second and fifth day. This was the primary outcome measurement of the study. GFR was calculated using the Cockroft-Gault equation.(7) The secondary outcome measures included adverse reactions, duration of elective ventilation, duration of intensive care unit stay and duration of hospital stay.

\section{Statistical analysis}

A pilot study recruiting 20 patients (10 in each group) was done initially. The mean and standard deviation of serum creatinine and GFR values were calculated. Using these values, it was found that a sample size of 70 patients (35 in each group) would give a 95\% confidence interval (5\% level of significance) and a power of $80 \%$. Independent sample $t$-test (Student's $t$-test) and $x^{2}$-test were employed to compare the two groups with respect to continuous and categorical variables respectively. Repeated measures analysis of variance was used to compare the creatinine values (as well as GFR) over the four assessment intervals between the groups. The level of significance was fixed at 0.05. Statistical Package for Social Sciences (SPSS, version 11; SPSS, Chicago, Illinois, USA) was used for data analysis.

\section{Results}

The results were analyzed for 70 patients (35 in each group). The anthropometric and demographic data were comparable in both the NAC and the control group (Table 1). The two groups did not differ significantly in the intraoperative characteristics (Table 1). 
Serum creatinine and GFR were measured preoperatively and on first, second and fifth postoperative days (Table 2). There was no difference in the mean serum creatinine levels between the two groups ( $P$ value $0.798 ; F$ value 0.066 ). There was no difference in the mean GFR between the groups ( $P$ value $0.597 ; F$ value 0.283 ). Three patients in the NAC group and four patients in the control group developed postoperative renal dysfunction and the difference between the groups was not statistically significant (Table 3). There were no differences in the secondary outcome measures between the groups.In one patient in the NAC group, mechanical ventilation was reinstituted on the first postoperative day because of haemodynamic instability. Another patient from the same group underwent re-exploration surgery because of postoperative bleeding and subsequent hypotension, $6 \mathrm{~h}$ following OPCABG. Both the patients recovered uneventfully. One patient in the control group underwent sternal wound debridement 1 month following OP-CABG and recovered with no complications.

Table 2. Serum creatinine and glomerular filtration rate

\begin{tabular}{cccccc}
\hline & \multicolumn{5}{c}{ Assessments [ mean (SD)] } \\
\cline { 2 - 6 } Parameter & Preoperative & $\begin{array}{c}\text { First } \\
\text { p/o day }\end{array}$ & $\begin{array}{c}\text { Second } \\
\text { p/o day }\end{array}$ & $\begin{array}{c}\text { Fifth } \\
\text { p/o day }\end{array}$ & $\mathrm{F}(\mathrm{P})$ \\
\hline Serum creatinine $\left(\mu \mathrm{mol} \cdot \mathrm{l}^{-1}\right)$ & & & & \\
NAC & $86(18)$ & $85(21)$ & $86(20)$ & $83(16)$ & 0.066 \\
Control & $88(19)$ & $86(21)$ & $87(22)$ & $83(21)$ & $(0.798)$ \\
GFR $\left(\mathrm{ml} \cdot \mathrm{s}^{-1}\right)$ & & & & & \\
NAC & $79(29)$ & $80(27)$ & $80(31)$ & $82(31)$ & 0.283 \\
Control & $73(20)$ & $77(27)$ & $76(28)$ & $80(33)$ & $(0.597)$ \\
\hline
\end{tabular}

GFR - glomerular filtration rate. 
Table 3 Number of patients who developed postoperative renal dysfunction

\begin{tabular}{lcc}
\hline & \multicolumn{2}{c}{ Group $[n(\%)]$} \\
\cline { 2 - 3 } Criteria & $\mathrm{NAC}(n=35)$ & Control $(n=35)$ \\
\hline $\begin{array}{l}\text { Patients whose postoperative serum } \\
\text { creatinine increased by }>25 \% \text { of } \\
\text { the preoperative value }\end{array}$ & $3(8.6)$ & $4(11.4)$ \\
\hline
\end{tabular}

NAC, $N$-acetylcysteine.

Four patients who were excluded from the study neither developed renal dysfunction (as per the criteria chosen for the study) nor suffered any other complication. The secondary outcome measures were similar to those patients who were included for analysis.

\section{Discussion}

Occurrence of postoperative renal dysfunction remains one of the important complications following cardiac surgery and has a multifactorial etiology. In patients undergoing cardiac surgery on cardiopulmonary bypass (CPB), the duration of $\mathrm{CPB}$, systemic inflammatory response, hypoperfusion and loss of pulsatile perfusion are thought to have a role in the development of postoperative renal dysfunction.(8) Preoperative, intraoperative and postoperative haemodynamic factors have a prominent role in the development of postoperative acute renal failure.(9) Circulatory failure during cardiac surgery can cause ischaemic and toxic injury to the kidneys, which leads to the depletion of local antioxidants and formation of free oxygen radicals. ${ }^{10}$

It is a paradox that serum creatinine has limitations but despite this, serum creatinine is often used as a gold standard to compare novel biomarkers. $^{37}$ 
Several drugs (dopamine, diuretics, atrial natriuretic peptide and fenoldopam) have been evaluated for preventing postoperative renal dysfunction with inconsistent results. NAC has anti-inflammatory and antioxidant properties, which can attenuate several mechanisms of renal injury (systemic inflammatory response, free radical injury and ischaemia(10)) during cardiac surgery. It may provide renal protection by acting as an antioxidant and vasodilator via the nitric oxide pathway.(11)

This prospective randomized controlled study did not show any beneficial renal protective effect of NAC, in patients who are at high risk of developing postoperative renal dysfunction, following elective OPCABG.

Similar results were seen in studies done by Burns et al.,(2) Hynninen et al.,(12) Ristikankare et al.,(13) Haase et al.,(14) Hamamsy et al. (15) and Wijeysundera et al. (16) in patients undergoing cardiac surgery. The studies conducted so far have been in patients undergoing cardiac surgery (CABG, valvular surgeries, aortic aneurysm repair) using cardiopulmonary bypass. $(2,12-17)$ We studied the effect of NAC on renal dysfunction in patients undergoing off-pump CABG, as $70 \%$ of coronary bypass graft operations are carried out using the offpump technique at our centre.

It is proposed that OP-CABG has a less detrimental effect on renal function than CABG using cardiopulmonary bypass. $(8,18)$ This finding was not confirmed by the studies conducted later.(19) The controversy regarding the beneficial effect of OP-CABG over CABG using cardiopulmonary bypass continues. We consider that the off-pump $C A B G$ is less invasive than the on-pump technique and hence we used a lower dose of NAC than in the studies done by Hynninen et al.,(12) Ristikankare et al.,(13) Haase et al.,(14) Hamamsy et al. (15) and Wijeysundera et al. (16)

The dose of NAC used in this study is based on the dosing regimen adopted for preventing radiocontrast-induced 
nephropathy. $(4,6,11)$ Marenzi et al. (20) used NAC for two postoperative days to prevent renal dysfunction in patients undergoing angioplasty. Nitescu et al. (21) proposed that the repeated administration of lower doses of NAC may be as effective in attenuating renal ischaemic reperfusion injury as higher doses when given immediately following the ischaemic insult, as shown in their study in rats subjected to renal ischaemia reperfusion injury. Laisalmi-Kokki et al. (22) indicated a probable increase in the risk of remote renal injury with the use of NAC in the clinical setting of renal ischaemia/reperfusion.

The primary outcome of this study was to determine the proportion of patients developing postoperative renal dysfunction by measuring serum creatinine and GFR in the postoperative period. In order to adjust creatinine values for age, sex and body weight, the GFR was calculated according to the Cockroft-Gault equation. Other studies have employed additional parameters like urinary $\mathrm{N}$-acetyl-beta-Dglucosaminidase (NAG)/creatinine,(12,13) urinary albumin/creatinine ratio(12) and serum cystatin C.(12-14) The effect of NAC on serum creatinine values and estimated GFR without any effect on serum cystatin $C$ levels has been shown in volunteers with a normal renal function, indicating the need to consider the direct effects of NAC on serum creatinine levels and estimated GFR.(23)

In our study, the incidence of renal failure was low in both the groups and a total of $10 \%$ patients developed postoperative renal dysfunction (as defined by a postoperative rise in serum creatinine level of more than $25 \%$ from the preoperative value). The incidence of renal dysfunction did not differ between the groups (Table 3 ). Thus, it is evident that NAC did not have any beneficial effect in preventing renal dysfunction. The study by Fischer et al. (17) showed a beneficial effect of using NAC in cardiac surgery. This study, however, is retrospective with a small sample size. The patients had normal preoperative renal function and there was no mention of preoperative comorbidities in the selected 
patients. Barr and Kolodner(24) showed a renoprotective effect of perioperative NAC and fenoldopam in patients with chronic renal insufficiency undergoing cardiac surgery.

Our study was prospective and randomized with a statistically significant sample size involving a homogeneous group of patients undergoing OP-CABG. So far, we are not aware of any study done on the effect of NAC in preventing renal dysfunction in OP-CABG patients. The groups of patients selected for the study were at high risk of developing postoperative renal dysfunction. The assessment of serum creatinine and GFR using the Cockroft-Gault equation has proven to be economical and reliable for estimating postoperative renal dysfunction. $(25,26)$

The limitations of the present study are that the data were not analyzed with the intention-to-treat principle, the dose of NAC was low, which may not adequately prevent the antioxidant injury, and we used serum creatinine levels and the calculation of creatinine clearance (estimated GFR) to represent true GFR in the nonsteady state. Postoperative creatinine clearance values do not necessarily approximate directly measured GFR because creatinine concentration is not in a steady state. Timed measurements of creatinine clearance become inaccurate with decreasing GFR. However, other alternative measures of GFR using clearance of inulin or radiolabeled compounds are limited and not feasible.

\section{Acknowledgement}

The authors would like to thank Dr Lloyd Vincent MD (Med) DM (Neph) for his valuable suggestions. 


\section{References}

1. Mangano CM, Diamondstone LS, Ramsay JG, Aggarwal A, Herskowitz A, Mangano DT. Renal dysfunction after myocardial revascularization: risk factors, adverse outcomes, and hospital resource utilization. The Multicenter Study of Perioperative Ischemia Research Group. Ann Intern Med [Internet]. 1998 Feb 1 [cited 2019 Dec 11];128(3):194-203. Available from: http://www.ncbi.nlm.nih.gov/pubmed/9454527

2. Burns KEA, Chu MWA, Novick RJ, Fox SA, Gallo K, Martin CM, et al. Perioperative $\mathrm{N}$-acetylcysteine to prevent renal dysfunction in high-risk patients undergoing cabg surgery: a randomized controlled trial. JAMA [Internet]. 2005 Jul 20 [cited 2019 Sep 23];294(3):342-50. Available from: http://www.ncbi.nlm.nih.gov/pubmed/16030279

3. Conlon PJ, Stafford-Smith M, White WD, Newman MF, King S, Winn MP, et al. Acute renal failure following cardiac surgery. Nephrol Dial Transplant. 1999;14(5):1158-62.

4. Tepel M, Van Der Giet M, Schwarzfeld C, Laufer U, Liermann D, Zidek W. Prevention of radiographic-contrast-agent-induced reductions in renal function by acetylcysteine. $\mathrm{N}$ Engl $\mathrm{J}$ Med. 2000 Jul 20;343(3):180-4.

5. Shyu KG, Cheng JJ, Kuan P. Acetylcysteine protects against acute renal damage in patients with abnormal renal function undergoing a coronary procedure. J Am Coll Cardiol [Internet]. 2002 Oct 16 [cited 2019 Nov 20];40(8):1383-8. Available from: http://www.ncbi.nlm.nih.gov/pubmed/12392825

6. Kay J, Chow WH, Chan TM, Lo SK, Kwok OH, Yip A, et al. Acetylcysteine for Prevention of Acute Deterioration of Renal Function Following Elective Coronary Angiography and Intervention: A Randomized Controlled Trial. J Am Med Assoc. 2003 Feb 5;289(5):553-8. 
7. Miller RD, Cohen NH, Eriksson LI, Professor F, Chair A, WienerKronish JP. Miller's Anesthesia, 2-Volume Set. Elsevier; 2014. $3576 \mathrm{p}$.

8. Pramodh K, Vani, Muralidhar K. Renal function following CABG: On-pump vs off-pump. Indian J Thorac Cardiovasc Surg. 2003;19(4):169-73.

9. Zanardo G, Michielon P, Paccagnella A, Rosi P, Caló M, Salandin $\mathrm{V}$, et al. Acute renal failure in the patient undergoing cardiac operation. Prevalence, mortality rate, and main risk factors. $J$ Thorac Cardiovasc Surg [Internet]. 1994 Jun [cited 2019 Nov 20];107(6):1489-95.

Available

from:

http://www.ncbi.nlm.nih.gov/pubmed/8196394

10. Gormley SMC, McBride WT, Armstrong MA, Young IS, McClean E, MacGowan SW, et al. Plasma and urinary cytokine homeostasis and renal dysfunction during cardiac surgery. Anesthesiology. 2000;93(5):1210-6.

11. RGUHS University Library [Internet]. [cited 2019 Nov 20]. Available from: http://www.rguhs.ac.in/digitallibrary/Helinet about us.html

12. Hynninen MS, Nieme TT, Pöyhiä R, Raininko El, Salmenperä MT, Lepäntalo MJ, et al. N-acetylcysteine for the prevention of kidney injury in abdominal aortic surgery: A randomized, doubleblind, placebo-controlled trial. Anesth Analg. 2006;102(6):163845.

13. Ristikankare A, Kuitunen $\mathrm{T}$, Kuitunen A, Uotila L, Vento A, Suojaranta-Ylinen $\mathrm{R}$, et al. Lack of renoprotective effect of i.v. $\mathrm{N}$ acetylcysteine in patients with chronic renal failure undergoing cardiac surgery. Br J Anaesth. 2006;97(5):611-6.

14. Haase M, Haase-Fielitz A, Bagshaw SM, Reade MC, Morgera S, Seevenayagam $S$, et al. Phase II, randomized, controlled trial of high-dose $\mathrm{N}$-acetylcysteine in high-risk cardiac surgery patients. 
Crit Care Med [Internet]. 2007 May [cited 2019 Sep 23];35(5):1324-31. Available from: http://www.ncbi.nlm.nih.gov/ pubmed/17414730

15. El-Hamamsy I, Stevens LM, Carrier M, Pellerin M, Bouchard D, Demers $\mathrm{P}$, et al. Effect of intravenous $\mathrm{N}$-acetylcysteine on outcomes after coronary artery bypass surgery: A randomized, double-blind, placebo-controlled clinical trial. J Thorac Cardiovasc Surg. 2007 Jan;133(1):7-12.

16. Wijeysundera DN, Beattie WS, Rao V, Granton JT, Chan CT. Nacetylcysteine for preventing acute kidney injury in cardiac surgery patients with pre-existing moderate renal insufficiency. Can J Anesth. 2007;54(11):872-81.

17. Fischer UM, Tossios $\mathrm{P}$, Mehlhorn U. Renal protection by radical scavenging in cardiac surgery patients. Curr Med Res Opin. 2005 Aug;21(8):1161-4.

18. Loef BG, Epema AH, Navis G, Ebels T, Van Oeveren W, Henning $\mathrm{RH}$. Off-pump coronary revascularization attenuates transient renal damage compared with on-pump coronary revascularization. Chest. 2002;121(4):1190-4.

19. Schwann NM, Horrow JC, Strong MD, Chamchad D, Guerraty A, Wechsler AS. Does off-pump coronary artery bypass reduce the incidence of clinically evident renal dysfunction after multivessel myocardial revascularization? Anesth Analg. 2004 Oct;99(4):95964.

20. Marenzi G, Assanelli E, Marana I, Lauri G, Campodonico J, Grazi $\mathrm{M}$, et al. $\mathrm{N}$-acetylcysteine and contrast-induced nephropathy in primary angioplasty. N Engl J Med. 2006 Jun 29;354(26):277382.

21. Nitescu N, Ricksten SE, Marcussen N, Haraldsson B, Nilsson U, Basu $\mathrm{S}$, et al. $\mathrm{N}$-acetylcysteine attenuates kidney injury in rats subjected to renal ischaemia-reperfusion. Nephrol Dial 
Transplant. 2006 May;21(5):1240-7.

22. Laisalmi-Kokki M, Pesonen E, Kokki H, Valta P, Pitkänen $M$, Teppo AM, et al. Potentially detrimental effects of $\mathrm{N}$ acetylcysteine on renal function in knee arthroplasty. Free Radic Res. 2009;43(7):691-6.

23. Hoffmann U, Banas B, Fischereder M, Krämer BK. Nacetylcysteine in the prevention of radiocontrast-induced nephropathy: Clinical trials and end points. In: Kidney and Blood Pressure Research. 2004. p. 161-6.

24. Barr LF, Kolodner K. N-acetylcysteine and fenoldopam protect the renal function of patients with chronic renal insufficiency undergoing cardiac surgery. Crit Care Med. 2008;36(5):1427-35.

25. Wang F, Dupuis JY, Nathan H, Williams K. An Analysis of the Association Between Preoperative Renal Dysfunction and Outcome in Cardiac Surgery: Estimated Creatinine Clearance or Plasma Creatinine Level as Measures of Renal Function. Chest. 2003;124(5):1852-62.

26. Noyez L, Plesiewicz I, Verheugt FWA. Estimated creatinine clearance instead of plasma creatinine level as prognostic test for postoperative renal function in patients undergoing coronary artery bypass surgery. In: European Journal of Cardio-thoracic Surgery. 2006. p. 461-5. 


\section{CHAPTER 7}

\section{Effect of sodium bicarbonate infusion in off-pump coronary artery bypass grafting in patients with renal dysfunction - a pilot study.}

Muralidhar Kanchi, Manjunath R, Jos Massen, Lloyd Vincent, Kumar BelaniPublished in: Journal of Anaesthesiology Clinical Pharmacology 2018 Jul-Sep;34(3):301-306 


\begin{abstract}
Background: Acute kidney injury (AKI) following cardiac surgery is a major complication resulting in increased morbidity, mortality, and economic burden. The mortality is between 40 and $60 \%$ when renal replacement therapy is required. This study was designed to determine the benefit sodium bicarbonate supplementation in stable chronic kidney disease $(C K D)$ patients who undergo off-pump coronary artery bypass grafting (OP-CABG). Methods: We prospectively studied 60 non-dialysis CKD patients with GFR $\leq 60 \mathrm{ml} / \mathrm{min} / 1.73 \mathrm{~m}^{2}$ requiring elective OP-CABG. They were randomly allotted into two groups. One group received sodium bicarbonate $\left(\mathrm{NaHCO}_{3}\right)$ infusion at $0.5 \mathrm{mMol} / \mathrm{kg}$ first hour followed by $0.2 \mathrm{mMol} / \mathrm{kg} / \mathrm{hr}$ till the end of surgery and the other group received $0.9 \%$ sodium chloride. The serum creatinine, was estimated at specified intervals at prior to surgery, immediately after surgery and post-operative day $1,2,3$ and 4 . The study results were also compared to a simultaneous matched cohort of 30 patients without renal dysfunction underwent OP-CABG. Results: None of our study patients required renal replacement therapy and no mortality was observed in any of the groups during the perioperative and hospitalization period. Six $(20 \%)$ patients in the control group, 10 (33.3\%) patients in placebo group and 6 (20\%) patients in $\mathrm{NaHCO}_{3}$ group developed Stage-1 AKI. Conclusion: Perioperative infusion of $\mathrm{NaHCO}_{3}$ in OP-CABG reduced the incidence of Stage- 1 AKI by about $40 \%$ when compared to the placebo group. And this incidence was similar in patients with normal renal function undergoing OP-CABG. A larger group of patients may be required to suggest a significance of renal protective benefit of $\mathrm{NaHCO} 3$ in patients undergoing OP-CABG.
\end{abstract}

Keywords Acute kidney injury; Coronary artery bypass grafting; Cardiac surgery; Sodium bicarbonate; Creatinine. 


\section{Introduction}

Acute kidney injury (AKI) after cardiac surgery continues to be a major devastating complication because it can result in multi-organ dysfunction, death, increased resource utilization and high cost.(1)Globally 800,000 patients undergo coronary revascularization annually with the use of cardiopulmonary bypass (CPB). Approximately 77,000 patients in a year develops postoperative AKI, among which 14,000 require dialysis for the first time.(2) Up to $30 \%$ of patients undergoing coronary artery bypass grafting (CABG) sustain sufficient renal injury to meet the threshold criteria, i.e., a creatinine increase of $>0.3 \mathrm{mg} \%$ or $50 \%$ of their baseline within 48 hours of surgery. The reported incidence of $\mathrm{AKI}$ after cardiac surgery varies according to the definition of kidney injury as well as the institution reporting the results. Additionally, the current models poorly predict the likelihood of AKI. About $3 \%$ of patients sustain AKI following CABG of sufficient severity requiring dialysis. As many as $60 \%$ of patients requiring dialysis after CABG die before hospital discharge and the survivors continue with chronic renal disease with or without the need for dialysis.

Serum creatinine reflects the balance between the synthesis of creatinine and its excretion by the kidney. Creatinine production in the body varies with muscle mass, physical activity, protein intake and catabolism while creatinine excretion is dependent on the glomerular filtration rate (GFR). The serum creatinine and GFR are inversely and exponentially related. Halving of GFR implies that there will be doubling of creatinine concentration.(2)

Maintenance of volume status along with pretreatment with sodium bicarbonate $\left(\mathrm{NaHCO}_{3}\right)$ has been shown to be effective for prophylaxis for contrast for contrast induced nephropathy.(3) Alkalization reduces free radicals responsible for renal injury(4-7) and pretreatment with $\mathrm{NaHCO}_{3}$ has been demonstrated to be more protective than sodium 
chloride $(\mathrm{NaCl})$ in both doxorubicin and ischemia induced animal models of acute renal failure.(8-10) In a small, randomized, double-blind trial of 100 patients undergoing cardiac surgery who were at increased risk of AKI, a 24 hour infusion of sodium bicarbonate decreased the incidence of acute renal dysfunction.(11) Present study was designed to determine the effect of urinary alkalization with systemically administered $\mathrm{NaHCO}_{3}$ in those patients have preexisting renal dysfunction but not on maintenance dialysis and scheduled for OP-CABG.

\section{Patients and Methods}

We have prospectively evaluated 60 consecutive patients who underwent elective off pump coronary artery bypass graft (OP-CABG) between January-2012 and October-2016 at a tertiary care cardiac center. This study was approved by ethics committee and institutional review board. All these patients were identified by the presence of stable chronic kidney disease (CKD); i.e., non-dialysis dependent renal dysfunction with eGFR $\leq 60 \mathrm{ml} / \mathrm{min} / 1.73 \mathrm{~m}^{2}$ or creatinine $\geq 1.4 \mathrm{mg} \%$ prior to OPCABG. Preoperative eGFR was estimated by using modification of diet in renal disease (MDRD) formula, eGFR of $<60 \mathrm{ml} / \mathrm{min} / 1.73 \mathrm{~m}^{2}$ was taken as indicative of renal impairment.

We have excluded those patients scheduled for on-pump $C A B G$, emergency surgery, redo operations and if they had end-stage renal disease, chronic inflammatory disease/immune-suppression, corticosteroid therapy, age $<18$ years, enrolled in a conflicting research study, patients on renal replacement therapy and renal transplanted patients. All patients received a standard anesthetic consisting of midazolam, isoflurane, fentanyl, vecuronium or atracurium, endotracheal intubation and mechanical ventilation via an endotracheal tube to achieve normocarbia. Following median sternotomy and heparinization, the surgeons conducted distal coronary anastomosi/es was done on the beating-heart using 'octopus' (Medtronic Inc, Minneapolis, MA, USA) 
suction device tissue stabilizer for immobilization of the local heart muscle. Those requiring conversion to 'on-pump' (CPB) were excluded from the study.

\section{Surgical procedure}

Hemodynamic care included a targeted mean arterial pressure of at least $70 \mathrm{mmHg}$, central venous pressure of $8-12 \mathrm{mmHg}$, pulse pressure variation (PPV) of $\leq 12 \%$ using either Flotrac (Vigileo, I PX 1, Edward Lifesciences, Irvine, USA) or Lidco rapid (model POC-125, ADVANTECH, Taiwan) when not on IABP and cardiac index of $\geq 2.5$ $\mathrm{L} / \mathrm{min} / \mathrm{m}^{2}$. Epinephrine at $0.01-0.05 \mu \mathrm{g} / \mathrm{kg} / \mathrm{min}$ and nitroglycerine $0.05-$ $0.1 \mu \mathrm{g} / \mathrm{kg} / \mathrm{min}$ were used as inotrope/ vasodilator at the discretion of the anesthesia care team. All patients were electively ventilated postoperatively until the criteria for separation from ventilator and tracheal extubation were met. Postoperative analgesia was provided with fentanyl infusion at $0.5-1.0 \mu \mathrm{g} / \mathrm{kg} / \mathrm{hr}$ until removal of chest tube $/ \mathrm{s}$ and then only paracetamol. No nephrotoxic agents were used and nonsteroidal anti-inflammatory drugs were avoided in all patients.

The identified sixty patients with impaired renal function and not required dialysis and scheduled for elective OP-CABG were randomly allocated to two groups viz.: $\mathrm{NaHCO}_{3}$ group patients received $\mathrm{NaHCO}_{3}$ infusion at a rate of $0.5 \mathrm{mMol} / \mathrm{kg} / \mathrm{h}$ during the first hour of surgery followed by 0.2 $\mathrm{mMol} / \mathrm{kg} / \mathrm{h}$ till the end of surgery and standard care. The Placebo group patients received $0.9 \%$ sodium chloride infusion instead of $\mathrm{NaHCO}_{3}$ and standard care. In addition, there was an age-matched control group of 30 normal patients who had no renal dysfunction i.e., patients undergoing OP-CABG with a preoperative serum creatinine of $\leq 1.4 \mathrm{mg} / \mathrm{dl}$ and eGFR $\geq 60 \mathrm{ml} / \mathrm{min} / 1.73 \mathrm{~m}^{2}$. Anesthesia and surgery were similar in all the groups, mean arterial pressure and intravascular volume status was maintained with appropriate clinical measures during the course of surgery in all patients. Blood samples were drawn at specified intervals 
namely, at the beginning of surgery after anesthetic induction, at the end of surgery, and 24 hours after surgery, for measurement of serum creatinine, brain natriuretic peptide (BNP), troponin- $\mathrm{T}$, and prior to, at the end of surgery and at 24 hours after surgery.

The diagnosis of AKI postoperatively made using 'kidney disease; improving global outcomes' (KDIGO) criteria $^{13}$ in terms of increase in serum creatinine on any of the first 5 postoperative days: Stage-1 AKI was defined by rise in serum creatinine by $0.3 \mathrm{mg} / \mathrm{dL}$ or by an increase $\geq 1.5$ fold from the reference value; stage-2 AKI by a 2 to 2.9 fold increase in serum creatinine and stage $-3 \mathrm{AKI}$ by $\geq 3.0$ fold increase in serum creatinine, serum creatinine

Table1: Criteria used for initiating renal replacement therapy during the postoperative period

\begin{tabular}{lll}
\hline SI. & Condition & Description \\
\hline 1 & Oliguria & $\leq 200 \mathrm{ml} / 12 \mathrm{~h}$ \\
2 & Anuria & Urine output $0-50 \mathrm{ml} / 12 \mathrm{~h}$ \\
3 & Blood urea & $\geq 35 \mathrm{mMol} / \mathrm{L}$ or $\geq 98 \mathrm{mg} / \mathrm{dL}$ \\
4 & Serum Creatinine & $\geq 400 \mathrm{mMol} / \mathrm{L}$ or $\geq 4.5 \mathrm{mg} / \mathrm{dL}$ \\
5 & Uncompensated metabolic & $\mathrm{pH} \leq 7.1$ \\
& acidosis & \\
6 & Serum Potassium & $\geq 6.5 \mathrm{mMol} / \mathrm{L}$ or rapidly rising \\
7 & Serum Sodium & $\leq 110$ and $\geq 160 \mathrm{mMol} / \mathrm{L}$ \\
8 & Pulmonary edema & unresponsive to diuretics \\
9 & Uremic manifestations & encephalopathy \\
\hline
\end{tabular}


increase to $\geq 4 \mathrm{mg} / \mathrm{dL}$ or initiation of renal replacement therapy. Renal replacement therapy was instituted based on the criteria for commencement of RRT as listed in Table 1.

Coronary artery bypass grafting (CABG) related MI was defined by elevation of cardiac biomarker, i.e., troponin-C values $\left(\leq 10 \times 99^{\text {th }}\right.$ percentile URL) in patients with normal baseline cTn values along with either (i) new pathological $Q$ waves or new left bundle branch block (LBBB) or (ii) angiographic documented new graft or new native coronary artery occlusion, or (iii) imaging evidence of new loss of viable myocardium or new regional wall motion abnormality.

\section{Statistical analysis}

The data was analyzed by SPPS (Version 15, SPSS Inc., Chicago, USA) and Microsoft excel. Standard statistical methods for assessment on proportions, percentages and measures of central tendencies (mean, SD, median and range) were used. One-way ANOVA was used to determine the significance of variables between the groups.

\section{Results}

Basic demographics and clinical data of each group is described in Table 2. By design, the preoperative serum creatinine was significantly higher in the placebo group (group-P) and sodium bicarbonate group (group-B) correspondingly eGFR was significantly lower in both the group $P$ and $B$ when compared with group with normal renal function (group-A). The numerical Euroscore was higher in the groups $P$ and $B$ as compared to the group $A$. Two patients, one in group-A and one in group- $B$ were converted to on-pump due to surgical reasons. One patient in each of the groups $A$ and $P$ needed IABP for cardiac support. The incidence of further deterioration in renal function postoperatively is displayed in Table 3. There was no difference in outcome between the 3 
groups. None of the patients required re-exploration for bleeding or prolonged ventilation. All patients

Table 2: Demographic and clinical data of patients undergoing OP-

CABG in the study

\begin{tabular}{|c|c|c|c|c|}
\hline Variable & $\begin{array}{l}\text { Group-A } \\
\qquad(n=30)\end{array}$ & $\begin{array}{l}\text { Group-P \# } \\
\qquad(\mathrm{n}=30)\end{array}$ & $\begin{array}{l}\text { Group-B } \\
(n=30)\end{array}$ & $\begin{array}{c}P \\
\text { value }\end{array}$ \\
\hline Age (Years) & $57.11 \pm 9.5$ & $60.87 \pm 7.1$ & $60.81 \pm 9.2$ & 0.239 \\
\hline Male / Female & $28 / 2$ & $287 / 3$ & $29 / 1$ & \\
\hline Diabetes mellitus & $17(56 \%)$ & $15(65 \%)$ & $14(67 \%)$ & \\
\hline Hypertension & $17(56 \%)$ & $18(78 \%)$ & $15(72 \%)$ & 0.118 \\
\hline Euro Score & $2.30 \pm 1.97$ & $4.48 \pm 2.39^{\star *}$ & $4.67 \pm 2.22^{\star *}$ & $<0.001$ \\
\hline \multicolumn{5}{|l|}{ Pre-op eGFR } \\
\hline$\left(\mathrm{ml} / \mathrm{min} / 1.73 \mathrm{~m}^{2}\right)$ & $84.65 \pm 16.63$ & $49.05 \pm 10.89^{* *}$ & $50.44 \pm 7.17^{\star \star}$ & $<0.001$ \\
\hline $\begin{array}{l}\text { Pre-op Creatinine } \\
(\mathrm{mg} \%)\end{array}$ & $0.99 \pm 0.15$ & $1.43 \pm 0.15^{\star *}$ & $1.54 \pm 0.33^{* *}$ & 0.001 \\
\hline
\end{tabular}

§Group-A: Patients with normal renal function "Group-P: Patients with pre-existing renal dysfunction and received Sodium chloride; "Group-B: Patients with pre-existing renal dysfunction and received Sodium bicarbonate; eGFR - estimated glomerular filtration rate.

were discharged from intensive care unit and hospital in a hemodynamically stable condition. There was no incidence of stage-3 and stage-2 AKI in any of the group. Stage-1 AKI was observed in 6 patients out of $30(20 \%)$ in the control group among the 30 patients. Serum creatinine was elevated by $0.3 \mathrm{mg} \%$ from preoperative to a postoperative value (mean \pm SD of $1.0 \pm 0.12 \mathrm{mg} \%$ and $1.44 \pm 2.4 \mathrm{mg} \%$ respectively). Ten patients out of $30(33.3 \%)$ in placebo group had an 
elevation of serum creatinine from $1.45 \pm 0.15 \mathrm{mg} \%$ to $2.16 \pm 0.49 \mathrm{mg} \%$. Six patients out of $30(20 \%)$ in $\mathrm{NaHCO} 3$ group had a rise of serum creatinine from $1.46 \pm 0.24 \mathrm{mg} \%$ to $2.1 \pm 0.5 \mathrm{mg} \%$. There was no

Table 3: Renal deterioration following OP-CABG ( $p \geq 0.05$ by ANOVA between groups)

\begin{tabular}{cccc}
\hline Group & $\begin{array}{c}\text { Group-P } \\
\text { Placebo }(\mathrm{n}=30)\end{array}$ & $\begin{array}{c}\text { Group-D } \\
\text { Dopamine }(\mathrm{n}=30)\end{array}$ & $\begin{array}{c}\text { Group-A } \\
\text { Normal }(\mathrm{n}=29)\end{array}$ \\
\hline Need for ${ }^{\mathrm{R} R \mathrm{RT}}$ & 0 & 0 & 0 \\
${ }^{* *}$ Stage 3 AKI & 0 & 0 & 0 \\
${ }^{* *}$ Stage 2 AKI & 0 & 0 & 0 \\
${ }^{*}$ Stage 1 AKI & 10 & 12 & 6 \\
Urine output (ml) & & $2183.86 \pm 659$ & $2069.76 \pm 679$ \\
Day 1 postoperative & $2510 \pm 569$ & $3184.77 \pm 787$ & $3350 \pm 466$ \\
Day 2 postoperative & $2845.70 \pm 904$ & $3101.25 \pm 673$ & $2720.78 \pm 812$ \\
Day 3 postoperative & $2881.25 \pm 928$ & & \\
\hline
\end{tabular}

\#Group-P: Patients with pre-existing renal dysfunction and received Sodium chloride; 'Group-B: Patients with pre-existing renal dysfunction, received Sodium bicarbonate; §Group-A: Patients with normal renal function. "serum creatinine elevation by $0.3 \mathrm{mg} \%$; ${ }^{* *}$ serum creatinine increase by more than $2-2.9$-fold; ${ }^{* * *}$ serum creatinine elevation of $>3.0$ fold; ${ }^{\dagger} \mathrm{RRT}=$ renal replacement therapy; eGFR= estimated glomerular filtration rate.

difference in other variables with infusion of $\mathrm{NaHCO}_{3}$ as compared to placebo group (ANOVA $p>0.05$ for all variables). There was a significant increase in serum BNP levels at the end of surgery and at 24 hours postoperatively in groups $\mathrm{P}$ and $\mathrm{B}$ (Table 4). 
Table 4: Data of creatinine, troponin and BNP in three groups of patients

\begin{tabular}{|c|c|c|c|c|}
\hline Variable & $\begin{array}{l}\text { Group }-A^{\S} \\
(n=30)\end{array}$ & $\begin{array}{c}\text { Group - } P^{\#} \\
(n=30)\end{array}$ & $\begin{array}{l}\text { Group - } \mathrm{B}^{\mathbb{1}} \\
(\mathrm{n}=30)\end{array}$ & $P$ \\
\hline Creatinine 1 & $0.99 \pm 0.16$ & $1.56 \pm 0.43^{* *}$ & $1.48 \pm 0.41^{* *}$ & $<0.001$ \\
\hline Creatinine 2 & $1.01 \pm 0.27$ & $1.60 \pm 0.47^{* *}$ & $1.49 \pm 0.42^{\star *}$ & $<0.001$ \\
\hline Creatinine 3 & $1.04 \pm 0.16$ & $1.62 \pm 0.52^{* *}$ & $1.45 \pm 0.48^{*}$ & $<0.001$ \\
\hline Creatinine 4 & $1.03 \pm 0.17$ & $1.64 \pm 0.52^{* *}$ & $1.45 \pm 0.59^{*}$ & $<0.001$ \\
\hline Creatinine 5 & $0.96 \pm 0.15$ & $1.53 \pm 0.35^{\star}$ & $1.42 \pm 0.53$ & $<0.001$ \\
\hline Troponin 1 & $0.04 \pm 0.1$ & $0.18 \pm 0.4$ & $0.07 \pm 0.1$ & 0.605 \\
\hline Troponin 2 & $2.15 \pm 6.2$ & $5.69 \pm 12.5$ & $8.57 \pm 16.6$ & 0.006 \\
\hline Troponin 3 & $6.71 \pm 15.2$ & $3.69 \pm 5.6$ & $20.74 \pm 44.4$ & 0.017 \\
\hline BNP 1 & $89.77 \pm 85$ & $121.00 \pm 137$ & $140.53 \pm 188$ & 0.875 \\
\hline BNP 2 & $105.26 \pm 166$ & $202.71 \pm 243^{\star *}$ & $154.01 \pm 124^{*}$ & 0.226 \\
\hline BNP 3 & $349.87 \pm 483 \neq$ & $250.85 \pm 234 \neq$ & $390.37 \pm 217 \neq$ & 0.062 \\
\hline
\end{tabular}

$\S$ Group-A: Patients with normal renal function ${ }^{\#}$ Group-P: Patients with preexisting renal dysfunction and received Sodium chloride; 'Group-B: Patients with pre-existing renal dysfunction and received Sodium bicarbonate.

$\mathrm{BNP}=$ brain natriuretic peptide; $1=$ prior to surgery, $2=$ at end surgery, $3=24$ hours after surgery; ${ }^{*}=p<0.05 ;{ }^{* *}=<0.001$ for between group comparison; $\neq=p<0.05$, $\neq \neq=<0.001$ for within group comparison. 


\section{Discussion}

Acute kidney injury after cardiac surgery is not an uncommon complication after cardiac surgery. AKI is associated with increased in morbidity, mortality and hospital costs. Even when renal replacement therapy (dialysis) is avoided, milder forms of AKI are associated with adverse outcomes and degree of AKI correlates negatively with long term survival despite successful hospital discharge. Renal dysfunction after cardiac surgery is multifactorial in origin and there are multiple risk factors that contribute to the development of AKI.

Both the study groups (placebo and sodium bicarbonate) had pre-existing renal dysfunction. But none required renal replacement therapy and none demonstrated stage-2 or stage-3 AKI following the surgery. There was a $40 \%$ reduction in incidence of Stage-1 AKI in patients who received $\mathrm{NaHCO}_{3}$ compared placebo group (group $\mathrm{P}$ ) in patients who suffered from pre-existing renal dysfunction. However, the incidence of Stage-1 AKI was similar in patients received $\mathrm{NaHCO}_{3}$ and patients with normal renal function. This is suggestive of possible renal protective effect of $\mathrm{NaHCO} 3$ infusion in patients undergoing OP-CABG with preexisting renal dysfunction.

In a meta-analysis with a total of 1092 patients, the influence of alkalinization of urine with sodium bicarbonate was studied in patients undergoing cardiac surgery. The incidence of $\mathrm{AKI}$, requirement for renal replacement therapy, duration of postoperative mechanical ventilation, length of ICU/hospital stay and death was determined using accepted methods. Though the treatment methodology varied a little in each of the studies, $\mathrm{NaHCO}_{3}$ was infused at a dose $0.5 \mathrm{mMol} / \mathrm{kg} / \mathrm{h}$ for the first hour followed by $0.2 \mathrm{mMol} / \mathrm{kg} / \mathrm{h}$ infusion. There was no significant difference in the occurrence of $A K I$, need for RRT, length of stay in ICU, and hospital mortality in the two groups namely with $\mathrm{NaHCO}_{3}$ and without $\mathrm{NaHCO}_{3 .(12)}$ Hemolysis is relatively common in extracorporeal 
circulation which may predispose patients to AKI. Urinary acidity may enhance generation and toxicity of reactive oxygen species. In addition, activation of complement during cardiac surgery may precipitate AKI. Urinary alkalinization may protect the kidney from AKI induced by oxidant substrates, iron-mediated free radicals and tubular cast formation. In addition, urinary alkalinization could prevent generation of hemoglobin casts, inhibit endocytic hemoglobin uptake and attenuate tubular necrosis. Alkalinization of urine based on $\mathrm{NaHCO} 3$ infusion therapy has been reported to benefit patients with contrast-induced nephropathy.(3) This prospective randomized study showed the beneficial effect of $\mathrm{NaHCO}_{3}$ infusion in patients with stable CKD (with GFR $\leq 60$ $\mathrm{ml} / \mathrm{min} / 1.73 \mathrm{~m}^{2}$ ) undergoing off-pump CABG. The fundamental issue in the maintenance of renal integrity revolves round maintenance of oxygen supply and demand especially to the renal medulla. The factors which maintain this supply-demand balance are the mean arterial pressure during CPB and the oxygen-carrying capacity. Many authors have proposed renal protective strategies to prevent AKI or at least detect deterioration in the renal function in a timely manner to permit early intervention while evaluating genetic influences that may predispose the patients to AKI during cardiac surgery.

Our study findings are in disagreement with the results of another study reported recently by Kristeller JL. et al .However this prospective randomized study was done in patients undergoing cardiac surgery under cardiopulmonary bypass.(13)On the other hand, in a prospectively planned double-blind randomized controlled trial looking at sodium bicarbonate and renal function after cardiac surgery with individual patient data meta-analysis (IPDMA) on 877 patients, urinary alkalization using $\mathrm{NaHCO}_{3}$ did not decrease the overall incidence of $\mathrm{AKI}$, but it reduced severe $A K I$ and need for RRT in low-risk elective CABG.(14) Our study produced similar results showing a trend towards a reduction in stage-1 AKI with sodium bicarbonate infusion. The 
avoidance of cardiopulmonary bypass may have also played a role in influencing renal outcomes but is unlikely as shown by a recent report by Hynes and associates.(15)

\section{Conclusion}

Our current study findings show that the perioperative administration of sodium bicarbonate infusion in OP-CABG reduces the incidence of Stage-1 AKI in patients with preexisting renal dysfunction. We feel that paying attention to standard parameters to ensure renal perfusion and avoidance of renal toxins are important and use of sodium bicarbonate may be beneficial to reduce the worsening of renal dysfunction in patients undergoing OP-CABG with preexisting renal dysfunction not on dialysis. However, a study on larger group of patients required to strengthen our findings.

\section{Acknowledgement}

The authors would acknowledge Mr. Karthik for statistical input, Ms. Esai Malar and Ms. Hilda for support in data collection and Mr Annapandian VM for help in editing this document. 


\section{References}

1. Mangano CM, Diamondstone LS, Ramsay JG, Aggarwal A, Herskowitz A, Mangano DT. Renal dysfunction after myocardial revascularization: risk factors, adverse outcomes, and hospital resource utilization. The Multicenter Study of Perioperative Ischemia Research Group. Ann Intern Med [Internet]. 1998 Feb 1 [cited 2019 Dec 11];128(3):194-203. Available from: http://www.ncbi.nlm.nih.gov/pubmed/9454527

2. Miller RD, Cohen NH, Eriksson LI, Professor F, Chair A, WienerKronish JP. Miller's Anesthesia, 2-Volume Set. Elsevier; 2014. $3576 \mathrm{p}$.

3. Huber W, Huber T, Baum S, Franzen M, Schmidt C, Stadlbauer $\mathrm{T}$, et al. Sodium bicarbonate prevents contrast-induced nephropathy in addition to theophylline. Med (United States). 2016 May 1;95(21).

4. Bakris GL, Lass N, Gaber AO, Jones JD, Burnett JC. Radiocontrast medium-induced declines in renal function: a role for oxygen free radicals. Am J Physiol [Internet]. 1990 Jan [cited 2019 Dec 12];258(1 Pt 2):F115-20. Available from: http://www.ncbi.nlm.nih.gov/pubmed/2301588

5. Bakris GL, Gaber AO, Jones JD. Oxygen free radical involvement in urinary Tamm-Horsfall protein excretion after intrarenal injection of contrast medium. Radiology. 1990;175(1):57-60.

6. Katholi RE, Woods WT, Taylor GJ, Deitrick CL, Womack KA, Katholi CR, et al. Oxygen free radicals and contrast nephropathy. Am J Kidney Dis. 1998;32(1):64-71.

7. Lindinger MI, Franklin TW, Lands LC, Pedersen PK, Welsh DG, Heigenhauser GJF. $\mathrm{NaHCO} 3$ and $\mathrm{KHCO} 3$ ingestion rapidly increases renal electrolyte excretion in humans. J Appl Physiol. 2000 Feb;88(2):540-50. 
8. Atkins JL. Effect of sodium bicarbonate preloading on ischemic renal failure. Nephron. 1986;44(1):70-4.

9. Sporer H, Lang F, Oberleithner H, Greger R, Deetjen P. Inefficacy of bicarbonate infusions on the cource of postischaemic acute renal failure in the rat. Eur J Clin Invest [Internet]. 1981 Aug [cited 2019 Dec 12];11(4):311-5. Available from: http://doi.wiley.com /10.1111/j.1365-2362.1981.tb02122.x

10. Baroni EA, Costa RS, Volpini R, Coimbra TM. Sodium bicarbonate treatment reduces renal injury, renal production of transforming growth factor-beta, and urinary transforming growth factor-beta excretion in rats with doxorubicin-induced nephropathy. Am J Kidney Dis [Internet]. 1999 Aug [cited 2019 Dec 12];34(2):328-37. Available from: http://www.ncbi.nlm.nih. gov/pubmed/10430982

11. Haase M, Haase-Fielitz A, Bellomo R, Devarajan P, Story D, Matalanis $G$, et al. Sodium bicarbonate to prevent increases in serum creatinine after cardiac surgery: a pilot double-blind, randomized controlled trial. Crit Care Med [Internet]. 2009 Jan [cited 2019 Sep 23];37(1):39-47. Available from: http://www.ncbi.nlm.nih.gov/pubmed/19112278

12. Kim JH, Kim HJ, Kim JY, Sik Ahn H, Ahn IM, Choe WJ, et al. Meta-Analysis of Sodium Bicarbonate Therapy for Prevention of Cardiac Surgery-Associated Acute Kidney Injury. J Cardiothorac Vasc Anesth. 2015 Oct 1;29(5):1248-56.

13. Kristeller JL, Zavorsky GS, Prior JE, Keating DA, Brady MA, Romaldini TA, et al. Lack of effectiveness of sodium bicarbonate in preventing kidney injury in patients undergoing cardiac surgery: A randomized controlled trial. In: Pharmacotherapy. 2013. p. 710-7.

14. Bailey M, McGuinness S, Haase M, Haase-Fielitz A, Parke R, Hodgson $\mathrm{CL}$, et al. Sodium bicarbonate and renal function after 
cardiac surgery: A prospectively planned individual patient metaanalysis. Anesthesiology. 2015 Feb 2;122(2):294-306.

15. Hynes CF, Colo S, Amdur RL, Chawla LS, Greenberg MD, Trachiotis GD. Long-term Effects of Off-Pump Coronary Bypass Versus Conventional Coronary Bypass Grafting on Renal Function. Innov Technol Tech Cardiothorac Vasc Surg. 2016 Jan 1;11(1):54-8. 
Chapter 8

General discussion. 
Post-operative $\mathrm{AKI}$ is a common and major complication followed by coronary artery bypass grafting (CABG). About $2.3 \%$ of isolated CABG cases are vulnerable to $\mathrm{AKI}$, and the incidence is higher (14\%-15\%) in patients with preoperative chronic kidney disease (CKD). ${ }^{1}$

Despite the success of CABG with $\mathrm{CPB}$, the deleterious effects of $\mathrm{CPB}$ are well documented(1-4)

The recent success of beating heart coronary artery bypass grafting offered an opportunity to avoid CPB and its side effects. On the other hand, beating-heart surgery (off-pump surgery) demonstrated an overall early benefit, especially in patients traditionally considered at high risk for coronary artery bypass grafting. Recent studies confirmed that coronary grafting, on the beating heart is a viable alternative to conventional on-pump CABG and provides good long term graft patency.(5-7)

In our studies, we confirm the better preservation of renal function in off-pump patients. The incidence of acute renal insufficiency defined as serum creatinine $>1.3 \mathrm{mg} / \mathrm{dl}(114.9 \mu \mathrm{mol} / \mathrm{L})$, was $46.66 \%$ and $20 \%$ in on-pump and off-pump groups, respectively. There was a significant difference in the creatinine clearance values between the two groups at $24 \mathrm{~h}$ postoperatively $(p=0.045)$. Furthermore, in off-pump patients creatinine clearance reached, after a short decline at the first 24 $\mathrm{h}$, almost the normal preoperative values by 48 hours post-operatively (Chapter 2).

According to previous studies(8) age, hypertension disease and diabetes mellitus belong to the group of risk factors for acute renal insufficiency after cardiac surgery. We found a negative correlation of creatinine clearance with age. Creatinine clearance correlation was stronger in on-pump than in off-pump patients with respect to age. This indicates that elderly people undergoing on-pump CABG are more prone to develop acute renal dysfunction. However, we could not find any 
effects of hypertension and diabetes mellitus at the development of AKI in both groups in our study (Chapter 2).

Acute renal failure necessitating the use of RRT is a rare but serious complication after cardiopulmonary bypass. This level of AKI (stage 3) develops in $1 \%-5 \%$ of patients, however, it is associated with an in-hospital mortality of $50-70 \% .(9-11)$

For this reason, determination of perioperative factors contributing to the development of stage $3 \mathrm{AKI}$ early in the postoperative period is the main subject of many clinical studies. With this knowledge a therapeutic strategy towards preventing the occurrence or worsening of renal dysfunction in this group of patients might be determined. Multivariate regression analysis of data of 2585 adult patients who underwent cardiac surgery in the period November 2010 - October 2011 reveals that predictors of $\mathrm{AKI}$ after cardiac surgery include prior renal dysfunction, a critical preoperative state, diastolic dysfunction, and combined or major cardiac surgery (Chapter 3 ).

However, clinical determinants explain only a portion of the risk for the individual. Another factor that likely affects risk is intrinsic genetic variability. Identification of genetic factors may influence the therapeutic strategy in dealing with these patients at a high risk of developing AKI. Previously, it was reported that ACE I/D bar and polymorphism of APO-E gene $(12,13)$ are associated with development of AKI in cardiac surgery. Our study of genetics predisposing patients from the Indian population that underwent off-pump coronary bypass surgery, to acute kidney injury, discovered 18 genes associated with AKI post CABG (Chapter 4, Table 5). However, previously identified genetic variants, known to be associated with AKI were not found to be significant in this analysis. Study in a larger cohort is required to validate our results in the Indian subcontinent. 
A timely diagnostic of a possible kidney insult during cardiac surgery certainly is one of most important factors of preventing further deterioration of renal function. Early diagnostic may be facilitated by biomarkers. Biomarkers in this case are molecules or compounds that indicate direct tubular injury. Several AKI biomarkers have been identified, including neutrophil gelatinase-associated lipocalin (NGAL). Neutrophil gelatinase-associated lipocalin is an iron-transporting glycoprotein which accumulates in the kidney tubules and urine after nephrotoxic and ischemic insults.(14)[5] Both urine and plasma NGAL can potentially exert an effect on the intrarenal molecular and cellular events that occur during $A K I$, and both have been used to predict the onset and course of $\mathrm{AKI}(15)$. However, recent insights into the molecular nature of NGAL suggest that it might be released not only by tubular renal cells but also by neutrophils activated by systemic inflammatory triggers, such as cardio pulmonary bypass (CPB).(16-20) In addition, the relationship between NGAL and renal outcomes was not consistent in a number of studies.(21-25)

Our study in patients who underwent off-pump coronary bypass surgery demonstrated that NGAL increases in patients with AKI independently from cardiopulmonary bypass. NGAL in patients who developed AKI was significantly higher at $4 \mathrm{~h}$ after surgery than in those patients who did not develop AKI $(P<0.05)$. However, we could not confirm a previously reported(26) association between AKI progression and a rise in NGAL levels. Furthermore, the rise in urine NGAL levels at $4 \mathrm{~h}$ in these patients was not uniform (Chapter 5). Additionally, evaluation of "renal-dose" dopamine for prevention of kidney insult during OPCAB did not show any beneficial effects (Chapter 5).

Another, promising remedy for prevention of postoperative AKI is $\mathrm{N}$-acetylcysteine. $\mathrm{N}$-acetylcysteine is an antioxidant that directly scavenges reactive oxygen species, and it has been widely used to 
prevent radiocontrast nephropathy. However, data about the effectiveness of $\mathrm{N}$-acetylcysteine in prevention of kidney damage during cardiac surgery are conflicting. A recently published literature review demonstrated that intravenous infusion of NAC can prevent postoperative $\mathrm{AKI}$ in preexisting-renal-failure patients undergoing cardiac surgery (27). However, along with studies revealing positive effects of $\mathrm{N}$ acetylcysteine, there are reports about the absence of significant benefits from injection of $\mathrm{N}$-acetylcysteine as well(28-30).Our prospective and randomized study of $\mathrm{N}$-acetylcysteine for preventing postoperative renal dysfunction includes 74 patients who underwent coronary bypass surgery. So far, we are not aware of any study done on the effect of NAC in preventing renal dysfunction in off pump patients. In this group, we could not demonstrate beneficial effects of $\mathrm{N}$-acetylcysteine infusion for inhibition of renal injury (Chapter 6).

Previously, it was reported that maintenance of volume status along with pretreatment with sodium bicarbonate $\left(\mathrm{NaHCO}_{3}\right)$ is effective for prophylaxis of contrast-induced nephropathy.(31) Alkalization reduces free radicals responsible for renal injury(32-35). Pretreatment with $\mathrm{NaHCO}_{3}$ has also demonstrated protective effect in animal models of acute renal failure.(36-38)

Literature reports about the usefulness of alkalization in prevention of renal injury during cardiac surgery are contradictory. There are studies which have been demonstrated a beneficial effect of alkalization on the incidence of postoperative AKI(39-41). In parallel to these publications, other reports call for caution in using alkalization for the prevention of renal insults during cardiac interventions.(42) Our current study showed that the perioperative administration of sodium bicarbonate infusion in off pump CABG does reduce the incidence of Stage-1 AKI in patients with pre-existing renal dysfunction. We feel that paying attention to standard parameters to ensure renal perfusion and 
avoidance of renal toxins are important and the use of sodium bicarbonate may be beneficial to reduce the worsening of renal dysfunction in patients undergoing off pump CABG with pre-existing renal dysfunction and who are not on dialysis (Chapter 7 ).

Based on our studies we conclude that,

a) Post-operative AKI in cardiac surgery is common and a major complication. Prediction and prevention is potentially possible. Renal function can be better preserved in patients undergoing off-pump CABG than in patients undergoing on-pump CABG.

b) Age is an independent risk factor for post-operative AKI; hence elderly patients should be preferably allotted to off-pump CABG. Other predictors of AKI after cardiac surgery include prior renal dysfunction, a critical preoperative state, diastolic dysfunction, and combined or major cardiac surgery. In addition, there is evidence that some genetic factors predispose to postoperative AKI.

c) Neutrophil gelatinase-associated lipocalin can be used as a biomarker for predicting acute kidney injury during off-pump coronary artery bypass surgery.

d) The use of dopamine and $\mathrm{N}$-acetylcysteine does not produce any beneficial effects in high-risk patients undergoing off-pump CABG. However, administration of sodium bicarbonate during off-pump coronary artery bypass surgery does reduce the incidence of acute kidney injury. 


\section{References}

1. Elahi MM, Khan JS, Matata BM. Deleterious effects of cardiopulmonary bypass in coronary artery surgery and scientific interpretation of off-pump's logic. Vol. 8, Acute Cardiac Care. 2006. p. 196-209.

2. Murphy GJ, Angelini GD. Side effects of cardiopulmonary bypass: What is the reality? Vol. 19, Journal of Cardiac Surgery. 2004. p. 481-8.

3. Paparella D, Yau TM, Young E. Cardiopulmonary bypass induced inflammation: pathophysiology and treatment. An update. Eur J Cardiothorac Surg [Internet]. 2002 Feb [cited 2019 Nov 14];21(2):232-44. Available from: http://www.ncbi.nlm.nih.gov/ pubmed/11825729

4. Esper SA, Subramaniam K, Tanaka KA. Pathophysiology of cardiopulmonary bypass: Current strategies for the prevention and treatment of anemia, coagulopathy, and organ dysfunction. Vol. 18, Seminars in Cardiothoracic and Vascular Anesthesia. SAGE Publications Inc.; 2014. p. 161-76.

5. Omeroğlu SN, Kirali K, Güler M, Toker ME, Ipek G, Işik O, et al. Midterm angiographic assessment of coronary artery bypass grafting without cardiopulmonary bypass. Ann Thorac Surg [Internet]. 2000 Sep [cited 2019 Nov 14];70(3):844-9; discussion 850. Available from: http://www.ncbi.nlm.nih.gov/ pubmed/11016321

6. Mack MJ, Pfister A, Bachand D, Emery R, Magee MJ, Connolly $M$, et al. Comparison of coronary bypass surgery with and without cardiopulmonary bypass in patients with multivessel disease. $\mathrm{J}$ Thorac Cardiovasc Surg. 2004;127(1):167-73.

7. Yadava OP, Kundu A. "On" or "off" pump coronary artery bypass grafting-Is the last word out? Vol. 65, Indian Heart Journal. 2013. 
p. 187-90.

8. O'Neal JB, Shaw AD, Billings FT. Acute kidney injury following cardiac surgery: Current understanding and future directions. Vol. 20, Critical Care. BioMed Central Ltd.; 2016.

9. Lassnigg A, Schmidlin D, Mouhieddine M, Bachmann LM, Druml $W$, Bauer $P$, et al. Minimal changes of serum creatinine predict prognosis in patients after cardiothoracic surgery: a prospective cohort study. J Am Soc Nephrol [Internet]. 2004 Jun [cited 2019 Oct 15];15(6):1597-605. Available from: http://www.ncbi.nlm. nih.gov/pubmed/15153571

10. Rosner MH, Okusa MD. Acute kidney injury associated with cardiac surgery. Clin J Am Soc Nephrol [Internet]. 2006 [cited 2019 Sep 18];1(1):19-32. Available from: http://www.ncbi. nlm.nih.gov/entrez/query.fcgi?cmd=Retrieve\&db=PubMed\&dopt= Citation\&list_uids $=17699187$

11. Skarupskienè I, Adukauskienè D, Kuzminskienè J, Rimkutè L, Balčiuvienè V, Žiginskienè E, et al. Mortality prediction in patients with acute kidney injury requiring renal replacement therapy after cardiac surgery. Med. 2017 Jan 1;53(4):217-23.

12. Lu JCT, Coca SG, Patel UD, Cantley L, Parikh CR. Searching for Genes That Matter in Acute Kidney Injury: A Systematic Review for the Translational Research Investigating Biomarkers and Endpoints for Acute Kidney Injury (TRIBE-AKI) Consortium. Clin J Am Soc Nephrol. 2009;4:1020-31.

13. Isbir SC, Tekeli A, Ergen A, Yilmaz H, Ak K, Civelek A, et al. Genetic polymorphisms contribute to acute kidney injury after coronary artery bypass grafting. Heart Surg Forum [Internet]. 2007 [cited 2019 Oct 15];10(6):E439-44. Available from: http://www.ncbi.nlm.nih.gov/pubmed/17921131

14. Page US, Washburn T. Using tracking data to find complications that physicians miss: the case of renal failure in cardiac surgery. 
Jt Comm J Qual Improv [Internet]. 1997 Oct [cited 2019 Nov 20];23(10):511-20. Available from: http://www.ncbi.nlm.nih.gov /pubmed/9383670

15. Alge JL, Arthur JM. Biomarkers of AKI: A review of mechanistic relevance and potential therapeutic implications. Clin J Am Soc Nephrol. 2015;10(1):147-55.

16. Nicoara A, Patel UD, Phillips-Bute BG, Shaw AD, Stafford-Smith $\mathrm{M}$, Milano $\mathrm{CA}$, et al. Mortality trends associated with acute renal failure requiring dialysis after CABG surgery in the United States. Blood Purif. 2009 Dec;28(4):359-63.

17. Kelly KJ. Distant effects of experimental renal ischemia /reperfusion injury. J Am Soc Nephrol [Internet]. 2003 Jun [cited 2019 Nov 20];14(6):1549-58. Available from: http://www.ncbi. nlm.nih.gov/pubmed/12761255

18. Rabb H, Wang Z, Nemoto T, Hotchkiss J, Yokota N, Soleimani M. Acute renal failure leads to dysregulation of lung salt and water channels. Kidney Int. 2003;63(2):600-6.

19. Deng J, Hu X, Yuen PST, Star RA. Alpha-melanocyte-stimulating hormone inhibits lung injury after renal ischemia/reperfusion. Am J Respir Crit Care Med [Internet]. 2004 Mar 15 [cited 2019 Nov 20];169(6):749-56. Available from: http://www.ncbi.nlm.nih.gov /pubmed/14711793

20. Kramer AA, Postler G, Salhab KF, Mendez C, Carey LC, Rabb H. Renal ischemia/reperfusion leads to macrophage-mediated increase in pulmonary vascular permeability. Kidney Int. 1999;55(6):2362-7.

21. Wijeysundera DN, Karkouti K, Dupuis JY, Rao V, Chan CT, Granton JT, et al. Derivation and validation of a simplified predictive index for renal replacement therapy after cardiac surgery. J Am Med Assoc. 2007 Apr 25;297(16):1801-9.

22. Aronson S, Fontes ML, Miao Y, Mangano DT, Investigators of the 
Multicenter Study of Perioperative Ischemia Research Group, Ischemia Research and Education Foundation. Risk index for perioperative renal dysfunction/failure: critical dependence on pulse pressure hypertension. Circulation [Internet]. 2007 Feb 13 [cited 2019 Sep 20];115(6):733-42. Available from: http://www.ncbi.nlm.nih.gov/pubmed/17283267

23. Doberneck Rc, Reiser $\mathrm{Mp}$, Lillehei $\mathrm{Cw}$. Acute renal failure after open-heart surgery utilizing extracorporeal circulation and total body perfusion. Analysis of 1000 patients. J Thorac Cardiovasc Surg [Internet]. 1962 Apr [cited 2019 Nov 20];43:441-52. Available from: http://www.ncbi.nlm.nih.gov/pubmed/13886739

24. Abel RM, Beck CH, Buckley MJ, Austen WG. Renal Dysfunction Following Open-Heart Operations. Arch Surg. 1974;108(2):1757.

25. Yeh Tj, Brackney El, Hall Dp, Ellison Rg. Renal Complications Of Open-Heart Surgery: Predisposing Factors, Prevention, And Management. J Thorac Cardiovasc Surg [Internet]. 1964 Jan [cited 2019 Nov 20];47:79-97. Available from: http://www.ncbi.nlm.nih.gov/pubmed/14113178

26. Koyner JL, Garg AX, Coca SG, Sint K, Thiessen-Philbrook H, Patel UD, et al. Biomarkers predict progression of acute kidney injury after cardiac surgery. J Am Soc Nephrol. 2012 May;23(5):905-14.

27. He G, Li Q, Li W, Wang L, Yang J, Zeng F. N-Acetylcysteine for Preventing of Acute Kidney Injury in Chronic Kidney Disease Patients Undergoing Cardiac Surgery: A Metaanalysis. Heart Surg Forum. 2018 Dec 19;21(6):E513-21.

28. Mei M, Zhao HW, Pan QG, Pu YM, Tang MZ, Shen BB. Efficacy of N-Acetylcysteine in Preventing Acute Kidney Injury After Cardiac Surgery: A Meta-Analysis Study. J Investig Surg. 2017 Jan 6;1-10. 
29. Ashworth A, Webb ST. Does the prophylactic administration of Nacetylcysteine prevent acute kidney injury following cardiac surgery? Interact Cardiovasc Thorac Surg. 2010 Sep 1;11(3):303-8.

30. Adabag AS, Ishani A, Koneswaran S, Johnson DJ, Kelly RF, Ward HB, et al. Utility of $\mathrm{N}$-acetylcysteine to prevent acute kidney injury after cardiac surgery: A randomized controlled trial. Am Heart J. 2008 Jun;155(6):1143-9.

31. Tepel M, Van Der Giet M, Schwarzfeld C, Laufer U, Liermann D, Zidek W. Prevention of radiographic-contrast-agent-induced reductions in renal function by acetylcysteine. $\mathrm{N}$ Engl $\mathrm{J}$ Med. 2000 Jul 20;343(3):180-4.

32. Shyu KG, Cheng JJ, Kuan P. Acetylcysteine protects against acute renal damage in patients with abnormal renal function undergoing a coronary procedure. J Am Coll Cardiol [Internet]. 2002 Oct 16 [cited 2019 Nov 20];40(8):1383-8. Available from: http://www.ncbi.nlm.nih.gov/pubmed/12392825

33. Kay J, Chow WH, Chan TM, Lo SK, Kwok OH, Yip A, et al. Acetylcysteine for Prevention of Acute Deterioration of Renal Function Following Elective Coronary Angiography and Intervention: A Randomized Controlled Trial. J Am Med Assoc. 2003 Feb 5;289(5):553-8.

34. Miller RD, Cohen NH, Eriksson LI, Professor F, Chair A, WienerKronish JP. Miller's Anesthesia, 2-Volume Set. Elsevier; 2014. 3576 p.

35. Pramodh K, Vani, Muralidhar K. Renal function following CABG: On-pump vs off-pump. Indian J Thorac Cardiovasc Surg. 2003;19(4):169-73.

36. Zanardo G, Michielon P, Paccagnella A, Rosi P, Caló M, Salandin $\mathrm{V}$, et al. Acute renal failure in the patient undergoing cardiac operation. Prevalence, mortality rate, and main risk factors. $\mathrm{J}$ 
Thorac Cardiovasc Surg [Internet]. 1994 Jun [cited 2019 Nov 20];107(6):1489-95. Available from: http://www.ncbi.nlm.nih.gov/ pubmed/8196394

37. Gormley SMC, McBride WT, Armstrong MA, Young IS, McClean E, MacGowan SW, et al. Plasma and urinary cytokine homeostasis and renal dysfunction during cardiac surgery. Anesthesiology. 2000;93(5):1210-6.

38. RGUHS University Library [Internet]. [cited 2019 Nov 20]. Available from: http://www.rguhs.ac.in/digitallibrary/Helinet about us.html

39. Bailey M, McGuinness S, Haase M, Haase-Fielitz A, Parke R, Hodgson $\mathrm{CL}$, et al. Sodium bicarbonate and renal function after cardiac surgery: A prospectively planned individual patient metaanalysis. Anesthesiology. 2015 Feb 2;122(2):294-306.

40. Huber W, Huber T, Baum S, Franzen M, Schmidt C, Stadlbauer $T$, et al. Sodium bicarbonate prevents contrast-induced nephropathy in addition to theophylline. Med (United States). 2016 May 1;95(21).

41. Wetz AJ, Bräuer A, Quintel M, Heise D. Does sodium bicarbonate infusion really have no effect on the incidence of acute kidney injury after cardiac surgery? A prospective observational trial. Crit Care. 2015 Apr 22;19(1).

42. Schiffl H. Sodium bicarbonate infusion for prevention of acute kidney injury: No evidence for superior benefit, but risk for harm? Vol. 47, International Urology and Nephrology. Kluwer Academic Publishers; 2014. p. 321-6. 


\section{Summary}

Post-operative AKI in cardiac surgery is a common major complication. This can be fairly predicted and can be controlled by certain precautious measures. Age is the independent risk factor for post-operative AKI. Other predictors of AKI after cardiac surgery include prior renal dysfunction, a critical preoperative state, diastolic dysfunction, and combined or major cardiac surgery. In addition, there is evidence that some genetic factors predispose to postoperative AKI. Also, perioperative changes of neutrophil gelatinase-associated lipocalin concentration state it as a biomarker for predicting acute kidney injury during off-pump coronary artery bypass surgery.

There was demonstrated that renal function can be better preserved in patients undergoing off-pump CABG than on-pump CABG. Hence patients predisposed to development AKI should be preferably allotted to off-pump CABG. Unfortunately, we could not find evidence any beneficial effects of the use of dopamine and/or $\mathrm{N}$-acetylcysteine in high-risk patients undergoing off-pump CABG. However, perioperative infusion of $\mathrm{NaHCO}_{3}$ in patients with GFR $\leq 60 \mathrm{ml} / \mathrm{min} / 1.73 \mathrm{~m}^{2}$ reduced the incidence of Stage- 1 AKI by about $40 \%$ when compared to the placebo group.

Conclusion.

a) Renal function can be better preserved in patients undergoing off-pump than on-pump CABG.

b) Age, prior renal dysfunction, a critical preoperative state, diastolic dysfunction, and combined or major cardiac surgery are an independent risk factors for development postoperative AKI. In addition, there is evidence that some genetic features predispose to postoperative AKI. 
c) Neutrophil gelatinase-associated lipocalin can be used as a biomarker for predicting acute kidney injury during off-pump coronary artery bypass surgery.

d) Administration of sodium bicarbonate during off-pump coronary artery bypass surgery does reduce the incidence of acute kidney injury. 


\section{Samenvatting}

Postoperatief acuut nierfalen (AKI) na hartoperaties komt vaak voor en geldt als een ernstige complicatie. Het optreden ervan kan redelijk worden voorspeld en de ernst ervan kan worden beperkt met bepaalde voorzorgsmaatregelen. Leeftijd is een onafhankelijke risicofactor voor postoperatieve AKI. Andere voorspellers van AKI na hartchirurgie zijn onder meer een eerdere nierfunctiestoornis, een kritieke preoperatieve toestand, diastolische disfunctie en gecombineerde of zware hartchirurgie. Bovendien zijn er aanwijzingen dat sommige genetische factoren predisponeren voor postoperatieve AKI. Ook stellen perioperatieve veranderingen van neutrofiel gelatinase-geassocieerde lipocaline (NGAL) concentratie het als een biomarker voor het voorspellen van acuut nierfalen tijdens off-pump coronaire bypassoperaties.

Er werd aangetoond dat de nierfunctie beter behouden kan worden bij patiënten die CABG zonder pompgebruik van de hartlong machine (off-pump) ondergaan; dan in geval van CABG met hartlong machine. Daarom moeten patiënten die vatbaar zijn voor de ontwikkeling van AKI bij voorkeur worden toegewezen aan off-pump CABG. Helaas konden we geen bewijs vinden van enige gunstige effecten van het gebruik van dopamine en/of $\mathrm{N}$-acetylcysteïne bij hoog risicopatiënten die off-pump CABG ondergingen. Echter, perioperatieve infusie van $\mathrm{NaHCO} 3$ bij patiënten met GFR $\leq 60 \mathrm{ml} / \mathrm{min} / 1,73 \mathrm{~m} 2$ verminderde de incidentie van stadium-1 AKI met ongeveer $40 \%$ in vergelijking met de placebogroep.

De volgende conclusies konden worden getrokken:

a) De nierfunctie kan beter worden behouden bij patiënten die een off-pump ondergaan dan bij een on-pump CABG.

b) Leeftijd, eerdere nierfunctiestoornis, een kritieke preoperatieve toestand, diastolische disfunctie en gecombineerde of zware hartchirurgie zijn onafhankelijke risicofactoren voor de 
ontwikkeling van postoperatieve AKI. Bovendien zijn er aanwijzingen dat sommige genetische kenmerken predisponeren voor postoperatieve AKI.

c) Neutrofiel gelatinase-geassocieerde lipocaline kan worden gebruikt als een biomarker voor het voorspellen van acuut nierfalen tijdens een off-pomp CABG.

d) Toediening van natriumbicarbonaat tijdens off-pump coronaire bypassoperaties vermindert de incidentie van acuut nierfalen. 


\section{Valorization}

The present thesis introduces and studies the frequency and causes of renal damage in cardiac surgery patients, with an emphasis on off pump coronary artery bypass grafting. Which is especially important for a country like India where as many as $90 \%$ of $C A B G$ is being done as an off-pump procedure.

The incidence of renal damage associated with CABG surgery is rather high, and there is evidence that the rate of this complication increased during the last decade. About $2.3 \%$ of isolated CABG cases is vulnerable to $A K I$, and the incidence is higher $(14 \%-15 \%)$ in patients with preoperative chronic kidney disease. ${ }^{1}$ It has been shown that even a small increase in serum creatinine in the postoperative period, is an independent risk factor for increased mortality. ${ }^{2-5}$ Not surprisingly the occurrence of renal dysfunction adds to the length of ICU say, hospital stay and the cost of treatment. ${ }^{6-8}$

Better understanding of the etiology of renal complications and the development of methods how to prevent them will pave the way for better outcome in CABG surgery. Cardiopulmonary bypass (CPB) and consequent changes in homeostasis are recognized as a main risk factor contributing to the development of AKI in cardiac surgical patients. Hemodilution, emboli either particulate, or gaseous, or micro, or macroscopic, as well as intraoperative haemodynamic instability and all causes of postoperative low output syndrome, all may be involved in the genesis of $\mathrm{AKI}$ in patients undergoing cardiac surgery. ${ }^{9-11}$

Renal function is better preserved in patients undergoing offpump CABG than on-pump CABG. According to our data (Chapter 2) avoiding CPB leads to the more than $50 \%$ decrease in renal dysfunction in early postoperative period. Increased age proves to be a risk factor for patients undergoing on-pump CABG and hence elderly people have to be preferably allocated to off-pump rather than to on-pump CABG. 
However, the causes which determine the occurrence of renal complications following CABG are not limited to the deleterious effects of CPB only. Among the important preoperative factors are advanced age, reduced left ventricular function, and emergency surgery, preoperative use of intraaortic balloon pump, elevated preoperative serum glucose and creatinine..$^{9,12}$ Multivariate logistic analysis (Chapter 3), demonstrated that, in addition to the complexity of surgery, the following factors independently predicted acute renal injury requiring renal replacement therapy $(p<0.05)$ : preoperative critical state, pre-existing renal dysfunction, preoperative diastolic dysfunction, and combined cardiac surgery. The genetic predisposition for the development of renal injury after the surgery has been addressed also. Previous genome wide association studies (GWAS) done in Caucasians have identified up to 9 genetic polymorphisms in CABG patients developing AKI. ${ }^{13}$ Evaluation of genetic polymorphism of Indian population uncovered 18 genes associated with the development postoperative AKI (Chapter 4). Further investigation in this area could result in discriminating specific pathophysiological mechanisms of renal injury and a more exact definition of the group of patients requiring special attention in renal protection during surgery.

The pharmacological renal protection during cardiac surgery is one of the most discussed topics in literature. In the past decades, many drugs such as dopamine agonists, sodium bicarbonate, $\mathrm{N}$-acetylcysteine, antioxidants and atrial natriuretic peptide (to name but a few) were investigated for a possible nephroprotective action in both surgical and ICU patients, however, never with great results. ${ }^{14-16}$ In particular, no drug has been clearly proven to prevent the progression of AKI towards the need for RRT and, most disappointing, end-stage renal failure and 'chronic' haemodialysis. ${ }^{17}$ Unfortunately, our data (Chapter 6) also did not support the hope for the effectiveness of $\mathrm{N}$-acetylcysteine in the prevention of renal dysfunction after off-pump coronary artery bypass 
surgery. However, infusion of sodium bicarbonate in off-pump coronary artery bypasses grafting in patients with renal dysfunction did reduce the incidence of Stage-1 AKI by about $40 \%$ when compared to a placebo group (Chapter 7).

To conclude, most of the questions discussed in this thesis are at the frontline of the quest for safer cardiac surgery, reducing the frequency and severity of renal injury. This thesis demonstrates the necessity in careful selection of patients prone to renal injury by comorbidities, age or even genetic factors. These patients require special attention in preoperative treatment, intraoperative support, and postoperative care. Using our results, we hope to be able to allocate all patients to their designated care modality and decrease the frequency of renal injury during cardiac surgery.

And last, but not least, this thesis provides a clear definition of directions for further investigations in the prevention of $A K I$ in patients undergoing off-pump CABG. 


\section{References}

1. Mangano CM, Diamondstone LS, Ramsay JG, et al. Renal dysfunction after myocardial revascularization: risk factors, adverse outcomes, and hospital resource utilization. The Multicenter Study of Perioperative Ischemia Research Group. Annals of internal medicine 1998; 128: 194-203.

2. Lassnigg A, Schmidlin D, Mouhieddine M, et al. Minimal changes of serum creatinine predict prognosis in patients after cardiothoracic surgery: A prospective cohort study. Journal of the American Society of Nephrology 2004; 15: 1597-1605. DOI: 10.1097/01.ASN.0000130340.93930.DD.

3. Ryckwaert F, Boccara G, Frappier J-M, et al. Incidence, risk factors, and prognosis of a moderate increase in plasma creatinine early after cardiac surgery. Critical care medicine 2002; 30: 1495-1498. DOI: 10.1097/00003246-200207000-00016.

4. Loef BG, Epema AH, Smilde TD, et al. Immediate postoperative renal function deterioration in cardiac surgical patients predicts inhospital mortality and long-term survival. Journal of the American Society of Nephrology : JASN 2005; 16: 195-200. DOI: 10.1681/ ASN.2003100875.

5. Brown JR, Cochran RP, Dacey LJ, et al. Perioperative increases in serum creatinine are predictive of increased 90-day mortality after coronary artery bypass graft surgery. Circulation 2006; 114: 1409-413. DOI: 10.1161/CIRCULATIONAHA.105.000596.

6. Chertow GM, Burdick E, Honour M, et al. Acute kidney injury, mortality, length of stay, and costs in hospitalized patients. Journal of the American Society of Nephrology 2005; 16: 3365-3370. DOI: 10.1681/ASN.2004090740. 
7. Lysak N, Bihorac A and Hobson C. Mortality and cost of acute and chronic kidney disease after cardiac surgery. Curr Opin Anaesthesiol 2017; 30: 113-117. DOI: 10.1097/ACO.0000000000000422.

8. Alshaikh HN, Katz NM, Gani F, et al. Financial Impact of Acute Kidney Injury After Cardiac Operations in the United States. Ann Thorac Surg 2018; 105: 469-475. 2017/12/26. DOI: 10.1016/j.athoracsur.2017.10.053.

9. Maitra G, Ahmed A, Rudra A, et al. Renal dysfunction after offpump coronary artery bypass surgery- risk factors and preventive strategies. Indian J Anaesth 2009; 53: 401-407.

10. Vermeulen Windsant IC, Snoeijs MG, Hanssen SJ, et al. Hemolysis is associated with acute kidney injury during major aortic surgery. Kidney international 2010; 77: 913-920. DOI: 10.1038/ki.2010.24.

11. Miller RD, Cohen NH, Eriksson LI, et al. Miller's Anesthesia, 2Volume Set. 8th ed.: Elsevier, 2014, p.3576.

12. Mirmohammad-Sadeghi M, Naghiloo A and Najarzadegan MR. Evaluating the relative frequency and predicting factors of acute renal failure following coronary artery bypass grafting. ARYA Atheroscler 2013; 9: 287-292.

13. Lu JCT, Coca SG, Patel UD, et al. Searching for Genes That Matter in Acute Kidney Injury: A Systematic Review for the Translational Research Investigating Biomarkers and Endpoints for Acute Kidney Injury (TRIBE-AKI) Consortium. Clin J Am Soc Nephrol 2009; 4: 10201031. DOI: $10.2215 / C J N .05411008$.

14. Kellum JA, Lameire N, Aspelin $P$, et al. Diagnosis, evaluation, and management of acute kidney injury: A KDIGO summary (Part 1). Critical Care 2013; 17. DOI: 10.1186/cc11454.

15. Landoni G, Bove T, Szekely A, et al. Reducing mortality in acute kidney injury patients: systematic review and international web-based 
survey. J Cardiothorac Vasc Anesth 2013; 27: 1384-1398. 2013/10/10. DOI: 10.1053/j.jvca.2013.06.028.

16. Zacharias M, Mugawar M, Herbison GP, et al. Interventions for protecting renal function in the perioperative period. Cochrane Database Syst Rev 2013: CD003590. 2013/09/13. DOI: 10.1002/14651858.CD003590.pub4.

17. Egan Talmage D, M.D. Miller's Anesthesia, 6th Edition. Anesthesiology: The Journal of the American Society of Anesthesiologists 2005; 103: 673-673. 


\section{Acknowledgements}

I am thankful to Prof. Jos Maessen for accepting to be my promoter and guide. He has always been kind, understanding, and giving freedom to work with immense faith. He is a man who leads by example of innovative thinking, open nature, and futuristic mindset. I am honored to have worked under his guidance.

I take this opportunity to convey my heartfelt gratitude and sincere thanks to Dr. Deviprasad Shetty, Chairman, Narayana Health City, Bangalore, India, for his value addition and constant encouragement.

I express my sincere gratitude to my co-promoters Dr. Kumar Belani, Minnesota University, USA and Dr. Lloyd Vincent, Narayana health City, Bangalore, for their continuous support, motivation, and valuable suggestions in the pursuit of my PhD studies.

It has been kind of Dr. Shyam Vasudeva Rao, Dr. Collin Dorie and Dr. J Smith, for their support during my PhD research studies.

Dr. Praveen Kumar, Narayana Institute of Cardiac Sciences, Bangalore, thank you from my bottom of heart for everything. 


\section{Curriculum vitae}

Name Dr. Muralidhar Kanchi

Sex

Male

Date of Birth

$19^{\text {th }}$ Oct 1953

Contact address

No 80, "SHAILAJA"

$8^{\text {th }}$ C-main, J - Block,

Koramangala,

Bangalore - 560034

Karnataka, India

Designation

Office address

Narayana Hrudayalaya Hospitals,

1) Director (Academic), Narayana Hrudayalaya

2) Professor, Anaesthesia and Intensive Care

3) TEE - Course Director, National TEE workshop

4)Board member, Indian College of Cardiac Anaesthesia

5) Professor of International Health, Medical School, University of Minnesota

6) Dean - Indian College of Anesthesiology

\#258/A, Bommasandra Industrial Area, Anekal taluk, Bangalore - 560 099, Karnataka, India

Contact number (office) 
Passport number

E-mail id
Z3117451; valid till $13^{\text {th }}$ Feb 2025

muralidhar.kanchi.dr@narayanahealth.org /

kanchirulestheworld@gmail.com 


\section{Qualifications}

\begin{tabular}{ccccc}
\hline \multirow{4}{*}{ Course Name } & $\begin{array}{c}\text { Name } \\
\text { of PG } \\
\text { Degre } \\
\mathrm{e}\end{array}$ & $\begin{array}{c}\text { Area of } \\
\text { Specialization/ } \\
\text { Specialty }\end{array}$ & $\begin{array}{c}\text { Year of } \\
\text { Qualifyin } \\
\text { g degree }\end{array}$ & $\begin{array}{c}\text { Name of } \\
\text { University / } \\
\text { Institute }\end{array}$ \\
\hline
\end{tabular}

MBBS

1975 Osmania

University

Post Graduate

Institute of

Medical

PG Degree

MD Anaestheisa

1982

Education and

Research,

Chandigarh, India

PGDHHM

Hospital

Administration

2005

IGNOU, New

Delhi

Fellowship in

cardiac

anaesthesia

(FIACTA)

Cardiac

Anaesthesia

Indian

Association of

2009 Cardiothoracic

Anaesthesiologis

ts (IACTA)

Indian

Association of

Fellowship in TEE

Transesophageal

Echocardiography

2010

Cardiothoracic

Anaesthesiologis

ts (IACTA)

National Institute

MBA

HR Management

of Business

Management,

Chennai

Fellowship of

Indian College of Anaesthesiology (FICA) Anaesthesiology 
Fellowship of

International
International
Cardiac Ultrasound
2012 Society of
Cardiovascular
Ultrasound

Society of

Cardiovascular

Ultrasound

(FISCU)

Fellowship of Indian College of

Cardiology

Cardiology

$2013 \quad \begin{aligned} & \text { Indian College of } \\ & \text { Cardiology }\end{aligned}$

Fellowship of

critical care

medicine

(FICCM)

Critical Care

Medicine

$2013 \quad \begin{aligned} & \text { Indian Society of } \\ & \text { Critical Care } \\ & \text { Medicine }\end{aligned}$

Fellowship of

American society

of

Echocardiography
Echocardiography
American society
of
Echocardiograph y (ASE)

Fellowship in

Paediatric

Anaestheisa

Indian

Anesthesia

2018

Association of

Paediatric

Anesthesia 


\section{Work experience}

Mar-1976 to Feb-1977

Jul-1977 to Dec-1979

Dec-1977 to Dec-1979

Jan-1980 to Dec-1982

Mar-1983 to Jun-1983

Jul-1983 to Nov-1986

Nov-1986 to Jun-1987
Compulsory rotatory internship at Gandhi Medical Collage Hospital, Secunderabad.

House Officer in the department of orthopedics at Post Graduate Institute of Medical Education and Research, Chandigarh, an autonomous institute of national importance under central government of India.

\section{Assistant Divisional Medical} Officer (Anaesthesia) in Indian railways.

Junior resident in anaesthesia at Post Graduate Institute of Medical Education and Research, Chandigarh, an autonomous institute of national importance under central government of India.

Senior Resident in anaesthesia at Jawaharlal Nehru Institute of Post Graduate Medical Education and Research, Pondicherry, a postgraduate institute under central government.

Lecturer in anaesthesia at Shree Chitra Tirunal Sciences and Technology, Trivandrum, an autonomous institute of national importance under central government of India.

Lecturer in anaesthesia at Nizam's Institute of Medical 
Sciences, Hyderabad, and an Autonomous Institute of super specialties under state government of Andhra Pradesh.

Jul-1987 to May-1989

Mar-1994 to Jun-1995

Apr-1999 to May-1999

May-1989 to May-1997

Jun-1997 to Apr-2001

Apr-2001 to Present
Assistant professor in anaesthesia at Nizam's Institute of super specialties.

Fellow in cardiothoracic anaesthesia, Glenfield General Hospital, Leicester, UK.

Fellow in cardiothoracic anaesthesia, Glenfield General Hospital, Leicester, UK.

Consultant anesthesiologist at B.M. Birla Heart Research Centre, Calcutta, a 150 bedded hospital devoted to cardiology and cardiac surgery.

Consultant anaesthesiologist and Head of the Department of

Anaesthesia, at Manipal Heart Foundation, a modern cardiac hospital dedicated to common man. Also, programme director for postdoctoral certificate course in cardiac anaesthesia (recognized by Manipal Academy of Higher Education (MAHE).

Consultant anesthesiologist, HOD Anesthesia \& Intensive Care, Director (Academic) at Narayana Hrudayalaya, Bangalore, India 


\section{Book chapters}

1) Anesthesia for Thoracic, Aortic and Thoracoabdominal Aortic Surgery. Muralidhar K, Year book of anesthesiology; 2016; chapter 20; page 255

2) Anesthetic implications if implantable cardiac devices, Muralidhar $\mathrm{K}$, Year book of anesthesiology; 2015; chapter 2; pages 13-27

3) Anesthesia for Pediatric Cardiac Catheterization and Intervention; Muralidhar K; Cardiac cauterization and imaging (from pediatrics to geriatrics); 2015; chapter -67

4) Intra-aortic Balloon Pump; Muralidhar K; Cardiac cauterization and imaging (from pediatrics to geriatrics); 2015; chapter - 68

5) Heparin Alternatives ; Muralidhar K; Manual of Extracorporeal Membrane Oxygenation (ECMO) in the ICU; 2014; chapter - 21; pages 128-132

6) Transesophageal Echocardiography of the tricuspid \&Pulmonary Valves. Poonam Malhotra Kapoor, Yatin Mehta, Muralidhar Kanchi, Rajiv Juneja. Jaypeedigital Explore Health Sciences, 2014, doi: $10.5005 /$ jp/books/12111. 


\section{List of publications}

1. Is laryngotracheal lignocaine necessary? (a study in cardiac surgical patients). Rao SM; Muralidhar K. Indian Journal of Anaesthesia. 1989 Apr; 37(2): 78-83.

2. Comments on dynamic cardiomyoplasty, Muralidhar K. J Cardiothorac Vasc Anesth. 1993 Apr; 7(2): 254-5.

3. Ventilation strategy for Video-assisted thoracoscopic clipping of patent ductus arteriosus in children. Muralidhar K, Shetty DP, Paediatr Anaesth. 2001 Jan; 11(1): 45-8

4. Bidirectional Glenn shunt: 170 cases, Muralidhar K, Asian Cardiovasc Thorac Ann. 2002 Mar; 10(1): 96.

5. Central venous pressure and pulmonary capillary wedge pressure monitoring; Muralidhar. K., 298 Indian J. Anaesth. 2002; 46 (4): 298-303.

6. Renal function following CABG: On-pump vs. off-pump, Pramodh, Vani, K Muralidhar, IJTCVS; 2003; 19: 169-173.

7. Prophylactic magnesium sulphate vs. lidocaine during off-pump coronary artery bypass grafting. Kanchi M, Prasad N, Garg D, Banakal SK, Eur J Anaesthesiol. 2004 Nov; 21(11): 914-5.

8. Influence of changes in the pulmonary artery pressure on ventilation requirements in patients undergoing mitral valve replacement; Muralidhar K, Rupert E, Singh R, Gowda N, Kumar V, Kumar S.; Ann Card Anaesth. 2004 Jul; 7(2): 144-8.

9. Influence of isoflurane on ischaemic heart disease in patients with coronary steal prone anatomy; Murugesan C, Murthy K, Garg R, Kumar S, Muralidhar K; Ann Card Anaesth. 2004 Jan; 7 (1): 51 54.

10. Ultra low dose aprotinin decreases blood loss and transfusion requirements in high risk two-valve replacement surgery; $\mathrm{K}$ Muralidhar, BR Harish, Sanjay Banakal, Rajnish Garg, Keshava Murthy, Sanjay Dhaded, Colin John, Praveen Kumar, DP Shetty, Annals of Cardiac Anaesthesia; Vol.8, No.2, 2005. 
11. "Fast Tracking" Paediatric Cardiac Surgical Patients, Muralidhar Kanchi, Annals of Cardiac Anaesthesia; 8, 1, 33-38; 2005.

12. Distal Carotid Perfusion in Combined Carotid Endarterectomy and OP-CABG. Rao PV, Hosabettu PK, Dhaded S, Mathew A, Punnen J, Kanchi M, Asian Cardiovasc Thorac Ann. 2007 Apr;15(2):164-6.

13. Tracheotomy in ICU: An insight into the present concepts. Muralidhar K. Indian Journal of Anaesthesia 2008; 52 (1): 28-37.

14. Bispectral index-guided anaesthesia for off-pump coronary artery bypass grafting. Kanchi Muralidhar, Sanjay Banakal, Keshav Murthy, Rajneesh Garg, G Radhika Rani, R Dinesh. Annals of Cardiac Anaesthesia 2008; 11: 104-109.

15. Teaching cardiac anaesthesia. Kanchi Muralidhar. Annals of Cardiac Anaesthesia 2008; 11:75-76.

16. TELE-EDUCATION IN CARDIAC ANAESTHESIA / INTENSIVE CARE. Kanchi M; Banakal S; Shetty D, ANESTH ANALG 2009; 108(SCA Suppl);1-104

17. Cardiac output measurement-using floTrac in off-pump CABG: radial artery vs. femoral artery. Kanchi M; Aggarwal V. ANESTH ANALG 2009; 108(SCA Suppl);1-104

18. Haemodynamic responses to direct conventional vs. video laryngoscopy in patients with coronary artery disease. Kanchi M; Nair H, ANESTH ANALG 2009; 108(SCA Suppl);1-104

19. Influence of colloid infusion on coagulation during off-pump coronary artery bypass grafting. Muralidhar K, Garg R, Mohanty S, Banakal S. Indian J Anaesth. 2010 Mar; 54(2): 147-53.

20. Interesting TEE image, Kanchi M, Ann Card Anaesth. 2010 SepDec; 13(3): 260.

21. Do we need a pulmonary artery catheter in cardiac anesthesia? An Indian perspective. Muralidhar Kanchi. Annals of Cardiac Anaesthesia. 2011. 14(1); 25-29

22. Good CPB practices for prevention of cerebral injury in cardiac surgery. Varun Shetty \& Muralidhar K. Indian Journal of ExtraCorporeal Technology Vol. 21, Issue 2, 2011 
23. A category I indication for transesophageal echocardiography; Kanchi M; J Cardiothorac Vasc Anesth. 2011 Feb;25(1):206-7

24. Haemodynamic response to endotracheal intubation in coronary artery disease: Direct versus video laryngoscopy; Kanchi $\mathrm{M}^{1}$, Nair HC, Banakal S, Murthy K, Murugesan C. Indian J Anaesth. 2011 May;55(3):260-5

25. Book review - Clinical practice of cardiac anaesthesia: Third Edition K Muralidhar, Annals of Cardiac Anaesthesia 16(1); 72; 2012

26. Renal replacement therapy in ICU: C Deepa, K Muralidhar, Journal of Anaesthesiology Clinical Pharmacology; 2012 (28); 3

27. High-resolution three-dimensional echocardiography of left atrial myxoma. Inderbitzin $\mathrm{DT}^{1}$, Seeberger M, Grapow M, Kaiser C, Muralidhar K, Eckstein FS. Asian Cardiovasc Thorac Ann. 2012 Dec; 20(6):741

28. Tele-education service using telemedicine network in healthcare industry. Mahadevan S, Muralidhar K, Shetty D; Telemed J E Health. 2012 Nov;18(9):699-702

29. Determinants of renal replacement therapy after adult cardiac surgery. Kanchi Muralidhar, Kakade Bhagyashri, Ratan Guptha, Nitin Hegde, Isthiaq Ahmed\& Lloyd Vincent.Asian Cardiovasc Thorac Ann. 2013 Oct;21(5):533-8

30. Practice guidelines for perioperative transesophageal echocardiography: Recommendations of the Indian association of cardiovascular thoracic anesthesiologists. Muralidhar K, Tempe D, Chakravarthy M, Shastry N, Kapoor PM, Tewari P, Gadhinglajkar SV, Mehta Y. Ann Card Anaesth. 2013 OctoberDecember; 16(4):268-278.

31. Continuing Antiplatelet Therapy before Cardiac Surgery. Muralidhar K. J Cardiothorac Vasc Anesth. 2014 Jul 15. pii: S1053-0770(14)00109-8.

32. Modified Blalock Taussig shunt: Comparison between neonates, infants and older children. K. Muralidhar. Annals of Cardiac Anaesthesia z Vol. 17:3 z Jul-Sep-2014. 197-199 
33. Recent advances in postoperative care of pediatric cardiac surgical patients. Dr. Muralidhar K. Journal of Pediatric Critical Care; VOL 1 - NO.2 April - June 2014; 26-38

34. Manual of extracorporeal membrane oxygenation in the ICU ( a book review); K Muralidhar; Annals of Cardiac Anaesthesia | JanMar-2015 | Vol 18 | Issue 1; Page: 117

35. Guidelines of the Indian Association of Cardiovascular and Thoracic Anaesthesiologists and Indian College of Cardiac Anaesthesia for perioperative transesophageal echocardiography fellowship examination. Muralidhar K, Tempe D, Mehta Y, Kapoor PM, Mukherjee C, Koshy T, Tewari P, Shastri N, Misra S, Belani K. Ann Card Anaesth. 2016 Oct;19(Supplement):S73-S78

36. An update on transesophageal echocardiography views 2016: 2D versus 3D tee views. Kapoor PM, Muralidhar K, Nanda NC, Mehta Y, Shastry N, Irpachi K, Baloria A. Ann Card Anaesth. 2016 Oct;19(Supplement):S56-S72. doi: 10.4103/0971-9784.192624.

37. Pulmonary Artery Catheter Use During Cardiac Surgery in the United States. Kanchi M. J Cardiothorac Vasc Anesth. 2016 Jul 15. pii: S1053-0770(16)30278-6.

38. Continuing antiplatelet therapy before cardiac surgery.Muralidhar K. J Cardiothorac Vasc Anesth. 2014 Oct;28(5):e45. doi: 10.1053/j.jvca.2014.03.011.

39. Utility of perioperative transesophageal echocardiography. $\mathrm{K}$ Muralidhar. Ann Card Anaesth 19, Suppl S1:2-5

40. Grading Aortic Stenosis with Mean Gradient and Aortic Valve Area: A Comparison between Preoperative Transthoracic and Precardiopulmonary Bypass Transesophageal Echocardiography. Muralidhar Kanchi, Journal of Cardiothoracic and Vascular Anesthesia Volume 31, Issue 2, April 2017, Pages e43-e44

41. Neutrophil gelatinase-associated lipocalin as a biomarker for predicting acute kidney injury during off-pump coronary artery bypass grafting. Muralidhar Kanchi, R Manjunath, Jos Massen, Lloyd Vincent, Kumar Belani. Annals of Cardiac Anaestehsia 10.4103/aca. ACA_48_17 